\title{
Electrode Kinetics of Porous Ni-3YSZ Cermet Operated in Fuel Cell and Electrolysis Modes for Solid Oxide Cell Application
}

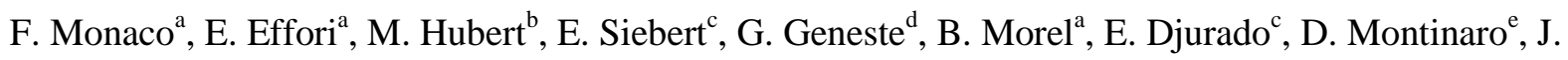 \\ Laurencin ${ }^{\mathrm{a} *}$ \\ ${ }^{a}$ Univ. Grenoble Alpes - CEA/LITEN, 38054, Grenoble, France \\ ${ }^{\mathrm{b}}$ European Synchrotron Radiation Facility (ESRF), 38000, Grenoble, France \\ ${ }^{c}$ Univ. Grenoble Alpes - CNRS, LEPMI, 38402 Saint Martin d'Hères, France \\ ${ }^{\mathrm{d}}$ CEA, DAM, DIF, F-91297 Arpajon, France \\ ${ }^{\text {e }}$ SOLIDpower S.p.A., 38017, Mezzolombardo, Italy
}

\begin{abstract}
The electrochemical reactions of hydrogen oxidation and steam reduction have been investigated for a porous cermet electrode made of $\mathrm{Ni}$ and $3 \mathrm{YSZ}$. The electrochemical characterizations have been performed over a large range of gas compositions at $700^{\circ} \mathrm{C}$. It has been shown that the fuel electrode response is activated by the potential under anodic current while a limiting current density appears under cathodic polarization. Moreover, the impedance diagrams exhibit a shape representative of a kind of finite-length Gerischer element with a low-frequency contribution sensitive to the steam content. To interpret these experimental results, a continuous dynamic model has been developed by describing the mass and charge transfers within the electrode. The reaction has been divided into a sequence of elementary steps considering two scenarios of charge transfer based on the oxygen and hydrogen spillover mechanisms. Threedimensional reconstructions obtained by synchrotron X-ray nano-holotomography have been used to provide the cermet structural properties for the simulations. The numerical computations have shown that the hydrogen spillover scenario is the most appropriate mechanism to reproduce correctly the experiments. Besides, the electrode response is controlled by the charge transfer at triple phase boundary lengths, the oxygen vacancies migration in the 3YSZ network and a pure chemical surface process depending on the polarization. In fuel cell mode, desorption of water molecules from 3 YSZ would co-limit the electrode response, while in electrolysis mode, the steam adsorption on Ni would become one of the rate determining steps. Finally, a sensitivity analysis has shown that surface diffusion would also play a key role in the electrode response.
\end{abstract}

Keywords: Reaction Mechanism, Ni-3YSZ cermet, SOFC, SOEC, Modeling, Electrochemical Impedance Spectroscopy, hydrogen spillover, oxygen spillover.

*Corresponding author: Telephone: +334387822 10,

E-mail: jerome.laurencin@cea.fr 


\section{Introduction}

Solid oxide cells (SOCs) are electrochemical devices operating at high temperature that can directly convert fuel into electricity (fuel cell mode - SOFC) or electricity into fuel (electrolysis mode SOEC). In recent years, the interest in SOCs has grown significantly thanks to their wide range of technological applications that could offer innovative solutions for the transition toward a renewable energy market. Indeed, SOCs present various advantages, such as large fuel flexibility and a very high efficiency without the use of expensive catalysts [1,2]. Besides, thanks to their very good reversibility in SOFC and SOEC modes [3-6], the same device can be used to produce hydrogen during the peaks of electricity production and electricity during the peaks of consumption. Therefore, these high-temperature systems appear as a relevant technology to match the fluctuations between the demand and the production caused by the intermittence of renewable energy sources [7].

The SOCs are composed of a dense electrolyte sandwiched between two porous electrodes. The reactions of hydrogen oxidation and steam reduction (Eq. (1a)) take place in the fuel electrode, while oxygen is consumed or produced (Eq. (1b)) in the air electrode. Between the two electrodes, the dense electrolyte is a pure ionic conductor allowing the migration of oxygen vacancies $\left(V_{O}^{\bullet \bullet}\right)$ from one electrode to the other.

$$
\begin{gathered}
H_{2}(g)+O_{o}^{x}(Y S Z) \underset{S O E C}{\stackrel{S O F C}{\rightleftarrows}} H_{2} O(g)+V_{o}^{\bullet \cdot}(Y S Z)+2 e^{-} \\
\frac{1}{2} O_{2}(g)+V_{o}^{\bullet \cdot}(Y S Z)+2 e^{-} \underset{S O F C}{\operatorname{SOEC}} O_{o}^{x}(Y S Z)
\end{gathered}
$$

The state of the art materials for the air electrode are mixed ionic and electronic conductors, such as Lanthanum Strontium Cobalt Ferrite (LSCF) [8], or a composite made of LSCF and Gadoliniumdoped Ceria (GDC) [9]. Besides, a thin barrier layer of GDC is generally added between the air electrode and the electrolyte to limit the reactivity at this interface [10]. The dense electrolyte is usually made of Yttria-Stabilized Zirconia (YSZ) with $8 \mathrm{~mol} . \%$ of yttria (8YSZ) to maximize the ionic conductivity [11]. Finally, the fuel electrode is a porous cermet of nickel and YSZ (Ni-YSZ), in which Ni ensures the electronic conductivity while YSZ serves as ionic conductor. The same YSZ stoichiometry as in the electrolyte (8YSZ) is used in the classical cermet. However, zirconia stabilized with $3 \%$ molar of yttria (3YSZ) is sometimes employed in order to enhance the electrode robustness. Indeed, this tetragonal structure (often referred to as Yttria doped Tetragonal Zirconia Polycrystalline, $3 \mathrm{Y}$-TZP) is known to have a much higher mechanical strength even though its ionic conductivity is lower than that of 8YSZ [12]. 
Despite their numerous advantages, the commercial attractiveness of SOCs is still limited by the high degradation rates compromising their lifetime expectations [10,13,14]. In this frame, it is still needed to improve the tradeoff between cell performances and durability. For this purpose, the elementary reaction mechanisms at the two electrodes need to be precisely understood. Indeed, they are involved in the underlying forces driving the material degradation [15]. Moreover, a deep knowledge of the reaction mechanisms could offer the possibility to optimize further the electrode microstructure or to adjust the materials composition for higher performances and stability $[16,17]$.

Concerning the reaction mechanism in the Ni-YSZ cermet, several experimental works have characterized the electrode behavior using polarization curves ( $\eta-i$ curves) and Electrochemical Impedance Spectroscopy (EIS) [18-33]. Traditionally, these studies were carried out using simplified geometries, such as Ni patterned electrodes, to control the microstructure. Indeed, in this condition, it is possible to establish the relation between the geometrical features of the electrode and its electrochemical response [18-22,28,29]. Nonetheless, despite their crucial importance for theoretical investigations, the full relevance of these studies for the SOCs application is questionable since the real porous electrodes exhibit a very complex microstructure that can strongly affect the reaction mechanism [16]. In this context, very few authors have conducted experiments on representative $\mathrm{Ni}$-YSZ porous electrodes to obtain information under more realistic conditions [23-26,30-33]. In these cases, the exact microstructural properties of the tested electrodes were unknown limiting the possibility for a deep analysis of the results. It is worth noting that most of these experimental studies have been focusing on electrodes made of Ni and 8YSZ, while much less attention has been paid to the characterization of Ni-3YSZ cermet. Besides, most of the works presented in the literature are focused on the reaction for hydrogen oxidation in SOFC mode, whereas there is a lack of investigations in electrolysis conditions. For example, very few studies have been specifically devoted to the electrode response in cathodic polarization [24,25,27] and even less have operated the electrode at high steam partial pressure $\left(\mathrm{pH}_{2} / \mathrm{pH}_{2} \mathrm{O}<1\right)$ [27].

As a general matter for the Ni-8YSZ cermet, it has been shown that the electrode reaction is strongly thermally activated and its kinetic rate is proportional to the density of active Triple Phase Boundary lengths (TPBls, defined by the lines where the percolated ionic (YSZ), electronic (Ni) and gas phases meet) $[19,20,26,29]$. Based on these observations, it has been proposed that the charge transfer at the TPBls should limit the overall electrode response [28]. Moreover, a strong dissymmetry in the two branches of the $\eta$-i curve has been highlighted $[18,23,25,26,28,32]$ with an 
increase of the polarization resistance $\left(\mathrm{R}_{\mathrm{pol}}\right)$ in cathodic polarization (SOEC mode) and a decrease in anodic polarization (SOFC mode) [26]. Finally, an important effect of $\mathrm{pH}_{2} \mathrm{O}$ on the kinetics has been found [21,24-28,33], while the impact of $\mathrm{pH}_{2}$ remains less pronounced [22]. Therefore, it has been inferred from these results that the interaction of steam molecules with the electrode surface could co-limit the global kinetics [25]. It is worth noting that very few experimental studies, which were all published by Jiang and co-authors, have been specifically devoted to the characterization of Ni-3YSZ cermet [34-37]. In their works, the tests were conducted at $1000^{\circ} \mathrm{C}$ in SOFC mode in dry and wet conditions $\left(\% \mathrm{H}_{2} \mathrm{O}_{\max }=14 \%\right)$. They have shown that the electrode response for the $\mathrm{Ni}$ 3 YSZ cermet is co-limited by the charge transfer at TPBls and by a surface process attributed to 'hydrogen dissociation/diffusion on Ni surface' [34]. Besides, they also highlighted a catalytic effect of steam on the reaction kinetics [35].

For the interpretation of the electrode response, a first modeling approach consists to simulate the impedance spectra with Equivalent Circuits (EC). In this frame, Gerischer-type elements are generally well-adapted when the electrode response is controlled by the diffusion of charged species associated with a purely chemical reaction [38-43]. Moreover, it has been recently pointed out that, for a composite electrode such as the Ni-YSZ cermet, the same type of shape for the impedance diagram could be obtained considering a transmission line model $[27,43]$. This model takes into account the resistance due the ionic conduction in the percolated electrolyte material associated all along the electrode thickness with the surface electrode reaction process represented by a parallel combination of a resistance and a constant phase element [43]. Depending on the nature and the microstructure of the electrode, different types of Gerischer elements may be used to reproduce the EIS diagrams. In particular, the classical Gerischer element is well adapted in the case of a semiinfinite diffusion when the reaction region does not extend beyond the electrode thickness [41]. On the contrary, when the extension of the reaction is larger than the electrode itself, the Finite-Length Gerischer (FLG) element must be employed to simulate the electrode response [40,42]. Finally, the fractal Gerischer element, which is characterized by a typical 'skewness' in the impedance diagram, has been proposed to account for the electrode surface roughness [38,43]. Nevertheless, it has been recently suggested that this shape of the impedance spectra could also be associated to physicochemical phenomena occurring in the electrode [38]. Even if the method based on EC simulations is a widespread and convenient approach to analyze the experimental EIS, their full physical meaning remains limited [38]. 
In complementarity with the EC simulations, physically-based modeling is an efficient tool to propose and check the relevance of reaction mechanisms. In this frame, several authors have studied the steam and hydrogen interaction with Ni/YSZ using Density Functional Theory (DFT) to determine the most energetically favorable configuration [44-56]. These theoretical investigations showed that the interaction of hydrogen with the Ni/YSZ system results in dissociative adsorption of $\mathrm{H}_{2}$ on the Ni surface $[44,49,50,54]$, whereas steam molecules can be adsorbed on both surfaces. On $\mathrm{Ni}$ surface, the adsorbed $\mathrm{H}_{2} \mathrm{O}$ could dissociate into a hydroxyl and a surface-attached hydrogen [52], and this hydroxyl can itself be dissociated into surface-attached hydrogen and oxygen [52], whereas the dissociation in two hydroxyl ions would be promoted on YSZ surface $[45,53]$. Chaopradith et al., for instance, have shown that the dissociated state of water is much more stable than the molecular state on the YSZ surface [53]. Other DFT studies have tentatively modeled the triple phase boundary and its impact on the energetics of the elementary processes [46-48,50,56]. Also, it was shown that the crystallographic termination of the Ni surface has an impact on the dissociation energies of water [52].

To account for both the experimental and DFT computational findings, three reaction pathways divided in a sequence of elementary steps have been mainly proposed in the literature. They differ from each other by the nature of the charge transfer across the Ni-YSZ interface with an interstitial process [33], an oxygen spillover mechanism [18], and a hydrogen spillover mechanism [57]. These three reaction pathways have been implemented by several authors into micro-kinetic models and the simulations have been compared to the response of $\mathrm{Ni}$ patterned electrodes [58-63]. The modeling results have shown that the hydrogen spillover would be the most relevant reaction mechanism for the Ni-8YSZ electrode [60-63] even if some recent studies have suggested that the oxygen spillover mechanism could also be involved in the electrode response [48,64]. Moreover, it is worth mentioning that most of the simulations were focused on the steady-state behavior of the electrode ( $\eta$-i curves) whereas very few studies have simulated the dynamic response to take advantage of the EIS measurements $[58,65]$. Besides, to the best of our knowledge, only one study has been dedicated to the micro-kinetic dynamic modeling of representative porous Ni-8YSZ cermet [65]. In that case, the simulations were carried out without knowing the exact microstructure of the cermet and considering a simplified charge transfer mechanism.

From this literature review, it appears that the detailed reaction mechanism of Eq. (1a) remains unclear, especially for porous Ni-3YSZ cermet electrode operated in SOEC condition. Indeed, as pointed out by Hanna et al. [16], there is still a clear need for 'more detailed experimental data and 
refinement of elementary kinetic and transport parameters to improve quantitative model prediction over a wide range of conditions'. In addition, it is necessary to apply these micro-kinetic models to porous cermet microstructures representative of the real SOCs application. Therefore, this work aims to investigate the electrode kinetics and the relevance of the oxygen and hydrogen spillover mechanisms for a typical porous Ni-3YSZ cermet by coupling: (i) electrochemical characterizations of a symmetric cell tested in anodic and cathodic polarizations over a wide range of $\mathrm{pH}_{2} / \mathrm{pH}_{2} \mathrm{O}$, (ii) 3D reconstruction of the Ni-3YSZ cermet obtained by synchrotron-based X-ray nanoholotomography to measure all the microstructural properties required for the simulations, and (iii) detailed micro-kinetic models of the porous electrode able to simulate the electrode response for different experimental conditions in terms of $\eta$-i curves and EIS diagrams.

\section{Materials and Methods}

\subsection{Cell Description}

In Figure 1, a schematic representation of the tested symmetric cell is shown. It is composed of a $8 Y S Z$ electrolyte support which is sandwiched between two porous electrodes made of $\mathrm{Ni}$ and 3 YSZ (Ni-3YSZ cermet). Thick electrolyte $(\approx 300 \mu \mathrm{m})$ provided by the Kerafol ${ }^{\circledast}$ were used for the cell manufacturing. The thickness of the electrodes was limited to $\approx 25 \mu \mathrm{m}$ in order to limit the impact of gas diffusion. In this condition, the reactions are expected to extend in the whole electrode thickness corresponding to the active Functional Layer (FL). Therefore, this configuration is at the same time representative of the real SOCs electrodes and adapted to analyze the kinetics of the reaction mechanism.

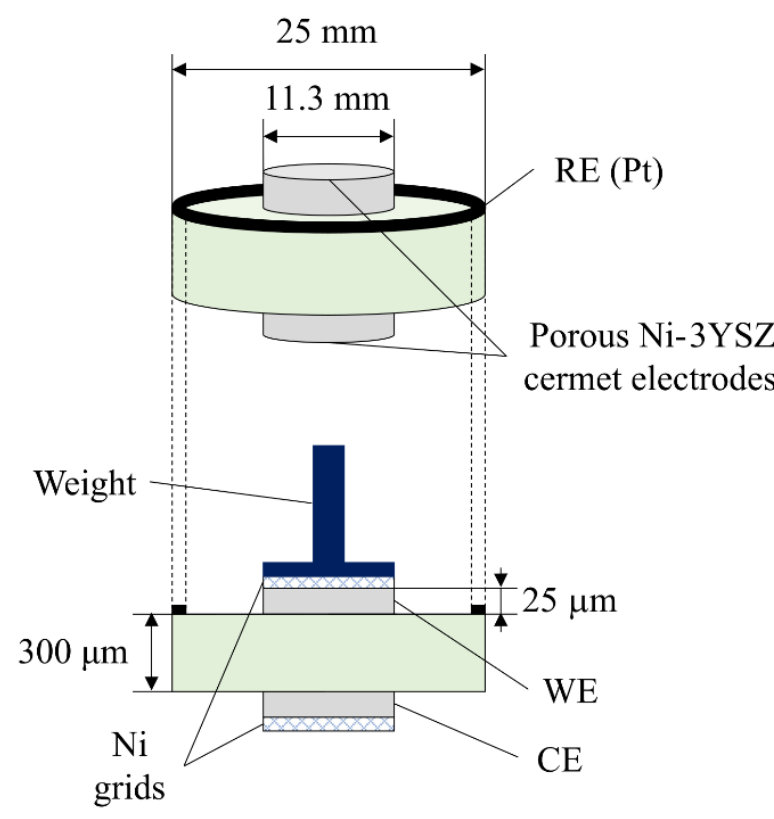

Figure 1: Symmetrical cell used for the experimental characterization. 
The Working and Counter Electrodes (WE and CE, respectively) have a circular shape with a diameter of $11.3 \mathrm{~mm}$ for a surface area of $\approx 1 \mathrm{~cm}^{2}$. They have been screen-printed on the two faces of the solid membrane (disk with a diameter of $\approx 25 \mathrm{~mm}$ ) and then sintered under air at around 1350 ${ }^{\circ} \mathrm{C}$. The nominal volume fractions used for the electrode preparation were 52 vol. $\%$ and 48 vol.\% for $\mathrm{NiO}$ and $3 \mathrm{YSZ}$, respectively. They correspond to a final composition of $39 \mathrm{vol} . \%$ of $\mathrm{Ni}$ and 61 vol.\% of 3 YSZ after the cermet reduction. A platinum wire was used as Reference Electrode (RE) and placed at the periphery of the cell on the upper surface of the electrolyte (Figure 1). Special attention has been paid to position the RE as far as possible from the electrodes. Moreover, the WE and CE were carefully aligned with each other and centered onto the electrolyte disk. Consequently, the geometrical rules to ensure the reliability of the measurements with a three-electrode configuration have been fulfilled [66]. Finally, two nickel grids having the same diameter as the electrodes and with a density of $3600 \mathrm{mesh} \cdot \mathrm{cm}^{-2}$ have been used as Current Collectors (CCs).

\subsection{Experimental Setup and Testing Conditions}

The test has been conducted in a specific ceramic holder consisting of a single gas chamber supplied by a mixture of $\mathrm{H}_{2}$ and $\mathrm{H}_{2} \mathrm{O}$. This experimental set-up was placed in a furnace for which the temperature changes were applied using a slow heating rate of $1^{\circ} \mathrm{C} \cdot \mathrm{min}^{-1}$ to avoid any mechanical damaging in the cell. It is worth noting that the setup was designed with the total volume of the gas chamber limited to $\approx 50 \mathrm{~cm}^{3}$ while all the measurements were performed with a high inlet flowrate of reactants $\left(1-6 \mathrm{Nl} \cdot \mathrm{h}^{-1}\right)$. These conditions were chosen to avoid any gas starvation in the electrodes, and hence, to limit the concentration overpotentials in the gas phase as much as possible. Moreover, a compressive load of $1 \mathrm{~kg}$ was applied to the current collectors to minimize the contact resistances between the electrodes and the grids. All these precautions were taken to avoid the pollution of the electrode response with artifacts coming from the experimental setup.

To investigate a wide range of gas compositions, specific attention has been paid to the water management to ensure a constant flowrate without fluctuations up to high steam content, and thus, to limit the perturbations in the measurements. For this purpose, the vapor was produced using a steam generator, which was kept in saturated conditions and was directly connected to a gas flowmeter. A second gas flowmeter was used for hydrogen, and the two fluxes were mixed in the inlet pipe before entering the chamber. All the tubes were kept at $\approx 130^{\circ} \mathrm{C}$ to avoid any 
condensation. Finally, the exhausting gas was sent to a heat exchanger to separate the liquid $\mathrm{H}_{2} \mathrm{O}$ and the $\mathrm{H}_{2}$.

Concerning the experimental protocol, two cells were tested to check the reproducibility according to the following procedure. The tested cells were reduced under pure $\mathrm{H}_{2}$ at $800^{\circ} \mathrm{C}$ for 24 hours. Subsequently, the cells were operated at $700^{\circ} \mathrm{C}$ for the whole duration of the test. In the first part of the characterization, the electrodes were swept under three gas compositions: $\mathrm{pH}_{2} / \mathrm{pH}_{2} \mathrm{O}=25 / 75$, $50 / 50$ and $75 / 25$. For each composition, the $\mathrm{i}-\mathrm{V}$ curves measured between the electrodes and the reference $\left(\mathrm{WE} / \mathrm{CE}\right.$ vs $\left.\mathrm{RE}=\mathrm{E}^{\text {meas }}(\mathrm{V} / \mathrm{ref})\right)$ were recorded in a potentiostatic mode between $+0.2 \mathrm{~V}$ and $-0.2 \mathrm{~V}$ with a step of $2 \mathrm{mV} \cdot \mathrm{s}^{-1}$. Besides, the impedance spectra at Open Circuit Potential (OCP) have been measured in a galvanostatic mode in the frequency range $10^{-1}-10^{6} \mathrm{~Hz}$ using a sinusoidal perturbation $\left(\mathrm{i}_{\mathrm{AC}}\right)$ of $+/-5 \mathrm{~mA} \cdot \mathrm{cm}^{-2}$. From the EIS data, the ohmic resistance $\left(\mathrm{R}_{\mathrm{s}}\right)$ and the polarization resistance have been obtained considering the intercepts of the diagram with the real axis at high frequency $\left(R_{s}\right)$ and low frequency $\left(=R_{s}+R_{p o l}\right)$. The overpotential of the WE at each current density ( $\eta-\mathrm{i}$ curve) has been determined by subtracting the ohmic contribution $\left(=R_{S} \cdot i_{D C}\right)$ to the overall voltage drop (i-V curve) (i.e. $\left.\eta(V / R e f)=\left(E_{W E}^{\text {meas }}(V / R e f)-R_{S} \cdot i_{D C}\right)-E_{W E}^{e q}(V / R e f)\right)$. In the second part of the test, a large range of gas compositions has been investigated $\left(\mathrm{pH}_{2} / \mathrm{pH}_{2} \mathrm{O}=\right.$ 20/80, 30/70, 40/60, 50/50, 60/40, 70/30 and 80/20) and for each condition, the EIS at OCP has been measured to determine the dependency of the polarization resistance on $\mathrm{pH}_{2}$ and $\mathrm{pH}_{2} \mathrm{O}$. All the measurements have been performed with an Autolab PGSTAT-302N electrochemical workstation. A third pristine cell, coming from the same batch, has been reduced using the same protocol and its microstructure has been reconstructed via synchrotron-based X-ray nano-holotomography.

\subsection{Reconstruction}

To perform the holotomography experiment, a micro-pillar with a diameter of $\approx 37 \mu \mathrm{m}$ containing the Ni-3YSZ electrode and a part of the electrolyte has been extracted from the reduced cell (Figure $2 a)$.

The specimen preparation has been carried out using a plasma-focused ion beam (pFIB) Vion $\left(\mathrm{FEI}^{\mathrm{TM}}\right)$, in which $\mathrm{Xe}^{+}$ions are used to mill the material allowing fast sample preparation. The details about the extraction procedure can be found elsewhere [14,67]. The micro-pillar, fixed on an Aluminum tip, has been characterized by X-ray holotomography at the Nano Imaging beamline ID16A of the European Synchrotron Radiation Facility (ESRF) [68]. The data acquisition and the algorithm for the reconstruction have been previously adapted to the SOC materials [69,70]. With 
this technique, a large representative volume of $\approx 40 \times 20^{2} \times \pi \mu \mathrm{m}^{3}$ can be reconstructed while keeping a fine spatial resolution of $\approx 40 \mathrm{~nm}$ (voxel size of $20 \mathrm{~nm}$ ) [67].

From the raw 3D reconstruction, the microstructural properties of the cermet have been computed and used as input parameters in the micro-scale kinetic models described hereafter.

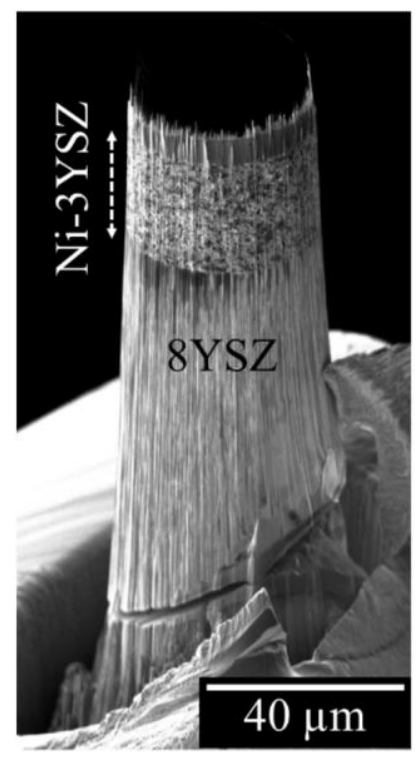

a)

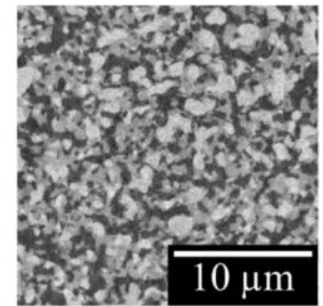

b)

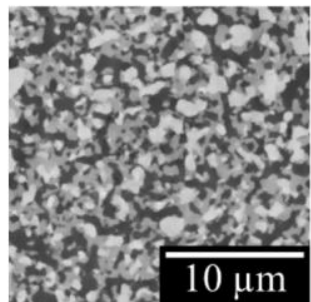

c)

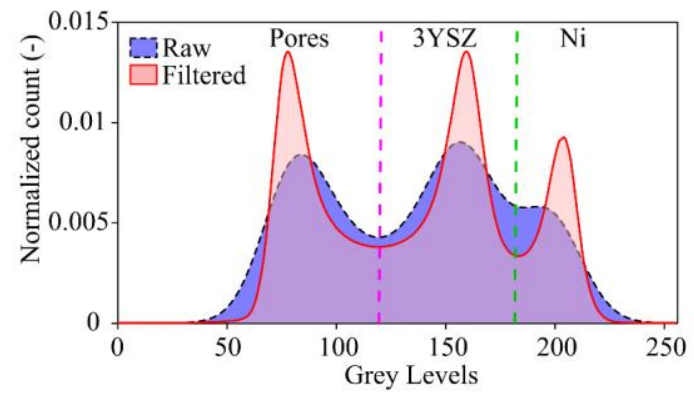

d)

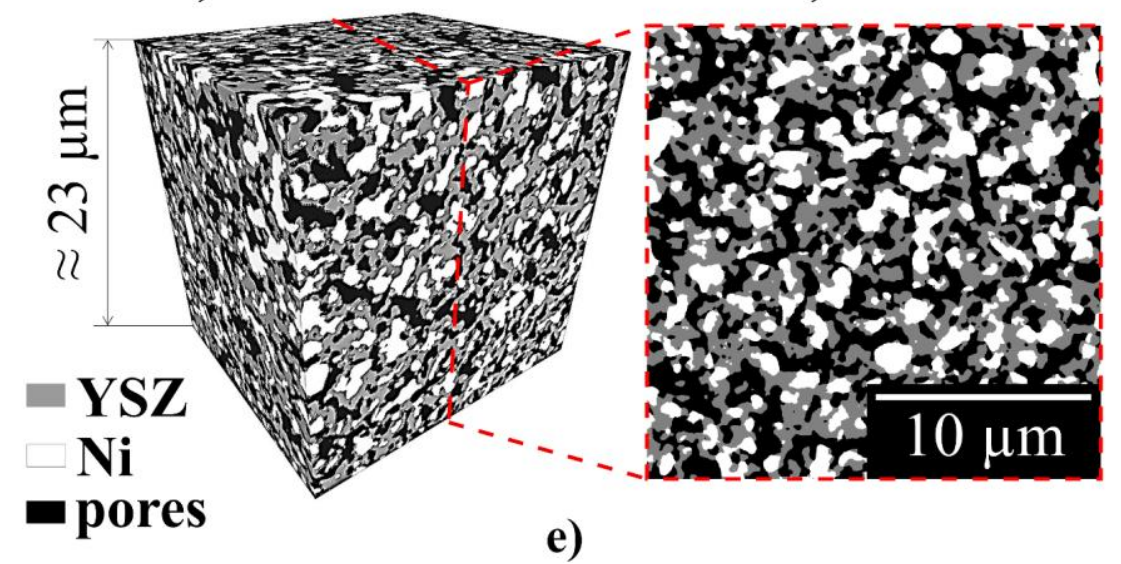

Figure 2: Procedure for the electrode reconstruction: a) Pillar extracted from the reduced cell containing the Ni-3YSZ electrode - b) 2D cross-section extracted from the raw reconstruction - c) 2D cross-section extracted from the filtered reconstruction - d) Grey-level histograms for the raw and filtered image highlighting the three phases present in the volume and the thresholds used in the segmentation (in pink and green, respectively) - e) 3D rendering volume and $2 \mathrm{D}$ cross-section extracted from the final segmented reconstruction.

\section{Models Description}

\subsection{General Assumptions and Reaction Mechanisms}

Two micro-kinetic models have been developed in parallel: Model I, in which the oxygen spillover mechanism has been implemented [18,58] and Model II, in which the hydrogen spillover 
mechanism has been considered [57,60,61]. In both models, an isothermal slice (1D) of the $\mathrm{Ni}$ 3YSZ electrode perpendicular to the electrolyte is considered. As shown in Figure 3a, the simulated domain includes the entire functional layer and half of the electrolyte $\left(0 \leq z \leq \ell_{E L}+\ell_{F L}\right)$.

The electrode is modeled as a continuous equivalent medium for which the kinetics rates of the reactions and the effective transport properties are scaled on the microstructural parameters deduced from the $3 \mathrm{D}$ reconstruction. Mass and charge balances are considered for all the simulated species including source/sink terms related to the reaction rates and a transient term to account for the timedependent response of the electrode.

The schematic reaction mechanisms implemented in the two models are depicted in Figure $3 \mathrm{~b}$ and Figure 3c for the oxygen (Model I) and hydrogen (Model II) spillover mechanisms, respectively. As a general approach, all the elementary reactions have been expressed using the mass-action kinetic theory $[71,72]$. In this frame, the chemical and electrochemical reactions can be written according to Eqs. (2a) and (2b), respectively.

$$
\begin{gathered}
\sum_{j=1}^{\text {react } C R} q_{j} R_{j} \underset{k^{b}}{\stackrel{k^{f}}{\rightleftarrows}} \sum_{k=1}^{\text {prod }_{C R}} q_{k} P_{k} \\
\sum_{j=1}^{\text {react }_{E R}} q_{O_{j}} R_{O_{j}}+n e^{-} \underset{k^{o x}}{\stackrel{k^{\text {red }}}{\rightleftarrows}} \sum_{k=1}^{\text {prod }_{E R}} q_{R_{k}} P_{R_{k}}
\end{gathered}
$$

In which $R / P$ are the reacting/produced species, $q_{j-k}$ are their respective stoichiometry coefficients, $n$ is the number of electrons transferred in the reaction and $k^{f}, k^{b}, k^{r e d}, k^{o x}$ denote the forward, backward, reduction and oxidation kinetic constants, respectively. 


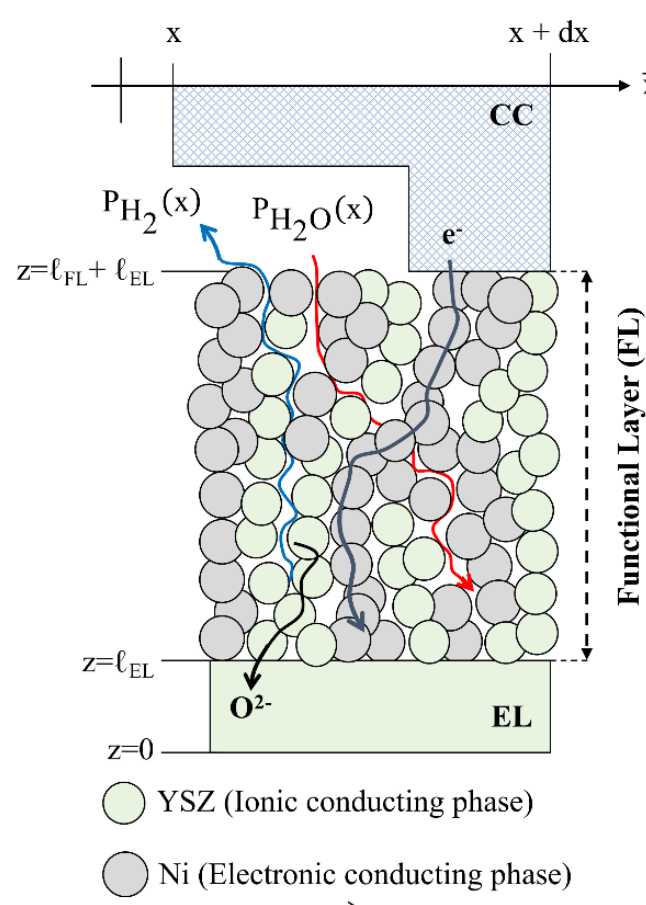

a)

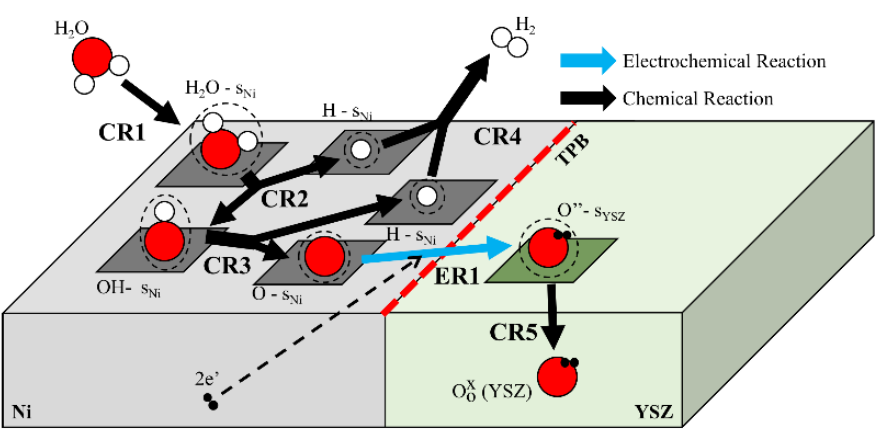

b)

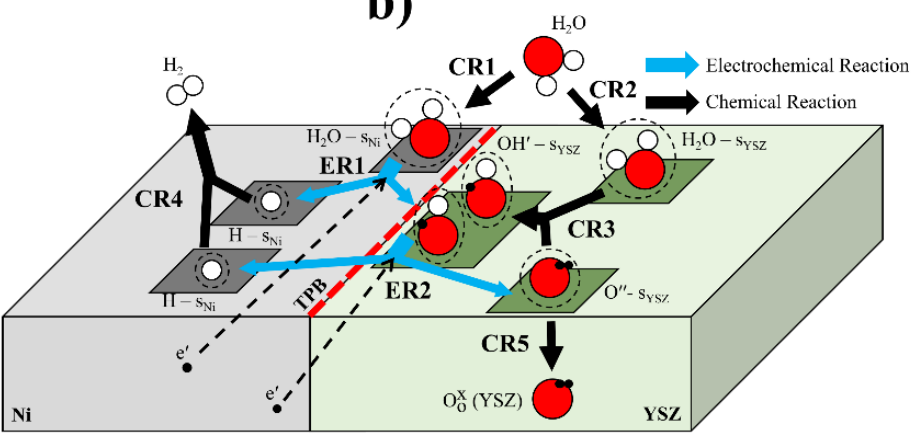

c)

Figure 3: Illustration of the Ni-3YSZ cermet modeling in electrolysis mode: a) Scheme of the electrode containing part of the electrolyte (EL), the functional layer (FL) and part of the current collector layer (CC) - b) Representation of the oxygen spillover mechanism implemented in Model I - c) Representation of the hydrogen spillover mechanism implemented in Model II.

For Model I based on the oxygen spillover charge transfer, the expressions of the reactions (2a) and (2b) are detailed in Table I. This reaction pathway was firstly implemented by Bierberle et al. [58] who assumed that the gas species only interact with the $\mathrm{Ni}$. In electrolysis mode (i.e. cathodic polarization), the steam is adsorbed on the Ni surface (CR1) before to be dissociated into a hydroxyl and a hydrogen adatom (CR2). The hydroxyl is further decomposed into an adsorbed oxygen and a hydrogen adatom (CR3). Finally, the two surface-attached hydrogen atoms are desorbed to produce the dihydrogen gaseous molecule in the electrode porosity (CR4). In parallel, the oxygen is electrochemically reduced according to the spillover reaction of charge transfer across the Ni/YSZ at the TPBls (ER1). Finally, the oxygen ions onto the YSZ surface are incorporated into the lattice by consuming one vacancy (CR5). The opposite mechanism occurs in fuel cell mode (i.e. anodic polarization) so that the total reaction mechanism is described by five chemical reactions (CR) and one electrochemical reaction (ER).

Table I: Reactions for Model I (expressed in electrolysis mode with the abbreviations CR and ER referring to the chemical and electrochemical reactions, respectively)

CR1 Steam adsorption on the Ni surface $\quad \mathrm{H}_{2} \mathrm{O}($ gas $)+\underset{\mathrm{N}_{\mathrm{N}} \mathrm{H}_{\mathrm{Ni}}^{D E S}}{\rightleftarrows} \mathrm{H}_{2} \mathrm{O}_{\mathrm{Ni}}$




$$
\begin{aligned}
& k_{\mathrm{H}_{2} \mathrm{O}_{\mathrm{Ni}}}^{\mathrm{DISS+}}
\end{aligned}
$$

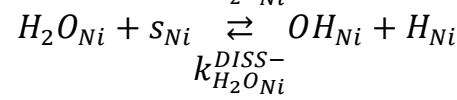

$$
\begin{aligned}
& k_{O H_{N i}}^{D I S S+} \\
& O H_{N i}+s_{N i} \underset{k_{O H}^{D I S S-}}{\stackrel{2}{\rightleftarrows}} O_{N i}+H_{N i} \\
& 2 H_{N i} \underset{k_{H_{2 N i}} \underset{H_{2 N i}}{\rightleftarrows}}{\stackrel{A_{D S S}}{D E S}} H_{2}(\text { gas })+2 s_{N i} \\
& k^{\text {red }} \\
& O_{N i}+s_{Y S Z}+2 e_{N i}^{-} \underset{k^{o x}}{\rightleftarrows} O_{Y S Z}^{2-}+s_{N i} \\
& k_{O_{Y S Z}^{2} \bar{C}}^{I N C} \\
& O_{Y S Z}^{2-}+V_{o}^{\ddot{O}}(Y S Z) \stackrel{\longrightarrow}{\rightleftarrows} O_{O}^{x}(Y S Z)+s_{Y S Z} \\
& k_{O_{Y S Z}^{2} \bar{C} Z}^{E X}
\end{aligned}
$$

CR3 Hydroxyl dissociation on Ni surface

CR4 Hydrogen desorption from the Ni surface

ER1

oxygen spillover from the Ni to the YSZ

CR5 Oxygen incorporation in the YSZ lattice

The detail of reactions (2a) and (2b) for Model II is provided in Table II. This model is based on the version of the hydrogen spillover mechanism proposed by Goodwin et al. [60]. In our approach, it is still assumed that hydrogen interacts only with $\mathrm{Ni}$ whereas a competitive adsorption/desorption of water is considered for both materials. Considering the cathodic polarization, steam can be adsorbed on Ni and YSZ surface (CR1 and CR2) and two intertwined pathways are possible to produce the hydrogen. On the one hand, the $\mathrm{H}_{2} \mathrm{O}$ attached to $\mathrm{Ni}$ can be electrochemically reduced at the TPBls to form one hydrogen on the Ni surface and one hydroxyl ion on the YSZ surface (ER1). On the other hand, the $\mathrm{H}_{2} \mathrm{O}$ attached to the $\mathrm{YSZ}$ can react with an oxygen ion on the surface to produce two hydroxyl ions (CR3). These $\mathrm{OH}^{-}$species attached on the YSZ surface are subsequently reduced

\begin{tabular}{|c|c|c|}
\hline CR1 & Steam adsorption on the Ni surface & 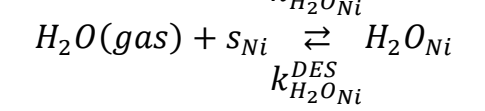 \\
\hline CR2 & Steam adsorption on the YSZ surface & $H_{2} \mathrm{O}($ gas $)+s_{Y S Z} \underset{k_{\mathrm{H}_{2} \mathrm{O}_{Y S Z}}^{D E S}}{\stackrel{k_{\mathrm{H}_{2} \mathrm{O}_{Y S Z}}^{A D S}}{\rightleftarrows}} H_{2} \mathrm{O}_{Y S Z}$ \\
\hline CR3 & $\mathrm{H}_{2} \mathrm{O}$ dissociation on $\mathrm{YSZ}$ surface & $H_{2} O_{Y S Z}+O_{Y S Z}^{2-} \underset{k_{H_{2} O_{Y}}^{D I S S Z}}{\stackrel{k_{H_{2} O_{Y S Z}}^{D I S S+}}{\rightleftarrows}} 2 O H_{Y S Z}^{-}$ \\
\hline
\end{tabular}
with a second charge transfer according to a hydrogen spillover mechanism, resulting in the formation of a hydrogen adatom on $\mathrm{Ni}$ and an oxygen ion on YSZ (ER2). Finally, the adsorbed hydrogens on $\mathrm{Ni}$ are desorbed in the gas phase (CR4) while the oxygen ion is incorporated in the YSZ lattice (CR5). As for Model I, the reaction is reversed in anodic polarization so that this mechanism is divided into five CR and two ER.

Table II: Reactions for Model II (expressed in electrolysis mode with the abbreviations CR and ER referring to the chemical and electrochemical reactions, respectively) 


$$
\begin{aligned}
& \text { CR4 Hydrogen desorption from the Ni surface } \\
& 2 H_{N i} \underset{k_{H_{2 N i}}^{A D S}}{\stackrel{k_{2 N i}^{D E S}}{\rightleftarrows}} H_{2}(\text { gas })+2 s_{N i} \\
& \text { ER1 First charge transfer reaction } \\
& H_{2} O_{N i}+s_{Y S Z}+1 e_{N i}^{-} \underset{k_{1}^{o x}}{\stackrel{k_{1}^{r e d}}{\rightleftarrows}} O H_{Y S Z}^{-}+H_{N i} \\
& \text { ER2 Second charge transfer reaction } \\
& k_{2}^{\text {red }} \\
& O H_{Y S Z}^{-}+s_{N i}+1 e_{N i}^{-\underset{k_{2}^{o x}}{\rightleftarrows}} O_{Y S Z}^{2-}+H_{N i}
\end{aligned}
$$

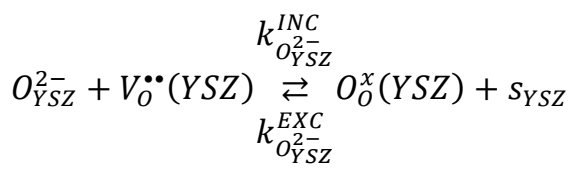

$$
\begin{aligned}
& \text { CR5 Oxygen incorporation in the YSZ lattice }
\end{aligned}
$$

In the next sections, the general set of equations used to express the reaction kinetics rates together with the charge and mass transfer in the electrodes phases are reported. The application of these general equations to Model I and Model II are detailed in Appendix A and B, respectively.

\subsection{Thermodynamics and Kinetics of the Reactions}

Considering the surface elementary steps of the two mechanisms, their kinetic rates can be written according to the general expression (3a) for the chemical reactions (2a) and using a Butler-Volmer formalism (3b) for the electrochemical reactions $(2 b)$.

$$
\begin{gathered}
v^{C R}=S p_{a-b} \cdot\left(k^{f} \cdot \prod_{j=1}^{\text {react } C R} a_{j}^{q_{j}}-k^{b} \cdot \prod_{k=1}^{\text {prod }}{ }_{C R} a_{k}{ }^{q_{k}}\right) \\
v^{E R}=\xi^{T P B l s} \cdot\left(k^{\text {red }} \cdot \prod_{j=1}^{\text {react }}{ }_{E R} a_{O_{j}}^{q_{O_{j}}} \cdot \exp \left(\frac{-\alpha_{r e d} n F}{R T} E\right)-k^{o x} \cdot \prod_{k=1}^{\operatorname{rrod}_{E R}} a_{R_{k}}{ }^{q_{R_{k}}} \cdot \exp \left(\frac{\alpha_{o x} n F}{R T} E\right)\right)
\end{gathered}
$$

In which $v$ is the kinetic rate $\left(\mathrm{mol} \cdot \mathrm{m}^{-3} \cdot \mathrm{s}^{-1}\right), a$ is the activity and $\alpha_{\text {red/ox }}$ are the reduction/oxidation transfer coefficients $\left(\alpha_{\text {red }}+\alpha_{o x}=1\right)$, which are taken as 0.5 each. $F, R$, and $T$ are Faraday's constant $\left(\mathrm{C} \cdot \mathrm{mol}^{-1}\right)$, the universal gas constant $\left(\mathrm{J} \cdot \mathrm{mol}^{-1} \cdot \mathrm{K}^{-1}\right)$ and the operating temperature $(\mathrm{K})$, respectively. As already mentioned, the kinetic rates of the reactions are dependent on the electrode microstructural properties. Therefore, the kinetic rates (3a) and (3b) for the equivalent homogeneous medium are respectively proportional to the $\mathrm{Ni} /$ gas or YSZ/gas interfacial specific surface area $\left(S p_{a-b}, \mathrm{~m}^{-1}\right)$ and the density of active TPBls $\left(\xi^{T P B l s}, \mathrm{~m}^{-2}\right)$. Finally, $E(z)$ is the local potential in the electrode (V) expressed as the difference between the local electronic potential in the $\mathrm{Ni}\left(\varphi_{e l}\right)$ and the local ionic potential in the $\mathrm{YSZ}\left(\varphi_{i o}\right)(\mathrm{Eq} .(4))$.

$$
E(z)=\varphi_{e l}(z)-\varphi_{i o}(z)=-\frac{\tilde{\mu}_{e^{-}}}{F}+\frac{\tilde{\mu}_{O^{2-}}}{2 F}
$$

Where $\tilde{\mu}_{e^{-}}$and $\tilde{\mu}_{O^{2-}}$ denote the electrochemical potentials $\left(\mathrm{J} \cdot \mathrm{mol}^{-1}\right)$ for the electrons in $\mathrm{Ni}$ and the oxygen ions in YSZ (considering: $\tilde{\mu}_{V_{o}}=-\tilde{\mu}_{O^{2-}}$ ). 
Ideal solutions for the gas and the surface species have been assumed in the models so that the activities are directly given by the partial pressure $\mathrm{p}_{\mathrm{i}}$ or the surface concentration $\mathrm{C}_{\mathrm{i}}$ through Eqs. (5a) and (5b).

$$
\begin{gathered}
a_{g a s, i}=\frac{p_{g a s, i}}{p_{r e f}} \\
a_{a d s, i}=C_{a d s, i_{S}}=\Gamma_{S} \theta_{a d s, i_{S}}
\end{gathered}
$$

Where $p_{g a s, i}$ represent the $\mathrm{i}$-th gas partial pressure (bar), $p_{\text {ref }}$ the reference pressure $(1 \mathrm{bar})$ and $\Gamma_{S}$ is the total density of sites available for adsorption on the surface $\mathrm{S}\left(\mathrm{mol} \cdot \mathrm{m}^{-2}\right)$. In Eq. $(5 \mathrm{~b}), \theta_{a d s, i_{S}}$ represents the surface coverage of $i$-th species on the surface S. In coherence with the previous expression of surface activities, a Langmuir isothermal model has been adopted with a monolayer coverage on the Ni or YSZ surface so that $\sum \theta_{a d s, i}+\theta_{s}=1$ (where $\theta_{s}$ represents the fraction of empty surface sites that are still available for adsorption).

Conversely to the other species that evolve with the position in the electrode and the polarization, the activities of the vacancies $V_{O}^{\bullet \bullet}(Y S Z)$ and oxygen atoms $O_{O}^{x}(Y S Z)$ in the bulk of YSZ have been taken constant. Indeed, the 3YSZ remains a good ionic conductor with a high concentration of charge carrier so that [73]:

$$
\begin{gathered}
a_{V_{O}^{*}}=\frac{C_{V_{O}}}{C_{O_{O}^{x}(Y S Z)}^{r e f}} \approx \text { cte } \quad \text { with } C_{V_{O}^{*}}=4 \cdot \frac{\% Y_{2} O_{3}}{V_{U C} \cdot N_{a}} \\
a_{O_{O}^{x}}=\frac{C_{O_{O}^{x}}^{r e f}}{C_{O_{O}^{x}(Y S Z)}^{r e f}} \text { with } C_{O_{O}^{x}} \approx C_{O_{O}^{x}(Y S Z)}^{r e f}=4 \cdot \frac{2-\% Y_{2} O_{3}}{V_{U C} \cdot N_{a}}
\end{gathered}
$$

Where $\% \mathrm{Y}_{2} \mathrm{O}_{3}$ is the molar percentage of Yttria in the $3 \mathrm{YSZ}$ (i.e. $\% \mathrm{Y}_{2} \mathrm{O}_{3}=0.03$ ), $\mathrm{V}_{U C}$ is the volume of the unit cell for the tetragonal zirconia $\left(\mathrm{m}^{3}\right)$ [74] and $N_{a}$ is Avogadro's number $\left(\right.$ atoms $\cdot \mathrm{mol}^{-1}$ ).

For each reaction i, the forward and backward kinetic constants are linked via the thermodynamic equilibrium constant $\left(K^{e q}\right)$. Regarding the chemical reactions, the equilibrium constants are determined from the thermodynamic data using Eqs. (7a) and (7b).

$$
\begin{gathered}
K_{i}^{e q}=\frac{k^{f, i}}{k^{b, i}}=\exp \left(\frac{-\Delta g_{i}^{0}(T)}{R T}\right) \\
\Delta g_{i}^{0}(T)=\sum_{j=1}^{\operatorname{prod}_{C R_{i}}}\left[h_{j}^{0}(T)-T s_{j}^{0}(T)\right]-\sum_{k=1}^{\text {react }_{C R_{i}}}\left[h_{k}^{0}(T)-T s_{k}^{0}(T)\right]
\end{gathered}
$$

In which $\Delta g_{i}^{0}$ represents the Gibbs free energy variation $\left(\mathrm{J} \cdot \mathrm{mol}^{-1}\right)$ for the $\mathrm{i}$-th reaction at standard pressure of reactants and products and $h_{m}^{0}, s_{m}^{0}$ represents the standard enthalpy and entropy of 
formation of the m-th species, expressed in $\left(\mathrm{J} \cdot \mathrm{mol}^{-1}\right)$ and $\left(\mathrm{J} \cdot \mathrm{K}^{-1} \cdot \mathrm{mol}^{-1}\right)$, respectively. The data for the standard enthalpies and entropies listed in Table III for the gas, the adsorbed and the bulk species are taken from the literature $[75,76]$ at an operating temperature of $700^{\circ} \mathrm{C}$.

Table III: Thermodynamic data for the species used in the models at $700^{\circ} \mathrm{C}[75,76]$

\begin{tabular}{lll}
\hline Species & Standard enthalpy $\left(\mathbf{J} \cdot \mathbf{m o l}^{\mathbf{1}}\right)$ & Standard entropy $\left(\mathbf{J}^{\cdot} \mathbf{K}^{-1} \cdot \mathbf{m o l}^{-\mathbf{1}}\right)$ \\
\hline$H_{2}(g)$ & $19.8 \times 10^{3}$ & 165.4 \\
$H_{2} O(g)$ & $-216.9 \times 10^{3}$ & 231.6 \\
$H_{N i}$ & $-31.8 \times 10^{3}$ & 40.7 \\
$H_{2} O_{N i}$ & $-273 \times 10^{3}$ & 130 \\
$O H_{N i}$ & $-193 \times 10^{3}$ & 106 \\
$O_{N i}$ & $-222 \times 10^{3}$ & 39 \\
$H_{2} O_{Y S Z}$ & $-273 \times 10^{3}$ & 98 \\
$O H_{Y S Z}^{-}$ & $-282.5 \times 10^{3}$ & 67 \\
$O_{Y S Z}^{2-}$ & $-236.4 \times 10^{3}$ & 0 \\
$O_{O}^{x}(Y S Z)$ & $-236.4 \times 10^{3}$ & 0 \\
$V_{O}^{\bullet}(Y S Z)$ & 0 & 0 \\
\hline
\end{tabular}

Once the equilibrium constants of the chemical reactions are determined, they are used to calculate the surface coverages at equilibrium for the adsorbed species taking advantage of the relation of $K^{e q}$ with the activities (Eq. (8)). Finally, the coverages at equilibrium are used to determine the equilibrium constants of the electrochemical reactions according to Eq. (9).

$$
\begin{gathered}
K_{C R_{i}}^{e q}=\frac{k^{f, i}}{k^{b, i}}=\frac{\prod a_{\text {prod }_{C R_{i}}}^{e q}}{\prod a_{\text {react }_{C R_{i}}}^{e q}} \\
K_{E R_{i}}^{e q}=\frac{k^{r e d, i}}{k^{o x, i}}=\frac{\prod a_{\text {rrod }_{E R_{i}}}^{e q}}{\prod a_{\text {react }_{E R_{i}}}^{e q}} \exp \left(\frac{n F}{R T} E^{e q}\right)
\end{gathered}
$$

It can be noticed that the equilibrium potential $\left(E^{e q}\right)$ is equal to the chemical potential of oxygen in the gas phase taken at the reference electrode. Indeed, it is assumed that the reference is at equilibrium and exposed to the same atmosphere: $E_{W E}^{e q}(V / R e f)=-\frac{\widetilde{\mu}_{e}^{W E}(i=0)}{F}+\frac{\widetilde{\mu}_{e}^{r e f}(i=0)}{F}=-\frac{\widetilde{\mu}_{e}^{W E}(i=0)}{F}+$ $\frac{\widetilde{\mu}_{O^{2-}}^{\text {electrolyte }}(i=0)}{2 F}-\frac{\widetilde{\mu}_{O_{2}(g a s)}^{r e f}}{4 F}=E^{e q}-\frac{\widetilde{\mu}_{O_{2}(g a s)}^{r e f}}{4 F}\left(\right.$ and $E_{W E}^{e q}(V / R e f)=0$, assumption which is well experimentally verified for our system). 


\subsection{Mass and Charge Transport for the Model Species}

In the models, Fick's law is used to describe the diffusion of gas and surface-attached species, whereas the electronic current in $\mathrm{Ni}$ and the ionic current in YSZ are computed considering classical Ohm's law.

(i) For the gas species, the mass balances and the equations to express the diffusive flux are reported in Eqs. (10a) and (10b).

$$
\begin{gathered}
\varepsilon_{\text {pores }} \frac{d C_{i}}{d t}=-\nabla \cdot \vec{N}_{i} \pm \dot{S}_{i} \\
\vec{N}_{i}=-D_{i}^{e f f} \nabla C_{i}
\end{gathered}
$$

In which $\varepsilon_{\text {pores }}$ is the pore volume fraction in the electrode while $C_{i}$ and $\vec{N}_{i}$ are the molar concentration $\left(\mathrm{mol} \cdot \mathrm{m}^{-3}\right)$ and flux $\left(\mathrm{mol} \cdot \mathrm{m}^{-2} \cdot \mathrm{s}^{-1}\right)$ of the i-th species. $\dot{S}_{i}$ represent the source/sink term associated with the reactions in which the $\mathrm{i}$-th species is produced $/$ consumed $\left(\mathrm{mol} \cdot \mathrm{m}^{-3} \cdot \mathrm{s}^{-1}\right)$ and $D_{i}^{e f f}$ represents the effective gas diffusion coefficient for the i-th species $\left(\mathrm{m}^{2} \cdot \mathrm{s}^{-1}\right)$.

The effective diffusion coefficient in (10b) is derived from the Dusty-Gas Model (DGM) by neglecting the permeation flux [77]. This last approximation is especially relevant for the microstructure of typical Ni-YSZ electrodes for which the mass transfer is fully limited by the gas diffusional process [78]. In this condition, the effective coefficient $\left(D_{i}^{\text {eff }}\right)$ given in Eq. (11) is a combination of the binary diffusion coefficient $\left(D_{i-j}^{\text {eff }}\right)$ and the Knudsen diffusion coefficient $\left(D_{K, i}^{\text {eff }}\right)$ for a multi-component gas mixture composed of $\mathrm{H}_{2}, \mathrm{H}_{2} \mathrm{O}$ and a neutral gas used as a diluent, such as nitrogen [77].

$$
D_{i}^{e f f}=\left(\frac{1}{D_{K, i}^{e f f}}+\frac{1}{D_{i-i . g .}^{e f f}}+\left(\frac{1}{D_{i-j}^{e f f}}-\frac{1}{D_{i-i . g .}^{e f f}}\right) \cdot\left(1-x_{i . g .}\right)\right)^{-1}
$$

Where $x_{i . g}$ is the molar fraction of inert gas in the gas flow (e.g. $\mathrm{N}_{2}$ ). The Knudsen diffusion coefficient is reported in Eq. (12a) while the binary diffusion coefficient is expressed according to Fuller's theory and is reported in Eq. (12b) [77].

$$
\begin{gathered}
D_{K, i}^{e f f}=\frac{\varepsilon_{\text {pores }}}{\tau_{\text {pores }}} \cdot \bar{r}_{\text {pores }} \cdot \frac{2}{3} \sqrt{\frac{8 \cdot 1000 \cdot R T}{\pi m_{i}}} \\
D_{i-j}^{e f f}=\frac{\varepsilon_{\text {pores }}}{\tau_{\text {pores }}} \cdot \frac{0.00143}{P_{\text {tot }} \cdot\left(\sqrt[3]{V_{i}}+\sqrt[3]{V_{j}}\right)^{2} \cdot \sqrt{\frac{2}{\frac{1}{m_{i}}+\frac{1}{m_{j}}}}} \cdot T^{1.75} \cdot 10^{-4}
\end{gathered}
$$


In which $\tau_{\text {pores }}$ is the apparent tortuosity factor for the gas phase, $\bar{r}_{\text {pores }}$ is the mean pores radius (m), $m_{i}$ is the molar mass of the i-th species expressed in $\mathrm{g} \cdot \mathrm{mol}^{-1}$ and $V_{i}$ is the Fuller volume of the i-th species taken from [79].

(ii) The diffusion and mass conservation of surface-attached species on $\mathrm{Ni}$ and YSZ have been modeled using Eq. (13a) and Eq. (13b), respectively.

$$
\begin{gathered}
\vec{N}_{a d s, i}=-S p_{a-b} D_{a d s, i_{S}} \nabla C_{a d s, i_{S}} \\
S p_{a-b} \frac{d C_{a d s, i_{S}}}{d t}=-\nabla \cdot \vec{N}_{a d s, i} \pm \dot{S}_{i}
\end{gathered}
$$

In which $D_{a d s, i_{S}}$ represents the surface diffusion coefficient of the i-th species on Ni or YSZ expressed in $\mathrm{m}^{2} \cdot \mathrm{s}^{-1}$. All the surface diffusion coefficients at $700^{\circ} \mathrm{C}$ are taken from the literature [61]. However, it can be pointed out that a rather large range of uncertainty is expected on these parameters, as the experimental determination of surface diffusion coefficients remains very challenging. Also, despite recent progress in the DFT description of the interaction of water with the YSZ surface [50,53], the mechanisms by which the hydroxyls migrate on the YSZ surface remain unclear, as well as their energy barriers, making it difficult to use available DFT results to estimate a diffusion coefficient of water or $\mathrm{OH}$ on this surface. Note that the crystallographic orientation of the surface, especially for $\mathrm{Ni}$, obviously impacts the energy barriers for diffusion, and thus the diffusion coefficients of the surface-attached species, contributing to increase the range of uncertainty on these coefficients.

(iii) The electronic and ionic current densities in the electrode are both computed with Eq. (14), in which the effective conductivity ( $\sigma_{\text {el or io }}^{\text {eff }}$ ) is expressed according to Eq. (15).

$$
\begin{gathered}
\vec{l}_{e l}=-\sigma_{e l}^{e f f} \nabla \varphi_{e l} \text { and } \vec{\imath}_{i o}=-\sigma_{i o}^{e f f} \nabla \varphi_{i o} \\
\sigma_{e l}^{e f f}=\frac{\varepsilon_{e l}}{\tau_{e l}} \sigma_{e l} \text { and } \sigma_{i o}^{e f f}=\frac{\varepsilon_{i o}}{\tau_{i o}} \sigma_{i o}
\end{gathered}
$$

Where $\sigma_{e l}$ and $\sigma_{i o}$ are the bulk electronic and ionic conductivities of $\mathrm{Ni}$ and $3 \mathrm{YSZ}\left(\mathrm{S} \cdot \mathrm{m}^{-1}\right)$, respectively [80]. The charge conservation equations for the electronic and ionic conductive phases are written in Eqs. (16a) and (16b), respectively.

$$
\begin{aligned}
& +S p_{N i-Y S Z} C_{d l} \frac{d E}{d t}=-\nabla \cdot \vec{\imath}_{e l} \pm \dot{S}_{e l} \\
& -S p_{N i-Y S Z} C_{d l} \frac{d E}{d t}=-\nabla \cdot \vec{\imath}_{i o} \pm \dot{S}_{i o}
\end{aligned}
$$


Where $C_{d l}$ is the capacitance of double layer arising between the Ni and the YSZ $\left(\mathrm{F} \cdot \mathrm{m}^{-2}\right)$ and $\dot{S}_{e l / i o}$ are the source/sink terms for the electronic and ionic charges $\left(\mathrm{A} \cdot \mathrm{m}^{-3}\right)$, related to the kinetics rates of the reactions in which those are consumed or produced via Eq. (17).

$$
\dot{S}_{e l / i o}=n F v_{e l / i o}
$$

It can be noticed that for the electronic and ionic charge conservation equations, a positive flux of charges is associated with a negative current so that, a reaction is considered as a sink if it produces charged species, and vice versa.

Inside the electrolyte, the ionic current is not associated with any reaction and no capacitance effect arises from the accumulation of charges due to the absence of the interface with the electronic conducting material, meaning that Eq. (16b) becomes:

$$
\nabla \cdot \vec{\imath}_{i o}=0
$$

It can be pointed out that all the diffusivities and conductivities in Eqs. (10) - (16) are expressed as a function of the electrode microstructural properties to take into account the effect of the cermet microstructure on the mass/charge transport phenomena. Only the effective ionic conductivity of the 8YSZ inside the electrolyte has been taken as the property for the dense material (i.e. $\varepsilon_{\text {io,electrolyte }}=\tau_{\text {io,electrolyte }}=1$ ). The intrinsic diffusion coefficients and conductivities used for the simulations at $700^{\circ} \mathrm{C}$ are reported in Table IV.

Table IV: Diffusion coefficients and conductivities at $\mathbf{7 0 0}^{\circ} \mathbf{C}[61,79,80]$

\section{Diffusion coefficients/conductivities}

\begin{tabular}{lll}
\hline$D_{H_{2}(g)-H_{2} O(g)}$ & $7.3 \times 10^{-4}$ & $\left(\mathrm{~m}^{2} \cdot \mathrm{s}^{-1}\right)$ \\
$D_{H_{2}}(g)-N_{2}(g)$ & $6.3 \times 10^{-4}$ & $\left(\mathrm{~m}^{2} \cdot \mathrm{s}^{-1}\right)$ \\
$D_{H_{2} O(g)-N_{2}(g)}$ & $2.1 \times 10^{-4}$ & $\left(\mathrm{~m}^{2} \cdot \mathrm{s}^{-1}\right)$ \\
$D_{K, H_{2} O(g), \text { normalized on } \bar{r}_{\text {pores }}=1 \mathrm{~m}}$ & $7.1 \times 10^{2}$ & $\left(\mathrm{~m} \cdot \mathrm{s}^{-1}\right)$ \\
$D_{K, H_{2}}(g)$, normalized on $\bar{r}_{\text {pores }}=1 \mathrm{~m}$ & $2.1 \times 10^{3}$ & $\left(\mathrm{~m} \cdot \mathrm{s}^{-1}\right)$ \\
$D_{H_{N i}}$ & $7.8 \times 10^{-8}$ & $\left(\mathrm{~m}^{2} \cdot \mathrm{s}^{-1}\right)$ \\
$D_{H_{2} O_{N i}}$ & $1.9 \times 10^{-8}$ & $\left(\mathrm{~m}^{2} \cdot \mathrm{s}^{-1}\right)$ \\
$D_{O_{N i}}$ & $3.2 \times 10^{-10}$ & $\left(\mathrm{~m}^{2} \cdot \mathrm{s}^{-1}\right)$ \\
$D_{O H_{N i}}$ & $1.4 \times 10^{-8}$ & $\left(\mathrm{~m}^{2} \cdot \mathrm{s}^{-1}\right)$ \\
$D_{H 2 O_{Y S Z}}$ & $1.5 \times 10^{-9}$ & $\left(\mathrm{~m}^{2} \cdot \mathrm{s}^{-1}\right)$ \\
$D_{O H_{Y S Z}}$ & $1.5 \times 10^{-9}$ & $\left(\mathrm{~m}^{2} \cdot \mathrm{s}^{-1}\right)$ \\
$D_{O_{Y S Z}^{2-}}$ & $8.1 \times 10^{-16}$ & $\left(\mathrm{~m}^{2} \cdot \mathrm{s}^{-1}\right)$ \\
$\sigma_{\text {el,Ni,bulk }}$ & $80 \times 10^{3}$ & $\left(\mathrm{~S} \cdot \mathrm{m}^{-1}\right)$
\end{tabular}




\begin{tabular}{llr}
$\sigma_{i o, 3 Y S Z, b u l k}$ & 0.797 & $\left(\mathrm{~S} \cdot \mathrm{m}^{-1}\right)$ \\
$\sigma_{i o, 8 Y S Z, b u l k}$ & 1.713 & $\left(\mathrm{~S} \cdot \mathrm{m}^{-1}\right)$ \\
\hline
\end{tabular}

\subsection{Summary of the Main Hypotheses for the Models}

Different assumptions have been made to simulate the electrode response and to simplify the determination of the most relevant reaction mechanism for the Ni-3YSZ cermet:

- The mixtures for the gaseous molecules and the adsorbed species have been treated as ideal solutions.

- In Model II, the YSZ surface has been simulated considering one single type of adsorption site for all the surface-attached species as in $[61,63]$. In this configuration, the surface attached oxygen ions, hydroxyl ions and molecular water are considered as competitively adsorbed on YSZ.

- To reduce the number of unknown fitting parameters in both models, the reaction of oxygen incorporation/excorporation in the YSZ lattice (CR5) has been assumed not limiting (i.e. $\left.k_{O_{Y S Z}^{2} \bar{C}}^{I N C} \gg 0\right)$. In Model II, since the reaction of $\mathrm{H}_{2} \mathrm{O}$ dissociation on the YSZ surface (CR3) is supposed to be very fast [53], it has also been considered as not limiting.

- Using these assumptions, in each model there are five free fitting parameters:

- For Model I:

$>$ The kinetic constant of steam adsorption on $\mathrm{Ni}\left(k_{\mathrm{H}_{2} \mathrm{O}_{N i}}^{A D S}\right)$;

$>$ The forward kinetic constant of steam dissociation on $\mathrm{Ni}\left(k_{\mathrm{H}_{2} \mathrm{O}_{\mathrm{Ni}} \mathrm{ISS}}^{\mathrm{I}}\right)$;

$>$ The forward kinetic constant of hydroxyl dissociation on $\mathrm{Ni}\left(k_{O H_{N i}}^{D I S S+}\right)$;

$>$ The kinetic constant of hydrogen desorption from $\mathrm{Ni}\left(k_{\mathrm{H}_{2 N i}}^{D E S}\right)$;

$>$ The reduction kinetic constant of the charge transfer reaction $\left(k^{\text {red }}\right)$.

- For Model II:

$>$ The kinetic constant of steam adsorption on $\mathrm{Ni}\left(k_{\mathrm{H}_{2} \mathrm{O}_{\mathrm{Ni}}}^{A D S}\right)$;

$>$ The kinetic constant of steam adsorption on $\operatorname{YSZ}\left(k_{\mathrm{H}_{2} O_{Y S Z}}^{A D S}\right)$;

$>$ The kinetic constant of hydrogen desorption from $\mathrm{Ni}\left(k_{H_{2 N i}}^{D E S}\right)$;

$>$ The reduction kinetic constant of the first charge transfer reaction $\left(k_{1}^{\text {red }}\right)$;

$>$ The reduction kinetic constant of the second charge transfer reaction $\left(k_{2}^{\text {red }}\right)$. 


\subsection{Numerical Implementation and Boundary Conditions}

The equations of charge/mass balances combined with the expressions of fluxes and source terms constitute a set of partial differential equations implemented in the commercial software for finite element computations Comsol Multiphysics ${ }^{\circledR}$ and solved in the time domain.

In both models, the overall electrode potential $E^{\text {tot }}$ is taken as the difference between the electronic potential in the $\mathrm{Ni}\left(\varphi_{e l}\right)$ at the $\mathrm{CC} / \mathrm{FL}$ interface and the ionic potential in the $\operatorname{YSZ}\left(\varphi_{i o}\right)$ at the FL/EL interface as shown in Eq. (19).

$$
E^{t o t}=\varphi_{e l}\left(z=\ell_{F L}+\ell_{E L}\right)-\varphi_{i o}\left(z=\ell_{E L}\right)
$$

This potential is used to compute the electrode overpotential ( $\left.\eta^{\text {calc }}(V)\right)$, according to Eq. (20), which is equivalent to the one deduced from the measurements versus the reference (i.e. $\eta(V / \operatorname{Ref})$ ).

$$
\eta^{\text {calc }}(V)=E^{\text {tot }}-E^{e q}
$$

To obtain the steady-state response of the electrode, the ionic potential is fixed in the YSZ (i.e. at $z=0$ in Figure 3a) and the local current densities, the local surface coverages on Ni and YSZ and all the other unknowns are computed.

To simulate the impedance spectra, the procedure reported in Hubert et al. [67] has been applied. For each frequency, a sinusoidal perturbation has been imposed to the ionic current in the electrolyte:

$$
i_{i o, E L}(z=0, t)=i_{i o, D C}+i_{i o, A C} \cdot \sin (2 \pi f t)
$$

Ten full cycles of the sinusoid have been simulated and the last two have been analyzed to calculate the impedance of the electrode from the time-dependent current and potential. Using this procedure, the solution has been determined for each point of the diagram keeping the full non-linearity of the system. The models have been run using the same amplitude for the perturbation as the experiment with $i_{i o, A C}=5 \mathrm{~mA} \cdot \mathrm{cm}^{-2}$ in the frequency range between $10^{-1}$ and $10^{6} \mathrm{~Hz}$ and seven points per decade have been calculated. In this work, only spectra at OCP have been simulated $\left(i_{i o, D C}=0\right)$. However, it is worth mentioning that, using this approach, the impedance spectra can be simulated with both models not only at OCP but also under polarization as detailed in [67].

The imposed boundary conditions are the same in both models and are summarized hereafter:

1) For the electronic Ni phase:

$$
\varphi_{e l}\left(z=\ell_{E L}+\ell_{F L}\right)=0 \text { and } i_{e l}\left(z=\ell_{E L}\right)=0
$$

2) For the ionic YSZ phase:

$$
i_{i o}\left(z=\ell_{E L}+\ell_{F L}\right)=0 \text { and } \varphi_{i o, D C}(z=0)=\text { imposed for the stationary solution, or }
$$




$$
i_{i o, E L}(z=0)=\text { imposed for the time-dependent solution. }
$$

3) For the gas phases:

$$
C_{i}\left(z=\ell_{E L}+\ell_{F L}\right)=\text { const. and } \vec{N}_{i}\left(z=\ell_{E L}\right)=0
$$

4) For the adsorbed phases:

$$
\vec{N}_{a d s, i}\left(z=\ell_{E L}+\ell_{F L}\right)=0 \quad \text { and } \quad \vec{N}_{a d s, i}\left(z=\ell_{E L}\right)=0
$$

\section{Results and Discussion}

\subsection{D Reconstruction}

A Region Of Interest (ROI) containing the cermet has been extracted from the whole reconstruction obtained by X-ray holotomography. A volume size of $\approx 23 \times 23 \times 23 \mu \mathrm{m}^{3}$ (cf. Figure 2) has been taken for the ROI, which is large enough to be well representative of the heterogeneous Ni-YSZ microstructure. Indeed, it has been already shown that the Representative Volume Elements (RVEs) for typical cermet electrode microstructures are ranging from around $12^{3} \mu \mathrm{m}^{3}$ to $15^{3} \mu \mathrm{m}^{3}$ [81] . In Figure 2b, a 2D slice of the ROI extracted from the raw reconstruction is shown. The three phases of the cermet can be identified by their corresponding grey-levels in the micrograph (darker: pores, grey: 3YSZ, clearer: Ni). Before computing the electrode microstructural properties, the 3D image has been segmented by labeling the $\mathrm{Ni}, \mathrm{YSZ}$ and pore phases. To facilitate this image processing, the volume has been previously filtered using in-house codes to increase the contrast between the different phases and separate the peaks on the histogram (Figure 2c). The filtering is based on the Malik-Perona method [82] and the procedure followed in this work is reported in [69]. The result of this step is highlighted in Figure $2 \mathrm{~d}$ in which the grey-level histograms before and after filtering are reported. As it can be seen, the application of the Malik-Perona filter allows a better separation of the peaks, which are more convoluted in the original reconstruction. Subsequently, the volume has been segmented and each of the three phases in the electrode has been labeled univocally using the lower and higher thresholds identified following the Otsu's approach [83]. These thresholds are given in Figure 2d (they are equal to 120 and 180, respectively). A 3D rendering volume and a $2 \mathrm{D}$ cross-section extracted from the segmented reconstruction are given in Figure 2e.

Finally, the isolated voxels have been identified and excluded from the volumes used for the computation. In this way, only the percolated networks of each phase have been considered to evaluate the microstructural parameters. All the properties extracted from the volume are given in 
Table V. The volume fractions $\left(\varepsilon_{a}\right)$, the interfacial specific surface areas between the phases $\left(S p_{a-b}\right)$, the mean radii $\left(\bar{r}_{a}\right)$ and the density of the active TPBl $\left(\xi^{T P B l s}\right)$ have been measured using the methods reported in [81]. Besides, the apparent tortuosity factors $\left(\tau_{a}\right)$ of each phase has also been computed by homogenization following the procedure reported in [84]. To check the accuracy of the microstructural properties deduced from the 3D reconstruction, the solid volume fractions obtained for the Ni and the 3YSZ have been compared to the expected ones. As it can be seen in Table 5, the volume fractions of Ni and 3YSZ are $23.7 \%$ and $36.4 \%$, respectively. They correspond to a cermet made of 39.4 vol.\% of $\mathrm{Ni}$ and 60.6 vol.\% of $3 \mathrm{YSZ}$. As this composition is in perfect agreement with the proportion used for the electrode manufacturing (Section 2.1), the full methodology for the electrode reconstruction can be considered validated.

\section{Table V: Microstructural properties of the connected phases in the Ni-3YSZ cermet electrode extracted from the 3D reconstruction}

\begin{tabular}{lll}
\hline Properties of the connected phases & & \\
\hline Pore volume fraction $\left(\varepsilon_{\text {pores }}\right)$ & 39.85 & $(\%)$ \\
Nickel volume fraction $\left(\varepsilon_{N i}\right)$ & 21.57 & $(\%)$ \\
3YSZ volume fraction $\left(\varepsilon_{Y S Z}\right)$ & 36.36 & $(\%)$ \\
Specific surface area between 3 YSZ and pores $\left(S p_{Y S Z-p o r e s}\right)$ & 2.09 & $\left(\mu \mathrm{m}^{-1}\right)$ \\
Specific surface area between pores and Ni $\left(S p_{\text {pores }-N i}\right)$ & 0.48 & $\left(\mu \mathrm{m}^{-1}\right)$ \\
Specific surface area between Ni and 3YSZ $\left(S p_{N i-Y S Z}\right)$ & 0.97 & $\left(\mu \mathrm{m}^{-1}\right)$ \\
Mean pore radius $\left(\bar{p}_{\text {pores }}\right)$ & 0.26 & $(\mu \mathrm{m})$ \\
Mean Ni particle radius $\left(\bar{r}_{N i}\right)$ & 0.29 & $(\mu \mathrm{m})$ \\
Mean 3YSZ particle radius $\left(\bar{r}_{Y S Z}\right)$ & 0.19 & $(\mu \mathrm{m})$ \\
Density of triple phase boundary lengths $\left(\xi^{T P B l s}\right)$ & 4.329 & $\left(\mu \mathrm{m}^{-2}\right)$ \\
Pore tortuosity factor $\left(\tau_{\text {pores }}\right)$ & 2.66 & $(-)$ \\
Ni tortuosity factor $\left(\tau_{N i}\right)$ & 17.01 & $(-)$ \\
3YSZ tortuosity factor $\left(\tau_{Y S Z}\right)$ & 2.75 & $(-)$ \\
\hline
\end{tabular}

\subsection{Experimental Results and Analyses}

In order to check the validity of the measurements with the three-electrode experimental setup, the $\eta$ - $\mathrm{i}$ curves and EIS diagrams vs the $\mathrm{RE}$ have been measured at $\mathrm{pH}_{2} / \mathrm{pH}_{2} \mathrm{O}=50 / 50$ for both electrodes (WE and CE). As shown in Figure 4a, an almost perfect superposition is found for the two polarization curves, indicating that the symmetric behavior of the cell is accurately obtained in the setup. Besides, the impedance spectra at OCP for the two electrodes and the complete symmetric cell are shown in Figure 4b. It can be noticed that the EIS diagrams of the two electrodes 
are also well superposed and their sum corresponds to the impedance of the complete cell. These results indicate the absence of misalignment between the electrodes and confirm the validity of the RE positioning. Finally, it can be pointed out that the data for the EIS are not perturbed with noise especially in the low-frequency range, meaning that the steam supply is stable without any fluctuation. From all these observations, it can be claimed that the experimental setup is completely reliable for the electrochemical characterizations.

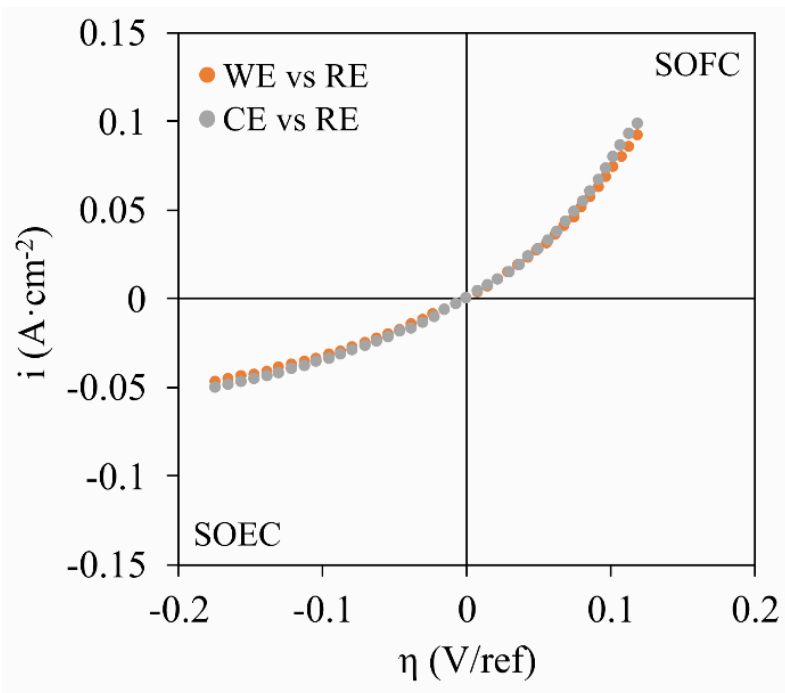

a)

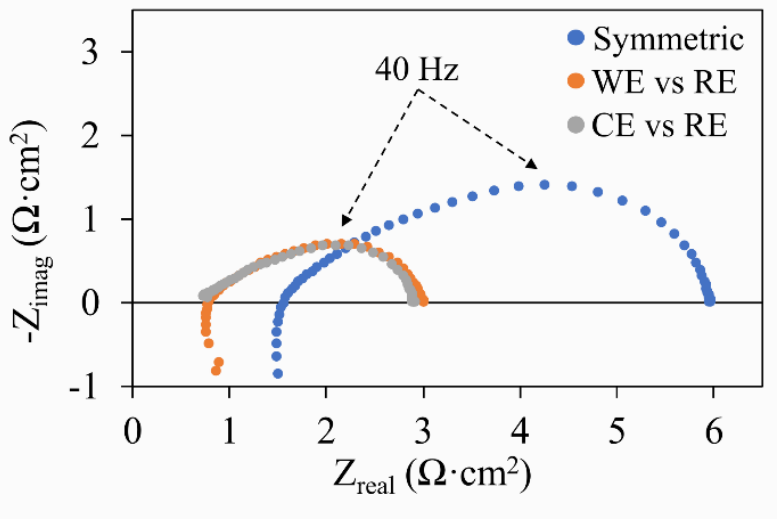

b)

Figure 4: Illustration of the validity of the measurements in the three-electrode setup (with $\mathrm{pH}_{2} / \mathrm{pH}_{2} \mathrm{O}$ $=50 / 50$ and $\mathrm{T}=7_{00}^{\circ} \mathrm{C}$ ): a) $\eta$-i curves recorded for the $\mathrm{WE}$ and the $\mathrm{CE}$ vs the $\mathrm{RE}-\mathrm{b}$ ) EIS diagrams at OCP recorded for the two half-cells and the symmetric cell.

Once the setup has been validated, the polarization curves at $\mathrm{pH}_{2} / \mathrm{pH}_{2} \mathrm{O}=50 / 50,25 / 75$ and 75/25 have been recorded and are provided in Figures $5 \mathrm{a}$ and $5 \mathrm{~b}$ (open symbols). A clear dissymmetry can be noticed between the two branches of the $\eta-i$ curve. The electrode response exhibits a strong potential-activated behavior in anodic polarization (SOFC mode) whereas a rather low limiting current density is observed in cathodic polarization (SOEC mode). This evolution highlights a modification in the nature of the rate limiting steps, or it could even indicate a transition in the activated reaction pathway when changing the operating mode from anodic to cathodic polarization. More precisely, the potential-activated behavior under anodic current suggests that the reaction rate could be mainly dominated by the electrochemical reaction of charge transfer, while the presence of a limiting current density under cathodic polarization would reveal a limitation by a chemical reaction in the adsorbed phases due to a low concentration of reactant. These statements are in good agreement with the experimental results already reported in the literature for a Ni-8YSZ cermet electrode [24-26]. Therefore, the co-limitation in electrolysis mode seems to appear irrespectively of the level of zirconia doping from 3 to $8 \mathrm{~mol} \%$ of yttria. This last remark might constitute a 
'weak' clue suggesting that the co-limitation in SOEC mode would be more related to an interaction of gas with Ni.

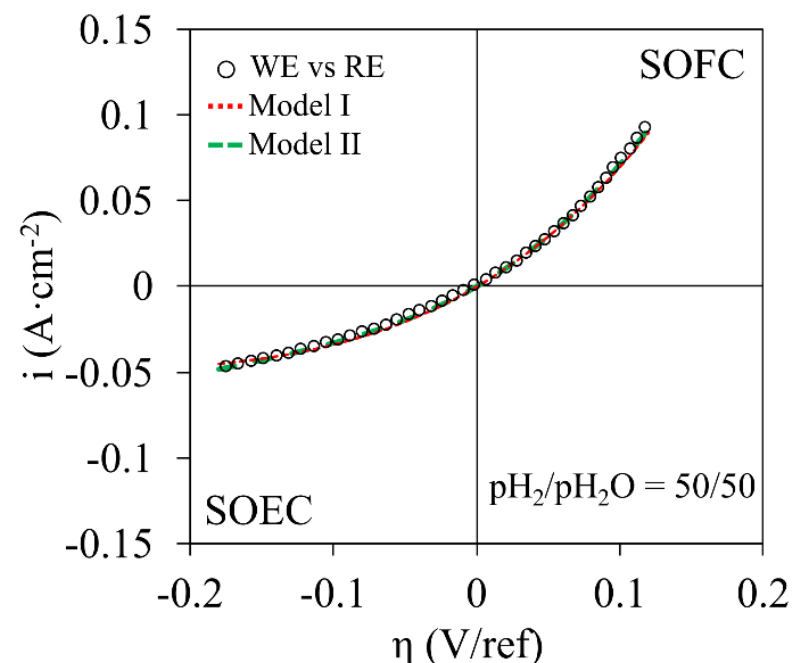

a)

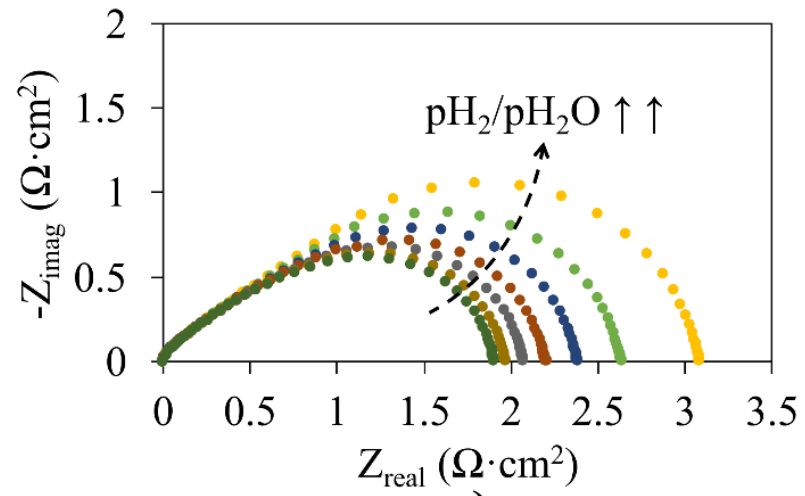

c)

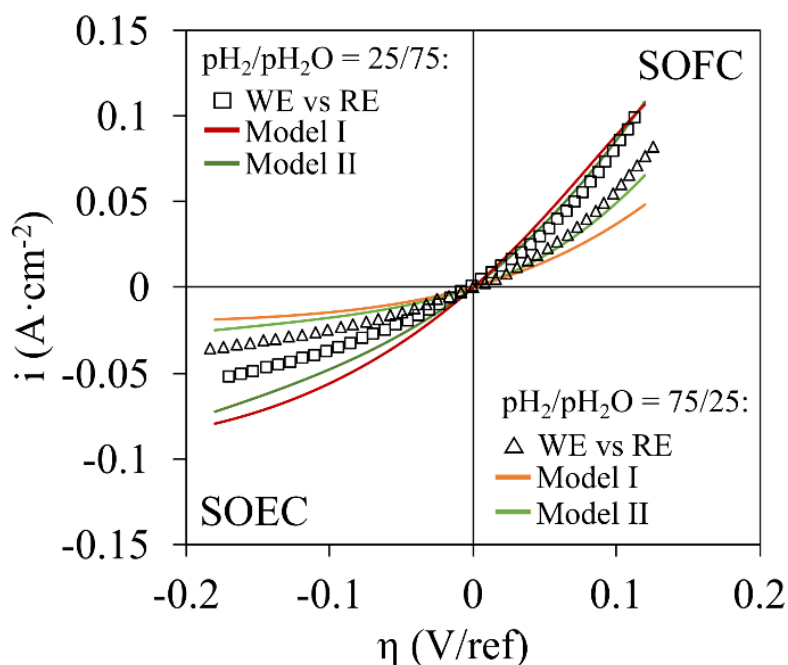

b)

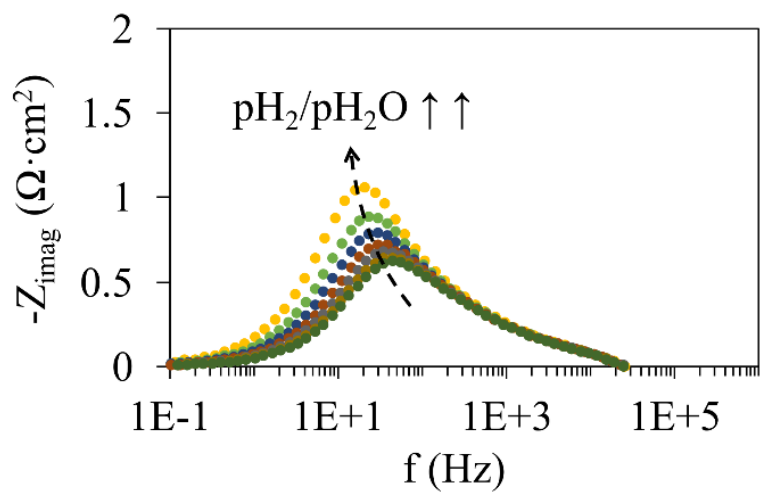

d)

Figure 5: Experimental and simulation results at $700^{\circ} \mathrm{C}$ : a) Experimental and simulated $\eta$-i curves with $\mathrm{pH}_{2} / \mathrm{pH}_{2} \mathrm{O}=50 / 50-$ b) Experimental and simulated $\eta$-i curves with $\mathrm{pH}_{2} / \mathrm{pH}_{2} \mathrm{O}=25 / 75$ and $\mathrm{pH}_{2} / \mathrm{pH}_{2} \mathrm{O}=75 / 25$ - Experimental Nyquist plot (c) and Bode plot (d) of the EIS diagrams at OCP measured at different $\mathrm{pH}_{2} / \mathrm{pH}_{2} \mathrm{O}(20 / 80,30 / 70,40 / 60,50 / 50,60 / 40,70 / 30,80 / 20)$.

From Figure $5 b$, it can be seen that the electrode performance in both polarizations is improved when the $\mathrm{pH}_{2} / \mathrm{pH}_{2} \mathrm{O}$ ratio is decreased. Moreover, it can be noticed in Figure $5 \mathrm{~b}$ that the dependency of the electrode response with the partial pressures is more pronounced in cathodic polarization. Based on this remark and considering that a decrease in the $\mathrm{pH}_{2} / \mathrm{pH}_{2} \mathrm{O}$ ratio corresponds to an increase in the partial pressure of steam, it can be suspected that the co-limiting step observed in electrolysis mode could be associated with an interaction of steam with the electrode surface.

To go further in the analysis, the impedance spectra have been acquired at OCP for a large range of gas compositions (Figures 5c and 5d). As a first comment, it can be seen that the Nyquist plots of the diagrams (Figure 5c) exhibit a global shape that tends toward a kind of FLG impedance with a slightly 'skewed' shape. This global shape of the EIS diagrams could be explained by the transport 
of oxygen vacancies in the 3YSZ backbone taking place in parallel to the electrochemical and chemical reactions in the electrode. In other words, the contribution with a line at around $45^{\circ}$ from the real axis in the Nyquist plot could be principally ascribed to the oxygen vacancies migration in the depth of the electrode. Moreover, the FLG type impedance behavior would suggest that the reaction could extend over a large distance in the depth of the electrode compared to the whole NiYSZ thickness [42]. It is worth noting that this shape of the electrochemical impedance spectra is in good agreement with the one published by Boukamp et al. [40] for porous Ni/Ti-doped YSZ electrodes. When changing the steam content in the gas flow, they have reported a 'minor dispersive contribution in the high-frequency region and a dominating dispersion down to $0.01 \mathrm{~Hz}$ '. This global trend is also coherent with the EIS evolutions as a function of the $\mathrm{pH}_{2} / \mathrm{pH}_{2} \mathrm{O}$ ratio as displayed in Figures $5 \mathrm{c}$ and $5 \mathrm{~d}$, even if a slight difference in the characteristic frequencies is detected.

From the analysis of the impedance diagrams as a function of the $\mathrm{pH}_{2} / \mathrm{pH}_{2} \mathrm{O}$ ratio, it can be clearly seen that low frequency contribution of the electrode response is the most affected by the variation of the reactants/products ratio (Figure $5 \mathrm{c}$ and $5 \mathrm{~d}$ ). Based on this observation, this contribution could be associated to a chemical reaction or to a gas diffusional process in the porosities of the electrode. Nevertheless, considering the microstructural properties obtained from the 3D reconstruction (Table V) and the low thickness of the functional layer, the gas diffusion is not expected to represent a limiting step for this type of electrode. Therefore, it could be suspected that the low frequency contribution in the EIS would be related to a chemical process occurring on the electrode surface.

The EIS data measured at OCP have been used to determine the dependency of the overall reaction rate on the partial pressure of hydrogen and steam. In this objective, the electrode polarization resistance at OCP has been classically expressed according to Eq. (22) [28].

$$
R_{p o l}=A \cdot p H_{2}^{-\alpha} \cdot p H_{2} O^{-\beta}
$$

In which $A$ is a proportionality factor and the exponents $\alpha$ and $\beta$ are the reaction orders with respect to $\mathrm{H}_{2}$ and $\mathrm{H}_{2} \mathrm{O}$ respectively. A least-square algorithm has been used to fit the exponents $\alpha$ and $\beta$ for all the tested compositions (i.e. $\mathrm{pH}_{2} / \mathrm{pH}_{2} \mathrm{O}=20 / 80,30 / 70,40 / 60,50 / 50,60 / 40,70 / 30,80 / 20$ ). A single solution for the two exponents has been found for all the experimental data in the investigated range of gas compositions. This result means that the reaction pathway is controlled by one single reaction mechanism at OCP whatever the steam content in the gas mixture. The fitted values for the two exponents are given in Table VI. A very low value has been obtained for the hydrogen $(\alpha=0.035)$ while the exponent on the steam partial pressure is much higher $(\beta=0.38)$. 
Therefore, the global reaction rate of the electrode at OCP is almost independent of $\mathrm{pH}_{2}$ whereas a clear influence of $\mathrm{pH}_{2} \mathrm{O}$ is found. All these dependencies derived from the analysis of the electrochemical impedance spectra confirm the behavior suggested by the $\eta$-i curves. Moreover, as already mentioned, changing the steam content affects mainly the diagrams in the medium and lowfrequency range while they remain almost unchanged at high frequencies (Figure 5d). This strong effect of the $\mathrm{pH}_{2} \mathrm{O}$ on the low frequency response of the electrode indicates that the surface processes co-limiting the electrode response should involve the steam and not the hydrogen.

Therefore, even at OCP, the electrode reaction rate is controlled by (i) the charge transfer, (ii) the oxygen vacancies migration in $3 \mathrm{YSZ}$, and (iii) a pure chemical surface process sensitive to the steam partial pressure. According to the literature [40,85], this impact of steam on a FLG-type element for the cermet could be attributed to a slow steam adsorption/desorption coupled with surface diffusion up to the TPBls.

Table VI: Determination of the order of reaction for $\mathrm{H}_{2}$ and $\mathrm{H}_{2} \mathrm{O}$ from the experimental and simulated EIS at $\mathrm{OCP}$ at $\mathrm{pH}_{2} / \mathrm{pH}_{2} \mathrm{O}=20 / 80,30 / 70,40 / 60,50 / 50,60 / 40,70 / 30,80 / 20$ and $\mathrm{T}=700^{\circ} \mathrm{C}$

\begin{tabular}{lll}
\hline & Reaction order for $\mathbf{H}_{\mathbf{2}}(\boldsymbol{\alpha})$ & Reaction order for $\mathbf{H}_{\mathbf{2}} \mathbf{O}(\boldsymbol{\beta})$ \\
\hline Experimental results & 0.035 & 0.38 \\
Model I (standard version calibrated on $\eta$-i curves) & 0.043 & 1.08 \\
Model II (standard version calibrated on $\eta$-i curves) & 0.066 & 0.81 \\
Model II - limited by CR5 kinetics & 0.119 & 0.55 \\
Model II - limited by CR3 kinetics & 0.024 & 0.86 \\
Model II - limited by surface diffusion & 0.046 & 0.77 \\
\hline
\end{tabular}

To conclude, it can be stated from the experimental results that the overall reaction rate for the porous Ni-3YSZ cermet electrode is co-limited at OCP by the charge transfer at the TPBls, the oxygen solid-state diffusion in the electrode thickness and a surface process, which is sensitive to the steam partial pressure. This surface process could be associated with a steam-solid phase interaction potentially followed by a surface diffusional transfer. Finally, the strong dissymmetry of the electrode polarization curve suggests that the contribution of this surface process on the overall reaction rate appears to be more and more pronounced when changing the operating mode from anodic to cathodic polarization. It could even indicate a change in the reaction pathway between the two operating modes. 


\subsection{Electrochemical Simulations for the Porous Ni-3YSZ Electrode}

\subsubsection{Models Calibration and Elements of Validation}

For the simulations with each model, the thermodynamic data and the diffusion coefficients have been taken from literature, whereas all the microstructural parameters characterizing the cermet morphology have been deduced from the 3D reconstruction (cf. data listed in Table III, Table IV and Table $\mathrm{V}$, respectively). The other parameters including the forward kinetic constants of the reactions are given in Table VII for both models. As the first step of the validation, the two models have been calibrated fitting the simulated $\eta-\mathrm{i}$ curve on the experimental one at $\mathrm{pH}_{2} / \mathrm{pH}_{2} \mathrm{O}=50 / 50$. The objective of these preliminary simulations was to identify the numerical values of the unknown kinetic parameters for the two studied models.

The results of the fitting procedure are shown in Figure 5a. It is worth noting that the error minimization between the experimental data and the simulated curves has led to determine a single set of solutions for the missing parameters of the two models. In this condition, it was found that both models can mimic accurately the $\eta-i$ curve. Indeed, the asymmetric behavior between the cathodic and the anodic branches is perfectly reproduced by the oxygen spillover mechanism (Model I) as well as the hydrogen spillover mechanism (Model II).

Table VII: Parameters used in the simulations at $700^{\circ} \mathrm{C}$

\begin{tabular}{|c|c|c|c|}
\hline \multicolumn{4}{|l|}{ Parameters used in both models } \\
\hline Density of available sites on Ni surface $\left(\Gamma_{N i}\right)$ & $1.7 \times 10^{-5}$ & $\left(\mathrm{~mol} \cdot \mathrm{m}^{-2}\right)$ & {$[16]$} \\
\hline Density of available sites on YSZ surface $\left(\Gamma_{Y S Z}\right)$ & $2.5 \times 10^{-5}$ & $\left(\mathrm{~mol} \cdot \mathrm{m}^{-2}\right)$ & {$[16]$} \\
\hline Double-layer capacitance at the Ni/YSZ interface $\left(C_{d l}\right)$ & 1.3 & $\left(\mathrm{~F} \cdot \mathrm{m}^{-2}\right)$ & {$[86]$} \\
\hline Volume of the unit cell for the YSZ $\left(V_{U C}\right)$ & 134.73 & $\left(\AA^{3}\right)$ & {$[74]$} \\
\hline \multicolumn{4}{|l|}{ Forward kinetic constants (Model I) } \\
\hline Steam adsorption on $\mathrm{Ni}\left(k_{\mathrm{H}_{2} \mathrm{O}_{\mathrm{Ni}}}^{A D S}\right)$ & $2.5 \times 10^{2}$ & $\left(\mathrm{~s}^{-1}\right)$ & Fitted \\
\hline Steam dissociation on $\mathrm{Ni}\left(k_{\mathrm{H}_{2} \mathrm{O}_{\mathrm{Ni}}}^{D I S S+}\right)$ & $1 \times 10^{10}$ & $\left(\mathrm{~m}^{2} \cdot \mathrm{s}^{-1} \cdot \mathrm{mol}^{-1}\right)$ & Fitted \\
\hline Hydroxyl dissociation on $\mathrm{Ni}\left(k_{O H_{N i}}^{D I S S+}\right)$ & $7.5 \times 10^{10}$ & $\left(\mathrm{~m}^{2} \cdot \mathrm{s}^{-1} \cdot \mathrm{mol}^{-1}\right)$ & Fitted \\
\hline Hydrogen desorption from $\mathrm{Ni}\left(k_{H_{2 N i}}^{D E S}\right)$ & $1.6 \times 10^{7}$ & $\left(\mathrm{~m}^{2} \cdot \mathrm{s}^{-1} \cdot \mathrm{mol}^{-1}\right)$ & Fitted \\
\hline
\end{tabular}


Charge transfer reaction in the reduction direction $\left(k^{r e d}\right)$

$2 \times 10^{3} \quad\left(\mathrm{~m}^{3} \cdot \mathrm{s}^{-1} \cdot \mathrm{mol}^{-1}\right) \quad$ Fitted

Oxygen incorporation in the YSZ $\left(k_{O_{Y S Z}^{I N C}}^{I N C} / C_{O_{O}^{x}(Y S Z)}^{r e f}\right)$

$5 \times 10^{4} \quad\left(\mathrm{~m}^{3} \cdot \mathrm{s}^{-1} \cdot \mathrm{mol}^{-1}\right)$

Assumed as not

limiting

Forward kinetic constants (Model II)

Steam adsorption on $\mathrm{Ni}\left(k_{\mathrm{H}_{2} \mathrm{O}_{\mathrm{Ni}}}^{A D S}\right)$

$1.25 \times 10^{2}$

$\left(\mathrm{s}^{-1}\right)$

Fitted

Steam adsorption on YSZ $\left(k_{\mathrm{H}_{2} \mathrm{O}_{Y S Z}}^{A D S}\right)$

$1 \times 10^{2}$

$\left(\mathrm{s}^{-1}\right)$

Fitted

Steam dissociation on YSZ $\left(k_{\mathrm{H}_{2} \mathrm{O}_{Y S Z}}^{\text {ISS+ }}\right)$

$2.5 \times 10^{13} \quad\left(\mathrm{~m}^{2} \cdot \mathrm{s}^{-1} \cdot \mathrm{mol}^{-1}\right)$

Assumed as not

Hydrogen desorption from $\mathrm{Ni}\left(k_{\mathrm{H}_{2 N i}}^{D E S}\right)$

$8.1 \times 10^{7}$

$\left(\mathrm{m}^{2} \cdot \mathrm{s}^{-1} \cdot \mathrm{mol}^{-1}\right)$

limiting

First charge transfer reaction in the reduction direction $\left(k_{1}^{\text {red }}\right)$

$1 \times 10^{3}$

$\left(\mathrm{m}^{3} \cdot \mathrm{s}^{-1} \cdot \mathrm{mol}^{-1}\right)$

Fitted

Second charge transfer reaction in the reduction direction $\left(k_{2}^{\text {red }}\right)$

$7.5 \times 10^{2}$

$\left(\mathrm{m}^{3} \cdot \mathrm{s}^{-1} \cdot \mathrm{mol}^{-1}\right)$

Fitted

Oxygen incorporation in the $\operatorname{YSZ}\left(k_{O_{Y S Z}^{2-}}^{I N C} / C_{O_{O}^{x}(Y S Z)}^{r e f}\right)$

$5 \times 10^{4} \quad\left(\mathrm{~m}^{3} \cdot \mathrm{s}^{-1} \cdot \mathrm{mol}^{-1}\right)$

Assumed as not limiting

Once calibrated on the $\eta$ - $\mathrm{i}$ curve at $\mathrm{pH}_{2} / \mathrm{pH}_{2} \mathrm{O}=50 / 50$, the EIS diagram at OCP measured in the same conditions has been simulated with the two models (Figures 6a and 6b). It can be noticed that this validation step has been carried out without any further adjustments to the input model parameters. In this condition, it has been found that both models can predict with a good level of confidence the impedance diagram in terms of shape (Figure 6a) but also in terms of frequency distribution (Figure 6b). Based on these results, both reaction pathways appear to be suitable to predict the electrode response. At this stage, it is thus not possible to discriminate between the two elementary models for the porous Ni-3YSZ electrode. 


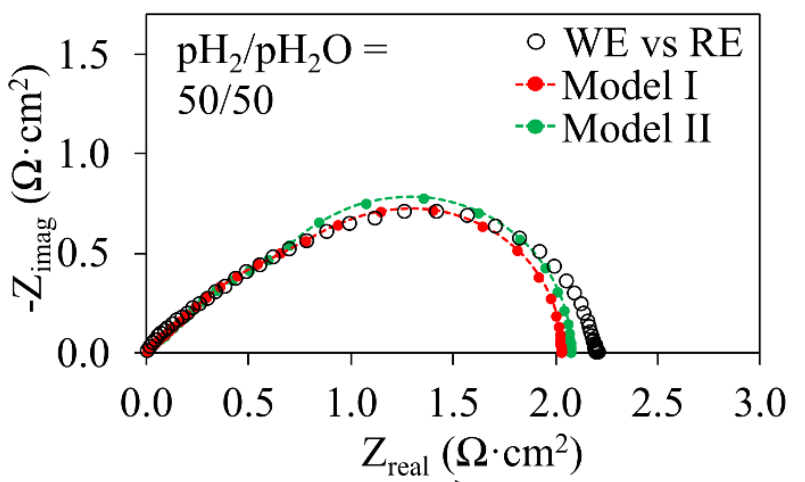

a)

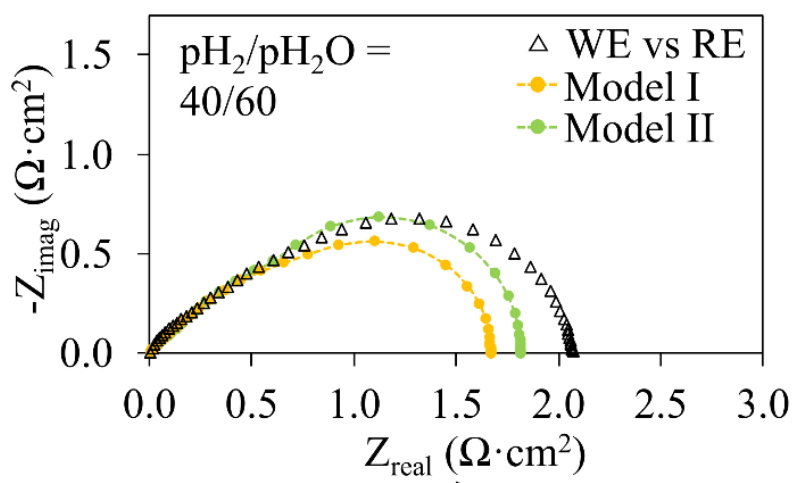

c)

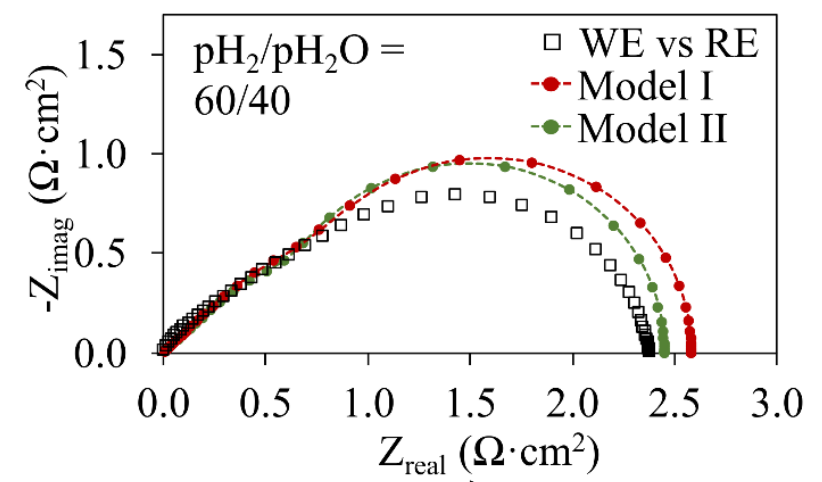

e)

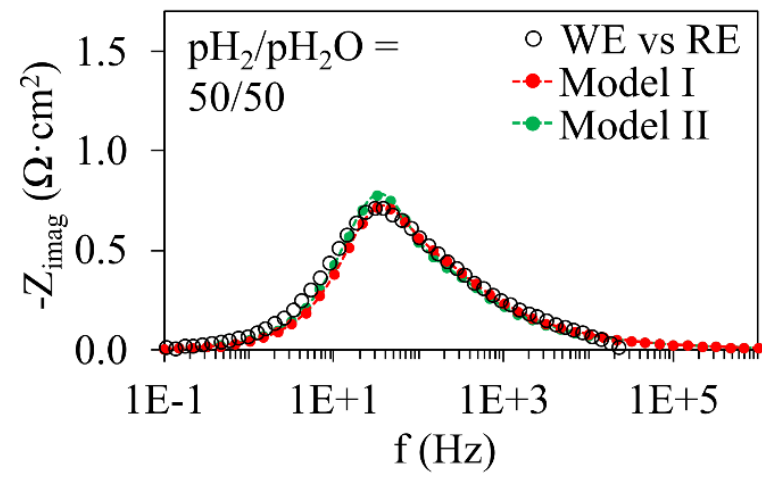

b)

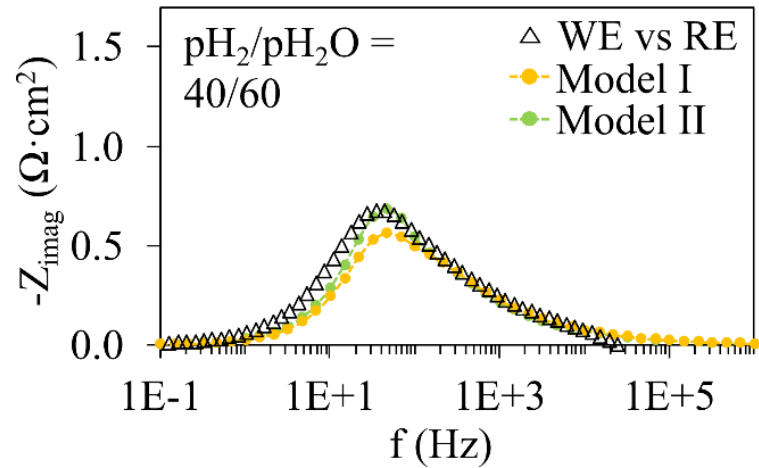

d)

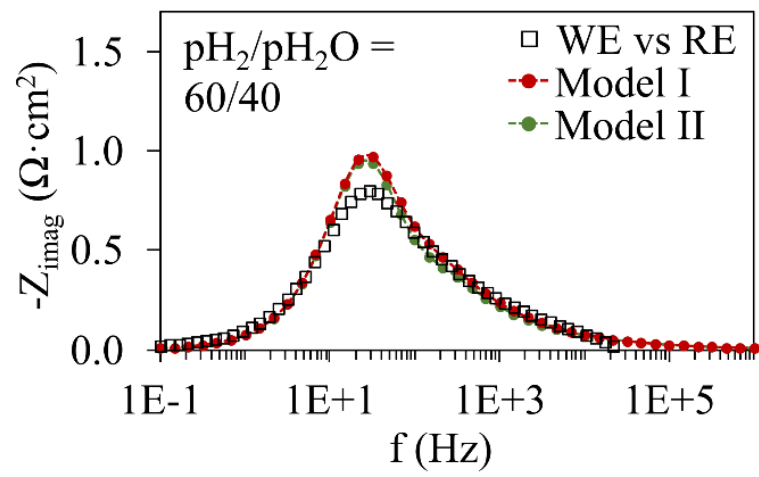

f)

Figure 6: Experimental and simulated impedance spectra at $\mathrm{OCP}$ with different $\mathrm{pH}_{2} / \mathrm{pH}_{2} \mathrm{O}$ : $\mathrm{Nyquist}$ (a) and Bode (b) plots with $\mathrm{pH}_{2} / \mathrm{pH}_{2} \mathrm{O}=50 / 50$ - Nyquist (c) and Bode (d) plots with $\mathrm{pH}_{2} / \mathrm{pH}_{2} \mathrm{O}=40 / 60$ - Nyquist (e) and Bode (f) plots with $\mathrm{pH}_{2} / \mathrm{pH}_{2} \mathrm{O}=60 / 40$.

To gain more insight into the most relevant mechanism, the $\eta$-i curves at different partial pressures have been simulated using the two calibrated models. As shown in Figure 5b, a slight difference is found between the simulated curves and the experimental results. Indeed, both models overestimate the effect of the steam partial pressure on the electrode response. This statement is also confirmed by the impedance spectra simulated at different $\mathrm{pH}_{2} / \mathrm{pH}_{2} \mathrm{O}$ (Figure 6). Indeed, although the two models can perfectly reproduce the electrode behavior in terms of frequency distribution, the decrease of the simulated polarization resistance with increasing the $\mathrm{H}_{2} \mathrm{O}$ partial pressure is higher than the experimental one (Figures $6 \mathrm{c}$ and $6 \mathrm{~d}$ ). In contrast, the opposite behavior is observed when 
decreasing the partial pressure of water (Figures 6e and 6f). Nevertheless, it can be noticed that the simulated curves obtained with Model II are significantly closer to the measured data suggesting that the mechanism based on the hydrogen spillover could be more relevant for a Ni-3YSZ cermet electrode. To support this claim, the exponents on the $\mathrm{H}_{2}$ and $\mathrm{H}_{2} \mathrm{O}$ partial pressures involved in the expression of the electrode polarization resistance at OCP (Eq. (22)) have been evaluated by computing the electrode response over the same range of gas compositions than the one used for the experiments. The results obtained with the calibrated models are given and compared to the experimental exponents in Table VI. Although the effect of $\mathrm{pH}_{2} \mathrm{O}$ is slightly overestimated in both cases, it is worth noting that the two models can retrieve the very low dependency of $R_{\text {pol }}$ on the hydrogen partial pressure. Regarding the exponent for $\mathrm{pH}_{2} \mathrm{O}$, it appears that the prediction given by Model II is more accurate than Model I even if the discrepancy between the experimental exponent and the calculated one remains noticeable. Therefore, the comparison between the reaction orders obtained for Model I and Model II reinforces the statement that the reaction mechanism based on the hydrogen spillover charge transfer appears to be the most suitable to describe the electrode response.

To conclude, the model based on the hydrogen spillover mechanism is found to capture the global electrode behavior acceptably, even if its predictability must be still improved. Therefore, it seems that the mechanism proposed for the Ni-8YSZ cermet is still valid for the porous Ni-3YSZ electrode. Consequently, Model II can be used to analyze the response of this type of electrode.

\subsubsection{Reaction Pathway and Electrode Rate Determining Steps with Model II}

Firstly, a sensitivity analysis has been performed by changing the tortuosity factor of the 3 YSZ which affects its ionic conductivity. As expected, it was found that the polarization curve is dependent on this parameter meaning that the electrode efficiency is partially limited by the oxygen vacancies migration from the electrolyte into the depth of the electrode. The EIS simulations have also confirmed that this limitation is related to the contribution at high frequencies, identified by the line at around $45^{\circ}$ in the impedance spectra. Besides, changing the density of active TPBls and the global electrode specific surface area has shown that the overall kinetic rate is affected by these parameters controlling the reactions of charge transfer, and the chemical processes at the solid-gas interface, respectively. From the analysis of the simulated EIS, both parameters have an effect on the skewed semi-circle at intermediate/low frequencies indicating a convolution of the overall reaction processes. This observation strengthens the interpretation of the experimental EIS diagrams as a kind of (finite-length) Gerischer element, which can be interpreted as a transmission line model 
$[27,43]$ for which the local resistance induced by the transport of vacancies is in parallel with a resistance and a capacitor associated with the reaction process. Moreover, the behavior in the high frequencies region corresponding to a straight line at an angle slightly lower than $45^{\circ}$ is in good agreement with the fractal Gerischer element. It has been recently pointed out that this shape of the impedance diagram could also be obtained considering a transmission line model in which the capacitor is substituted by a constant-phase element to take into account the dispersion of time constants of the reaction processes [43]. This remark reinforces the observation that the electrode behavior could be controlled by the vacancies migration in the ionic conductive network coupled with the electrochemical reactions at the TPBls and a chemical reaction occurring and at the solid/gas interface. Finally, it is worth mentioning that a sensitivity analysis on the surface diffusion coefficients has also revealed that the electrode response is noticeably improved when the diffusivity of the YSZ-attached hydroxyl ion is increased by a factor of five, suggesting that this species could play a key role on the electrode response.

To identify the nature of the gas-solid chemical reaction limiting the electrode response, the local kinetic rates for the steam adsorption on $\mathrm{Ni}$ (CR1) and YSZ (CR2) have been plotted in the electrode thickness (at $\mathrm{pH}_{2} / \mathrm{pH}_{2} \mathrm{O}=50 / 50$ for an electrode overpotential of $-0.06 \mathrm{~V}$ and $+0.06 \mathrm{~V}$ ) (Figures $7 \mathrm{~b}$ and $7 \mathrm{c}$ ). In the simulated conditions, it is found that both reactions extend in the whole electrode thickness suggesting that the entire functional layer contributes to the electrode response. This modeling result is fully consistent with the global shape of the experimental electrode impedance related to a type of finite-length Gerischer element (Figures 5c and 5d). Moreover, it can be noticed in Figures $7 \mathrm{~b}$ and $7 \mathrm{c}$ that the rate of adsorption/desorption reactions, CR1 and CR2, are activated in anodic and cathodic polarizations, indicating that steam interacts with both Ni and YSZ surfaces in both operating modes. 


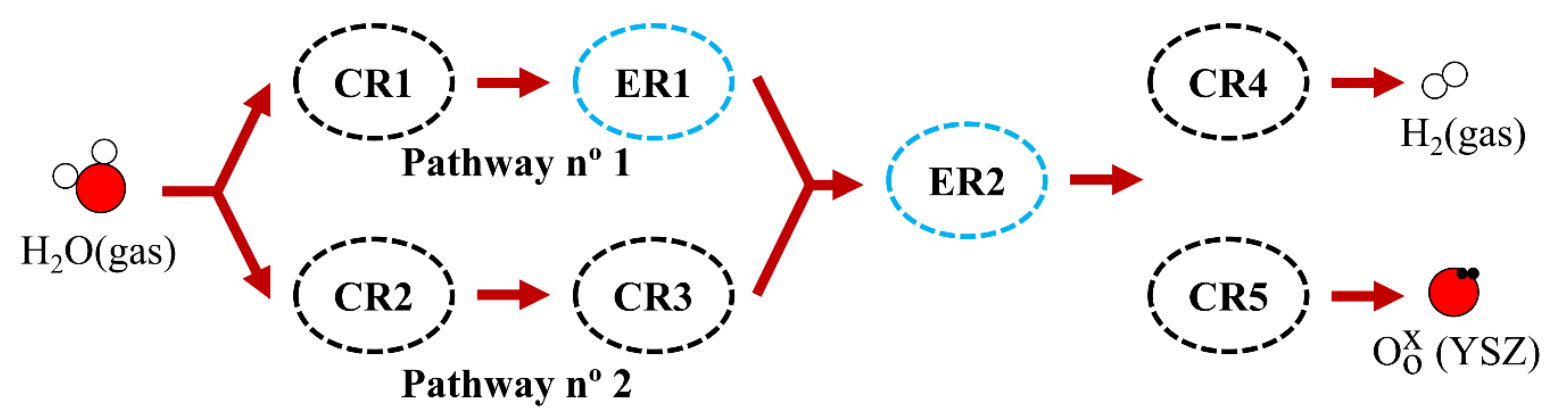

a)
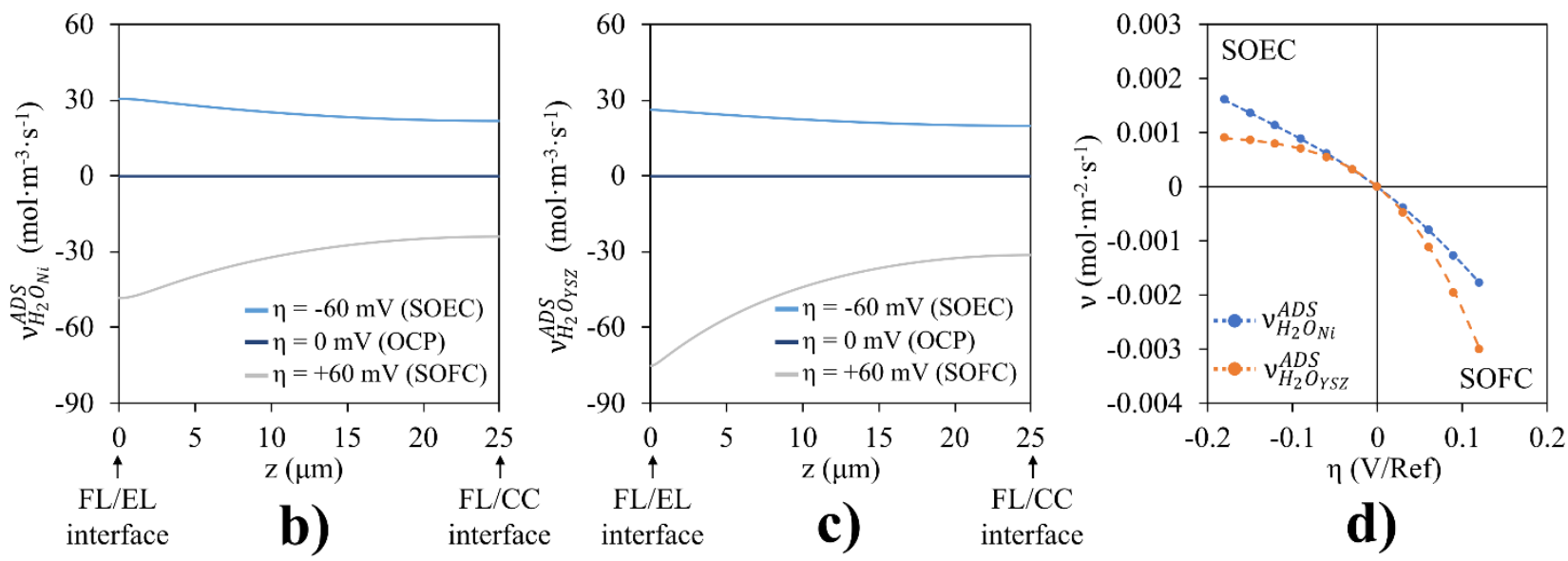

Figure 7: Results of the simulation with Model II on the steam interaction with Ni and YSZ surfaces with $\mathrm{pH}_{2} / \mathrm{pH}_{2} \mathrm{O}=50 / 50$ : a) Schematic representation of the two parallel pathways for the electrode reaction with Model II (given in electrolysis mode) - b) Local kinetic rate of $\mathrm{H}_{2} \mathrm{O}$ adsorption/desorption on $\mathrm{Ni}$ surface $(\mathrm{CR} 1)$ - c) Local kinetic rate of $\mathrm{H}_{2} \mathrm{O}$ adsorption/desorption on YSZ surface (CR2) - d) Kinetic rate of steam adsorption/desorption on Ni and YSZ integrated over the electrode thickness as a function of the overpotential.

Before identifying the precise role of YSZ and Ni surfaces on the mechanism, it is worth reminding that Model II is divided in seven elementary steps that can be separated in two possible pathways for the steam reduction/hydrogen oxidation reactions as illustrated in Figure $7 \mathrm{a}$. Considering an operation in electrolysis mode, pathway $\mathrm{n}^{\circ} 1$ corresponds to the steam adsorption on the Ni surface (CR1) followed by the electrochemical reduction at the TPBls (ER1). Alternatively, water can be adsorbed on the YSZ surface (CR2) and dissociated into two hydroxyl ions (CR3), which correspond to pathway $\mathrm{n}^{\circ} 2$. Finally, the common reactions belonging to both pathways correspond to the second charge transfer (ER2), the oxygen incorporation in YSZ (CR5) and the hydrogen desorption from $\mathrm{Ni}(\mathrm{CR} 4)$.

As reported hereafter, the relative contribution of these two pathways in the overall Ni-3YSZ electrode response has been evaluated depending on the anodic or cathodic polarization. In each case, the rate determining steps have also been identified. 
In electrolysis mode, the gaseous $\mathrm{H}_{2} \mathrm{O}$ is partially adsorbed on the Ni surface (Figure $7 \mathrm{~b}$ ). In this case, the adsorbed molecules are reduced directly at the TPBls by the first charge transfer reaction (ER1) according to the pathway $\mathrm{n}^{\circ} 1$ (cf. schematic representation in Figure 7a). In parallel, it can be seen in Figure $7 \mathrm{c}$ that the gaseous $\mathrm{H}_{2} \mathrm{O}$ molecules are also adsorbed on the YSZ surface where they dissociate in two hydroxyl ions according to the pathway $n^{\circ} 2$ (Figure $7 \mathrm{a}$ ). In both cases, the hydroxyl ions, which are produced by the two pathways, are commonly consumed by the second charge transfer (ER2).

In fuel cell mode, the opposite directions for the two pathways are found with part of the $\mathrm{H}_{2} \mathrm{O}$ produced via the oxidation at the TPB1s (Reverse-ER1 and Reverse-CR1) (pathway ${ }^{\circ} 1$ ) and part of the $\mathrm{H}_{2} \mathrm{O}$ formed directly on the YSZ surface via the reverse reaction of the water dissociation (Reverse-CR3 and Reverse-CR2) (pathway ${ }^{\circ} 2$ ).

Therefore, these simulation results show that two pathways are activated in parallel for the two operating modes as shown in Figure 7a.

To determine the contribution of each pathway to the total electrode response, the local kinetic rates integrated over the electrode thickness are plotted as a function of the overpotential in Figure $7 \mathrm{~d}$. Interestingly, a modification in the dominant pathway is highlighted. In fuel cell mode, most of the steam is produced by the water desorption from the YSZ surface according to the pathway $n^{\circ} 2$, whereas in electrolysis mode, the reaction mechanism is dominated by the pathway $\mathrm{n}^{\circ} 1$. Indeed, in this case, the contribution of the $\mathrm{H}_{2} \mathrm{O}$ adsorbed on $\mathrm{Ni}$ is higher compared to the reaction of adsorption on YSZ. Therefore, these modeling results suggest that the nature of the reaction pathway and the associated rate determining step related to the gas-solid interaction would change with the electrode polarization. Under anodic current (fuel cell mode), the reaction would be mainly controlled by the pathway $\mathrm{n}^{\circ} 2$, which involves the steam interaction with YSZ (cf. Figure 7a). On the contrary, the pathway $\mathrm{n}^{\circ} 1$, which is linked to the interaction of steam with $\mathrm{Ni}$, would be predominant under electrolysis current (cf. Figure 7a) (knowing that the rate of steam adsorption on YSZ becomes negligible under high cathodic polarization). This global behavior allows identifying the nature of the gas-solid interaction, which was highlighted experimentally, but also explains the dissymmetry of the electrode polarization curves in the two operating modes.

To deepen the analysis and clarify the detail of mechanisms, the local kinetic rates of the two charge transfer reactions (ER1 and ER2) are given in Figure 8 at $\mathrm{pH}_{2} / \mathrm{pH}_{2} \mathrm{O}=50 / 50$ and $-0.06 \mathrm{~V} /+0.06 \mathrm{~V}$. Whatever the electrode polarization, it can be seen that the rate of the second charge transfer reaction (ER2) is always higher with respect to the first one (ER1) (Figure 8). 

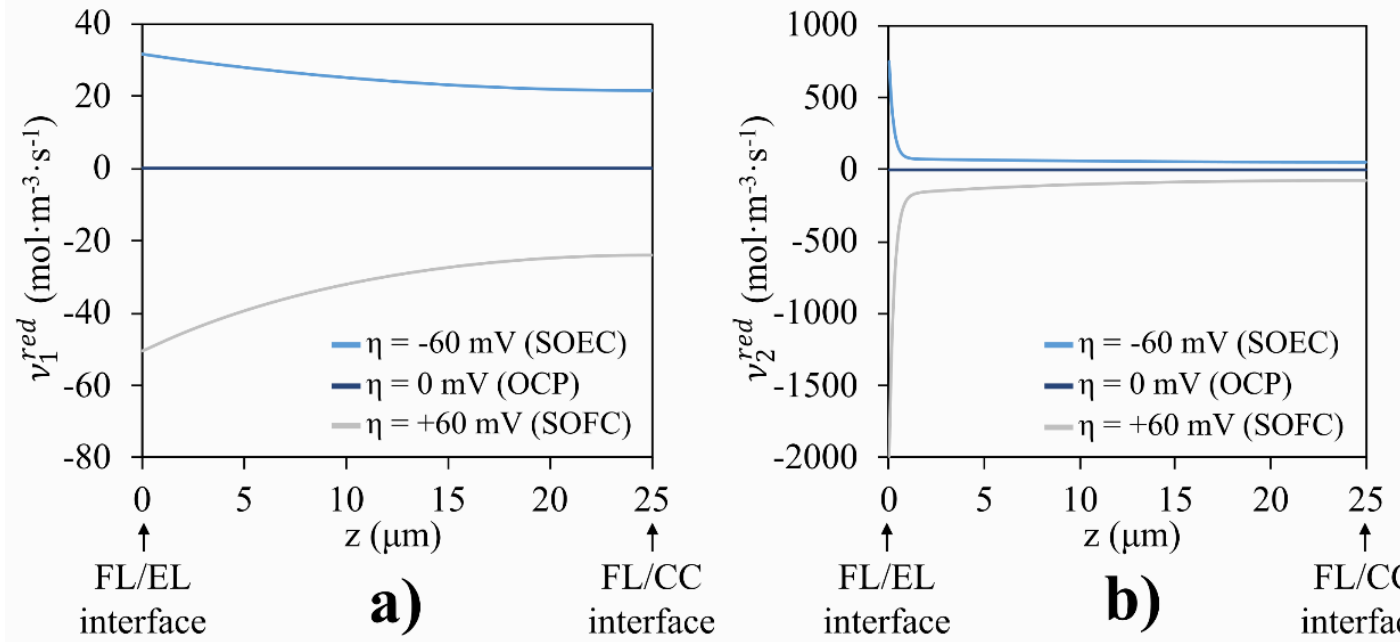

$\mathrm{FL} / \mathrm{EL}$

interface

b)

$\mathrm{FL} / \mathrm{CC}$

Figure 8: Kinetic rate of the charge transfer reactions at different polarizations with $\mathrm{pH}_{2} / \mathrm{pH}_{2} \mathrm{O}=$ 50/50: a) Local kinetic rate of the first charge transfer reaction (ER1) - b) Local kinetic rate of the second charge transfer reaction (ER2).

Besides, the charge transfer reaction ER2 is strongly promoted at the FL/EL interface whereas ER1 takes place more homogeneously along the electrode thickness. This difference in the distribution of the two reaction rates is related to the reacting species involved in the second charge transfer. Indeed, it is reminded that ER2 involves as product (or reactant in the fuel cell mode) the oxygen ions migrating in the electrolyte. Because of the very fast kinetic rate of the oxygen exchange from the surface into the bulk of YSZ, this reaction ER2 is thus strongly promoted in a region close to the electrolyte interface. To investigate the impact of these electrochemical reactions on the two reaction pathways, the surface coverages of hydroxyl ions and water attached to the YSZ as well as water attached to the $\mathrm{Ni}$ are given in Figure 9.
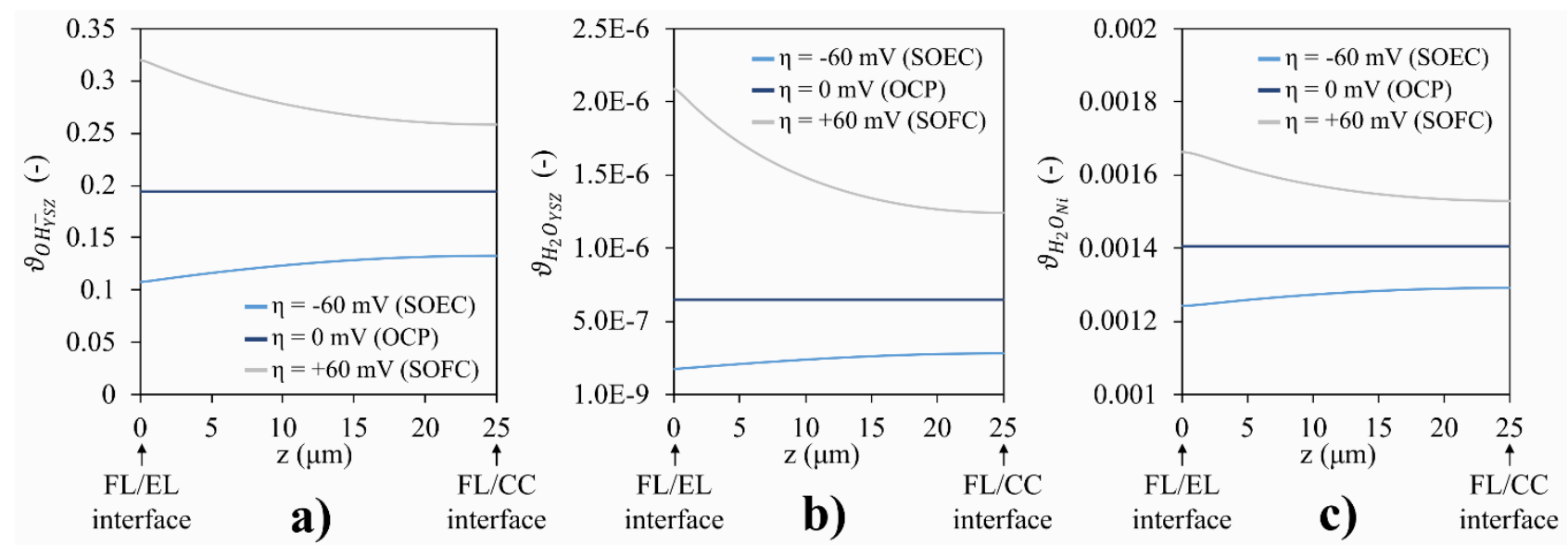

Figure 9: Local surface coverages at different polarizations with $\mathrm{pH}_{2} / \mathrm{pH}_{2} \mathrm{O}=50 / 50$ : a) $\mathrm{Hydroxyl}$ ions on the YSZ surface - b) $\mathrm{H}_{2} \mathrm{O}$ on the YSZ surface - c) $\mathrm{H}_{2} \mathrm{O}$ on the Ni surface.

In fuel cell mode for which the pathway $\mathrm{n}^{\circ} 2$ is predominant, the fast charge transfer ER2 corresponds to a production of surface-attached hydroxyl ions (Figure 9a). This increase favors both (i) the reverse reaction of water dissociation (Reverse-CR3) and (ii) the first charge transfer reaction 
(Reverse-ER1), leading to produce $\mathrm{H}_{2} \mathrm{O}$ on both the YSZ surface (Figure 9b) and the Ni surface (Figure 9c), respectively. Nevertheless, due to the fast kinetics of the reverse dissociation, a significant part of $\mathrm{H}_{2} \mathrm{O}$ is formed directly on the YSZ surface where the coverage of water is increased by almost one order of magnitude with respect to the equilibrium conditions. This increase promotes the direct desorption of water from the YSZ surface. All these evolutions provide an insight into the underlying mechanism explaining why the pathway $\mathrm{n}^{\circ} 2$ dominates the reaction mechanism under anodic polarization (fuel cell mode). It can be pointed out that the direct formation of $\mathrm{H}_{2} \mathrm{O}$ on the YSZ surface via the reverse reaction of dissociation is not considered in the reaction scheme proposed in other works [63] for which only the charge transfer reaction (ER1) is taken into account. However, based on our modeling results, it appears that the direct formation of water on the YSZ surface would also contribute to the electrode response. This possibility has been suggested by Goodwin et al. [60] even if it was finally not included in their modeling scheme. In electrolysis mode where the pathway $\mathrm{n}^{\circ} 1$ is dominant, the fast kinetic of ER2 triggers a significant consumption of $O H_{Y S Z}^{-}$(Figure 9a) which promotes the steam dissociation reaction on the YSZ surface (CR3) and the $\mathrm{H}_{2} \mathrm{O}$ reduction at the TPBls (ER1). The very fast dissociation reaction consumes the $\mathrm{H}_{2} \mathrm{O}$ on the YSZ surface causing a drop in the water surface coverage (Figure $9 b)$. This decrease of water attached on the YSZ surface is not balanced by the adsorption reaction (CR2) blocking the pathway $n^{\circ} 2$, so that the reduction of $\mathrm{Ni}$-attached $\mathrm{H}_{2} \mathrm{O}$ at the TPB1s (ER1) becomes the main source of hydroxyl ions on the YSZ surface (resulting in the activation of the pathway $\left.\mathrm{n}^{\circ} 1\right)$.

To summarize, the global reaction rate is dominated in fuel cell mode (i.e. anodic polarization) by the pathway $n^{\circ} 2$. In this case, most of the steam is produced on the YSZ surface and the reaction rate is mostly controlled by the charge transfer reaction (ER2) and the water desorption from the YSZ (reverse of CR2). In electrolysis mode (i.e. cathodic polarization), the pathway $\mathrm{n}^{\circ} 1$ becomes predominant. Indeed, the adsorption rate of $\mathrm{H}_{2} \mathrm{O}$ on the YSZ (CR2) becomes very slow yielding to activate the contribution of the first charge transfer reaction (ER1) and the steam adsorption on $\mathrm{Ni}$ (CR1). As this last reaction is not kinetically favored, it explains the appearance of a relatively low limiting current density in electrolysis mode.

As a general comment, it can be inferred from this numerical analysis that the second charge transfer at the TPB1s (ER2) and the variation in concentration for the YSZ-attached hydroxyl ions play a key role on the electrode response in both polarizations. This strong effect of YSZ-attached 
hydroxyl ions has been ascribed to their production/consumption and is consistent with the influence of the $O H_{Y S Z}^{-}$surface diffusivity on the electrode response.

\subsubsection{Sensitivity Analysis on Model II Parameters}

A complementary sensitivity analysis has been performed in an attempt to improve the Model II predictability regarding the dependence of the electrode response with $\mathrm{pH}_{2} \mathrm{O}$. This study has been realized with the purpose to check the validity of the assumptions concerning the non-limiting nature of the oxygen ions incorporation into YSZ and the water dissociation reactions on the YSZ surface (CR5 and CR3, respectively). Besides, according to the simulation results, the surface coverage of $O H_{Y S Z}^{-}$and its surface diffusion are expected to have an impact on the electrode response. However, as already stated, large uncertainty exists on the diffusion coefficients, especially for the surface-attached species. This means that the contribution of surface diffusion could have been slightly underestimated [61]. For this reason, a third sensitivity analysis has been carried out to investigate the impact on the reaction of the hydroxyl ions surface diffusivity.

The analyses have been carried out by lowering the value of the examined parameter to make the electrode response dependent on it (or to increase the dependency in case of the $O H_{Y S Z}^{-}$diffusivity). Afterward, the forward kinetic constants of the other reactions have been re-fitted on the experimental $\eta$ - $\mathrm{i}$ curve at $\mathrm{pH}_{2} / \mathrm{pH}_{2} \mathrm{O}=50 / 50$ and the EIS diagram at OCP has been simulated without any further adjustment. In addition, the reaction orders with respect to $\mathrm{H}_{2}$ and $\mathrm{H}_{2} \mathrm{O}$ have been evaluated and compared to the results obtained experimentally. The values of the hydroxyl diffusion coefficient and the forward kinetic constants used in the sensitivity analysis are reported in Table VIII while the results are given in Figure 10 and Table VI.

As shown in Figure 10a-c, it is possible to obtain a satisfactory fitting of the electrode $\eta$-i curve at $\mathrm{pH}_{2} / \mathrm{pH}_{2} \mathrm{O}=50 / 50$ in all three analyzed cases. Nevertheless, the EIS diagram calculated at OCP with the model limited by the oxygen ions incorporation/excorporation reaction (CR5) presents a different shape from the experimental spectrum (Figure 10d). Indeed, in this case, the impedance arc at $\approx 40 \mathrm{~Hz}$ appears to be similar to a pure semicircle with a more ideal capacitive behavior compared to the experimental one. Besides, the simulated characteristic frequency is clearly shifted towards higher values and does not match anymore the experimental data. For these reasons, it can be stated that the hypothesis on the not-limiting nature of the reaction CR5 is well confirmed. 
Table VIII: Parameters in the sensitivity analysis for Model II

\begin{tabular}{|c|c|c|c|c|}
\hline & $\begin{array}{l}\text { Limited by CR5 } \\
\text { kinetic }\end{array}$ & $\begin{array}{l}\text { Limited by CR3 } \\
\text { kinetic }\end{array}$ & $\begin{array}{l}\text { Limited by } \\
O H_{Y S Z}^{-} \text {diffusion }\end{array}$ & \\
\hline $\begin{array}{l}\text { YSZ-attached hydroxyl ions diffusion } \\
\text { coefficient }\left(D_{O H_{Y S Z}}\right)\end{array}$ & $1.45 \times 10^{-9}$ & $1.45 \times 10^{-9}$ & $1.45 \times 10^{-11}$ & $\left(\mathrm{~m}^{2} \cdot \mathrm{s}^{-1}\right)$ \\
\hline Steam adsorption on $\mathrm{Ni}\left(k_{\mathrm{H}_{2} \mathrm{O}_{\mathrm{Ni}}}^{A D S}\right)$ & $5 \times 10^{2}$ & $7.5 \times 10^{1}$ & $1.25 \times 10^{2}$ & $\left(\mathrm{~s}^{-1}\right)$ \\
\hline Steam adsorption on YSZ $\left(k_{\mathrm{H}_{2} \mathrm{O}_{Y S Z}}^{A D S}\right)$ & $5 \times 10^{2}$ & $1.5 \times 10^{2}$ & $1.25 \times 10^{2}$ & $\left(\mathrm{~s}^{-1}\right)$ \\
\hline Steam dissociation on YSZ $\left(k_{\mathrm{H}_{2} \mathrm{O}_{Y S Z}}^{D I S S+}\right)$ & $1 \times 10^{11}$ & $1 \times 10^{8}$ & $2.5 \times 10^{11}$ & $\left(\mathrm{~m}^{2} \cdot \mathrm{s}^{-1} \cdot \mathrm{mol}^{-1}\right)$ \\
\hline Hydrogen desorption from $\mathrm{Ni}\left(k_{H_{2 N i}}^{D E S}\right)$ & $4 \times 10^{12}$ & $8.1 \times 10^{7}$ & $8.1 \times 10^{8}$ & $\left(\mathrm{~m}^{2} \cdot \mathrm{s}^{-1} \cdot \mathrm{mol}^{-1}\right)$ \\
\hline $\begin{array}{l}\text { First charge transfer reaction in the } \\
\text { reduction direction }\left(k_{1}^{\text {red }}\right)\end{array}$ & $2 \times 10^{3}$ & $3 \times 10^{3}$ & $1 \times 10^{3}$ & $\left(\mathrm{~m}^{3} \cdot \mathrm{s}^{-1} \cdot \mathrm{mol}^{-1}\right)$ \\
\hline $\begin{array}{l}\text { Second charge transfer reaction in the } \\
\text { reduction direction }\left(k_{2}^{\text {red }}\right)\end{array}$ & $1 \times 10^{3}$ & $1 \times 10^{2}$ & $5 \times 10^{3}$ & $\left(\mathrm{~m}^{3} \cdot \mathrm{s}^{-1} \cdot \mathrm{mol}^{-1}\right)$ \\
\hline $\begin{array}{l}\text { Oxygen incorporation in the YSZ } \\
\left(k_{O_{Y S Z}^{I N C}}^{I N C} / C_{O_{O}^{r}(Y S Z)}^{r e f}\right)\end{array}$ & $2.5 \times 10^{-3}$ & $5 \times 10^{4}$ & $5 \times 10^{4}$ & $\left(\mathrm{~m}^{3} \cdot \mathrm{s}^{-1} \cdot \mathrm{mol}^{-1}\right)$ \\
\hline
\end{tabular}

When using the model limited by the kinetics of water dissociation (CR3), it is also possible to reproduce accurately the $\eta-i$ curves and the EIS diagrams (Figures 10d and 10e). Nevertheless, the reaction orders for $\mathrm{H}_{2}$ and $\mathrm{H}_{2} \mathrm{O}$ become less consistent in this case (cf. Table VI). In particular, the exponent for the steam partial pressure is increased with respect to the reference parameters of Model II, obtaining a value that is even less comparable to the experimental data. Therefore, the hypothesis of fast water dissociation on the YSZ surface is also confirmed.

Finally, the decrease of the hydroxyl ions diffusivity on the YSZ surface has been studied. From Figure 10, it can be seen that, increasing the limitation by $O H_{Y S Z}^{-}$diffusion, the polarization curves as well as the EIS diagrams at OCP are well captured by the model. Moreover, it can be seen in Table VI that the orders of reaction for hydrogen and water obtained with this model are more similar to the experimental data with respect to the ones calculated with the standard version of Model II. This result indicates that the impact of the surface diffusion of $O H_{Y S Z}^{-}$on the electrode response could be higher than in the standard case. From this point of view, the surface diffusivity of the hydroxyl ions appears to be a key property that would require a precise determination for a better prediction of the electrode behavior. Nevertheless, even in this last case, there is still a slight overestimation of the dependence of $\mathrm{R}_{\mathrm{pol}}$ with the steam partial pressure suggesting that more investigations are still needed for this type of electrode. In particular, complementary experimental characterizations would be useful by measuring for example impedance spectra under polarizations. Besides, a deeper understanding of the interactions between $\mathrm{H}_{2}$ or $\mathrm{H}_{2} \mathrm{O}$ molecules and the Ni-3YSZ 
system is still required to reduce the uncertainty on the surface diffusion coefficients for instance. From this point of view, Molecular Dynamics (MD) and DFT computations in combination with the micro-kinetic modeling are expected to bring valuable insights into the exact limiting steps for a real Ni-YSZ cermet electrode.

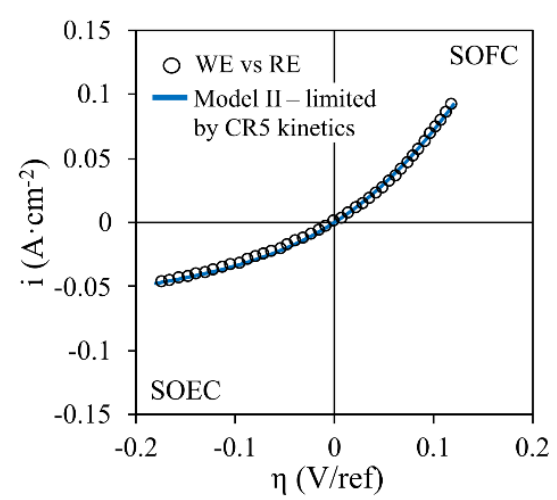

a)

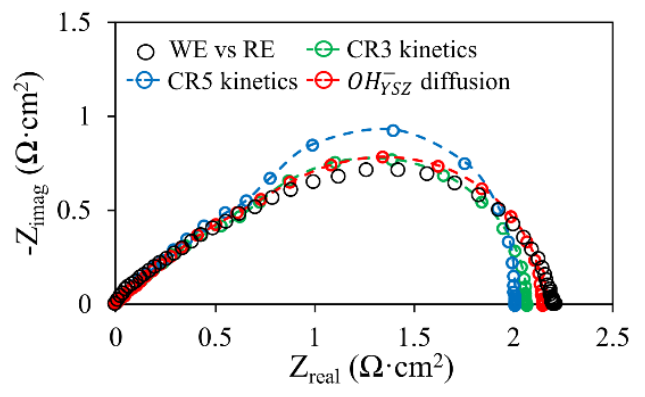

d)

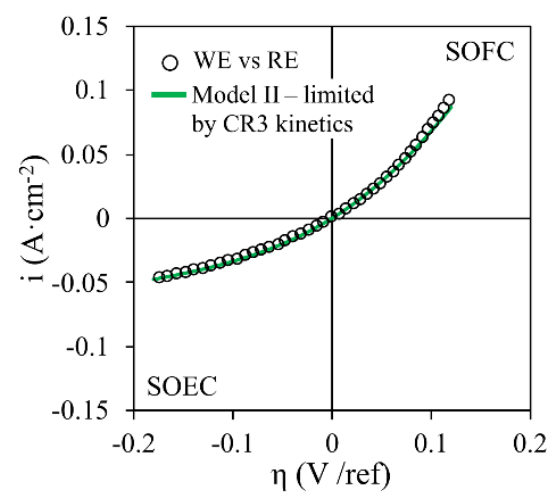

b)

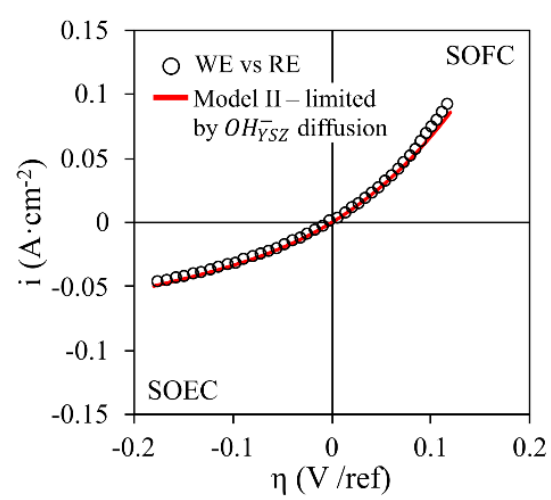

c)

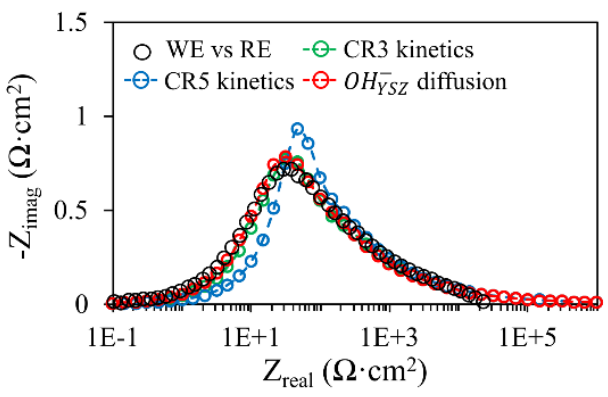

e)

Figure 10: Results of the sensitivity analysis on the parameters of Model II at $700^{\circ} \mathrm{C}$ : a) $\eta$-i curve at $\mathrm{pH}_{2} / \mathrm{pH}_{2} \mathrm{O}=50 / 50$ for the model limited by the incorporation/excorporation of $\mathrm{O}_{Y S Z}^{2-}$ in the YSZ (CR5) - b) $\eta$-i curve at $\mathrm{pH}_{2} / \mathrm{pH}_{2} \mathrm{O}=50 / 50$ for the model limited by the dissociation of $\mathrm{H}_{2} \mathrm{O}_{Y S Z}$ on the YSZ $(\mathrm{CR3})$ - c) $\eta$-i curve at $\mathrm{pH}_{2} / \mathrm{pH}_{2} \mathrm{O}=50 / 50$ for the model limited by the surface diffusion of $\mathrm{OH}_{Y S Z}^{-}$on the YSZ $\left(D_{O_{Y S Z}}\right)-$ Nyquist (d) and Bode (e) plots of the EIS diagrams at $\mathrm{OCP}$ at $\mathrm{pH}_{2} / \mathrm{pH}_{2} \mathrm{O}=50 / 50$.

\section{Conclusion}

In this work, the reaction mechanism for the hydrogen oxidation and steam reduction in a porous cermet electrode made of Ni and 3YSZ has been investigated. Experimental characterizations have been carried out at $700^{\circ} \mathrm{C}$ with symmetric cells using a three-electrode set-up over a large range of gas compositions. The $\eta-i$ curves have shown that electrode response is activated by the electrode potential in anodic polarization while a strong co-limitation is found under cathodic current. The electrode performances were found to be substantially improved increasing the steam partial pressure while the effect of the hydrogen was significantly lower. Impedance spectra at OCP have shown a shape exhibiting a type of finite-length Gerischer element. The skewed semi-circle at low frequencies was also found to be strongly sensitive to the steam content in the gas phase. Thanks to 
all these observations, it has been suggested that the co-limitation especially under electrolysis current is related to an interaction of steam with one of the electrode solid phases.

Two micro-kinetic elementary models, based on the oxygen and hydrogen spillover mechanisms, have been developed. To reduce the number of unknown parameters for the simulations, the real microstructural properties of the tested cermet have been deduced from a $3 \mathrm{D}$ electrode reconstruction obtained by synchrotron X-ray nano-holotomography. The validation of the two models has been conducted taking advantage of the experimental characterizations. It has been shown that the model based on the hydrogen spillover mechanism is the most appropriate to predict correctly the electrode response in terms of impedance spectra and polarization curves obtained at different gas compositions.

Once validated, the model based on the hydrogen spillover mechanism has been used to clarify the reaction pathway for the Ni-3YSZ electrode. The analysis of the simulated impedance diagrams at OCP has confirmed that the rate determining steps are (i) the charge transfer at TPBls, (ii) the oxygen vacancies migration in 3 YSZ network and (iii) a pure chemical surface process. Moreover, the simulations under polarizations have highlighted a change of reaction pathway from cathodic to anodic polarization.

In fuel cell mode, the charge transfer would be mainly controlled by the electrochemical oxidation of the hydroxyl ions and by the water desorption from the YSZ surface. In electrolysis mode, the adsorption rate of $\mathrm{H}_{2} \mathrm{O}$ on the YSZ would become very slow leading to the activation of the reaction pathway controlled by the steam adsorption on $\mathrm{Ni}$. This change of mechanism explains the strong dissymmetry of the electrode polarization curve. Moreover, it has been clearly shown that the attached hydroxyl ions on the YSZ surface play a key role in this electrode mechanism.

Finally, a sensitivity analysis of the main model assumptions has been carried out to improve the accuracy of the simulations. On the one hand, it has been confirmed that the hypotheses based on the non-limiting nature of the water dissociation on the YSZ surface as well as the incorporation of oxygen ions in the YSZ lattice are correct. On the other hand, it has been found that decreasing the surface diffusivity of the hydroxyl ions could improve the global quality of the model predictions. Knowing the uncertainty on this key parameter, it can be reasonably supposed that electrode response is also co-controlled by surface diffusion. 


\section{Acknowledgments}

This project has received funding from the Fuel Cells and Hydrogen 2 Joint Undertaking (JU) under grant agreement $n^{\circ} 874577$ (NewSOC project) and $n^{\circ} 825027$ (AD ASTRA project). The JU receives support from the European Union's Horizon 2020 research and innovation program and Denmark, France, Italy, Spain, Poland, Netherlands, Greece, Finland, Estonia, Germany, United Kingdom, Switzerland. The work has also been partially supported by the French National Agency (ANR) (ECOREVE project). The synchrotron radiation experiments were performed on beamline ID16A at the European Synchrotron Radiation Facility (ESRF), Grenoble, France. We are grateful to Dr. Peter Cloetens at the ESRF for providing assistance in using beamline ID16A. 


\section{List of Symbols}

\section{Roman Symbols:}

A Proportionality factor for the polarization resistance

$\left(\Omega \cdot \mathrm{m}^{2} \cdot \mathrm{bar}^{\alpha+\beta}\right)$

$a_{i}$

Thermodynamic activity for the i-th species

$(-)$ or $\left(\mathrm{mol} \cdot \mathrm{m}^{-2}\right)$

$C_{d l}$

Double-layer capacitance at the $\mathrm{Ni} / \mathrm{YSZ}$ interface

$\left(\mathrm{F} \cdot \mathrm{m}^{-2}\right)$

$C_{i} \quad$ Concentration of the $i$-th species

$\left(\mathrm{mol} \cdot \mathrm{m}^{-3}\right)$

$D_{i} \quad$ Diffusion coefficient for the $i$-th species

$\left(\mathrm{m}^{2} \cdot \mathrm{s}^{-1}\right)$

$D_{i-j}$

Binary diffusion coefficient for the $i$-th and $j$-th species

$\left(\mathrm{m}^{2} \cdot \mathrm{s}^{-1}\right)$

$D_{K, i}$

Knudsen diffusion coefficient for the i-th species

$\left(\mathrm{m}^{2} \cdot \mathrm{s}^{-1}\right)$

E

Electrode potential

$E^{e q}$

Equilibrium potential

$E^{\text {meas }}$

Measured potential

$e_{N i}^{-}$

Electron in the $\mathrm{Ni}$

$(-)$

$\mathrm{F}$

Faraday's constant

$\left(\mathrm{C} \cdot \mathrm{mol}^{-1}\right)$

$h_{m}^{0}$

Standard enthalpy of formation of the m-th species

$\left(\mathrm{J} \cdot \mathrm{mol}^{-1}\right)$

$i_{A C}$

Amplitude of the sinusoidal current density

$\left(\mathrm{A} \cdot \mathrm{cm}^{-2}\right.$ )

Steady-state current density

$\left(\mathrm{A} \cdot \mathrm{cm}^{-2}\right)$

$i_{D C}$

Electronic/ionic current densities in the electrode

$\left(\mathrm{A} \cdot \mathrm{cm}^{-2}\right)$

$K_{i}^{e q}$

Equilibrium constant of i-th reaction

$(-)$

$k_{j_{S}}^{i}$

Kinetic constant for the $i$-th reaction of the $j$-th species on the surface $S$

$\left(\mathrm{s}^{-1}\right)$ or $\left(\mathrm{m}^{2} \cdot \mathrm{s}^{-1} \cdot \mathrm{mol}^{-1}\right)$

$k_{i}^{r e d / o x}$

Reduction/oxidation kinetic constant for the i-th charge transfer reaction

$\left(\mathrm{m}^{3} \cdot \mathrm{s}^{-1} \cdot \mathrm{mol}^{-1}\right)$

$\ell_{E L}$

Thickness of the electrolyte

(m)

Thickness of the functional layer

(m)

$\ell_{F L}$

Molar mass of the i-th species

$\left(\mathrm{g} \cdot \mathrm{mol}^{-1}\right)$

Avogadro's Number

$N_{a}$

Molar flux of the i-th species

(atoms $\cdot \mathrm{mol}^{-1}$ )

$\left(\mathrm{mol} \cdot \mathrm{m}^{-2} \cdot \mathrm{s}^{-1}\right)$

$\vec{N}_{i}$

$n$

Number of electrons exchanged in the charge transfer reaction

$(-)$

Partial pressure of i-th gas species

(bar)

Reference pressure

(bar)

Total pressure

(bar)

Stoichiometric coefficient of i-th species

$(-)$

Universal gas constant

$\left(\mathrm{J} \cdot \mathrm{mol}^{-1} \cdot \mathrm{K}^{-1}\right)$

Polarization resistance

$\left(\Omega \cdot \mathrm{cm}^{2}\right)$

$R_{\text {pol }}$

Serial resistance

$\left(\Omega \cdot \mathrm{cm}^{2}\right)$

$R_{S}$

Mean radius of the $a$ phase

(m)

$\bar{r}_{a}$

Source term for the i-th species

$\left(\mathrm{mol} \cdot \mathrm{m}^{-3} \cdot \mathrm{s}^{-1}\right)$

Specific surface area between the $a$ and $b$ phases

$\left(\mathrm{m}^{-1}\right)$

$S p_{a-b}$

$s_{m}^{0}$

Standard entropy of formation of the m-th species

$\left(\mathrm{J} \cdot \mathrm{K}^{-1} \cdot \mathrm{mol}^{-1}\right)$

Free surface site on Ni surface

Free surface site on YSZ surface 
$V_{i} \quad$ Fuller's volume for the i-th species

\section{Chemical Species:}

\section{$\mathrm{H}_{2}$ (gas) Gaseous $\mathrm{H}_{2}$}

$H_{N i} \quad \mathrm{H}$ attached on Ni surface

$\mathrm{H}_{2} \mathrm{O}$ (gas) Gaseous $\mathrm{H}_{2} \mathrm{O}$

$\mathrm{H}_{2} \mathrm{O}_{\mathrm{Ni}} \quad \mathrm{H}_{2} \mathrm{O}$ attached on Ni surface

$\mathrm{H}_{2} \mathrm{O}_{Y S Z} \quad \mathrm{H}_{2} \mathrm{O}$ attached on $\mathrm{YSZ}$ surface

$O_{N i} \quad \mathrm{O}$ attached on Ni surface

$O_{O}^{x} \quad$ Oxygen in the YSZ lattice

$O_{Y S Z}^{2-} \quad \mathrm{O}^{2-}$ attached on YSZ surface

$O H_{N i} \quad \mathrm{OH}$ attached on Ni surface

$O H_{Y S Z}^{-} \quad \mathrm{OH}^{-}$attached on the YSZ surface

$V_{O}^{*} \quad$ Oxygen vacancy in the YSZ lattice

\section{Greek Symbols:}

$\begin{array}{ll}\alpha & \text { Reaction order for hydrogen } \\ \alpha_{\text {red } / o x} & \text { Reduction/oxidation transfer coefficients } \\ \beta & \text { Reaction order for steam } \\ \Gamma_{S} & \text { Total density of sites available for adsorption on the surface S } \\ \Delta g_{i}^{0} & \text { Standard Gibbs free energy variation for the i-th reaction } \\ \varepsilon_{a} & \text { Volume fraction of the } a \text { phase } \\ \eta & \text { Electrode overpotential } \\ \theta_{a d s, i s} & \text { Surface coverage of i-th species on surface S } \\ \theta_{S} & \text { Fraction of empty surface sites on surface S } \\ \tilde{\mu}_{i} & \text { Electrochemical potential of the i-th species } \\ v^{i} & \text { Kinetic rate of the i-th reaction } \\ \xi^{T P B l s} & \text { Triple phase boundaries lengths density } \\ \sigma_{e l / i o} & \text { Electronic conductivity of the Ni/Ionic conductivity of the YSZ } \\ \tau_{a} & \text { Apparent tortuosity factor of the } a \text { phase } \\ \varphi_{e l / i o} & \text { Electronic potential in the Ni/ionic potential in the YSZ }\end{array}$

$(-)$

$(-)$ $\left(\mathrm{mol} \cdot \mathrm{m}^{-2}\right)$ $\left(\mathrm{J} \cdot \mathrm{mol}^{-1}\right)$

$\left(\mathrm{J} \cdot \mathrm{mol}^{-1}\right)$ $\left(\mathrm{mol} \cdot \mathrm{m}^{-3} \cdot \mathrm{s}^{-1}\right)$ $\left(\mathrm{m}^{-2}\right)$ $\left(\mathrm{S} \cdot \mathrm{m}^{-1}\right)$ 


\section{List of Abbreviations}

3YSZ Yttria Stabilized Zirconia with $3 \mathrm{~mol} \%$ of yttria

3Y-TZP Tetragonal Polycrystalline Zirconia stabilized with $3 \mathrm{~mol} \%$ of yttria

8YSZ Yttria Stabilized Zirconia with 8 mol.\% of yttria

CC Current Collector

CE Counter Electrode

CR Chemical Reaction

DFT Density Functional Theory

DGM Dusty-Gas Model

EC Equivalent Circuit

EIS Electrochemical Impedance Spectroscopy

ER Electrochemical Reaction

ESRF European Synchrotron Radiation Facility

FL Functional Layer

FLG Finite-Length Gerischer

GDC Gadolinium-doped Ceria

LSCF Lanthanum Strontium Cobalt Ferrite

MD Molecular Dynamics

OCP Open Circuit Potential

pFIB Plasma-Focused Ion Beam

RE Reference Electrode

ROI Region of Interest

RVE Representative Volume Element

SOC Solid Oxide Cell

SOEC Solid Oxide Electrolysis Cell

SOFC Solid Oxide Fuel Cell

TPBls Triple Phase Boundaries lengths

WE Working Electrode

YSZ Yttria Stabilized Zirconia 


\section{Appendix A: Development of Model I for the oxygen spillover Mechanism}

As explained in Section 3, the oxygen spillover mechanism implemented in Model I is described by five chemical reactions and one electrochemical charge transfer reaction.

These reactions are accompanied by the surface diffusion of the adsorbed species $\left(\mathrm{H}_{\mathrm{Ni}}, \mathrm{H}_{2} \mathrm{O}_{\mathrm{Ni}}\right.$, $O H_{N i}, O_{N i}$ and $O_{Y S Z}^{2-}$ ), the ionic conduction in the YSZ, the electronic conduction in the nickel phase and gas diffusion in the pores of the electrode $\left(\mathrm{H}_{2}\right.$ and $\left.\mathrm{H}_{2} \mathrm{O}\right)$.

For each reaction, the kinetic rate is expressed according to Eqs. (3a) and (3b).

$$
\begin{aligned}
& v_{\mathrm{H}_{2} \mathrm{O}_{\mathrm{Ni}}}^{A D S}=S p_{\text {pores }-\mathrm{Ni}} \cdot \Gamma_{\mathrm{Ni}} \cdot\left(k_{\mathrm{H}_{2} \mathrm{O}_{\mathrm{Ni}}}^{A D S} \cdot \frac{p \mathrm{H}_{2} \mathrm{O}}{p_{\text {ref }}} \cdot \theta_{\mathrm{Ni}}-k_{\mathrm{H}_{2} \mathrm{O}_{\mathrm{Ni}}}^{D E S} \cdot \theta_{\mathrm{H}_{2} \mathrm{O}_{\mathrm{Ni}}}\right) \\
& v_{H_{2} O_{N i}}^{D I S S}=S p_{\text {pores }-N i} \cdot \Gamma_{N i}^{2} \cdot\left(k_{H_{2} O_{N i}}^{D I S S+} \cdot \theta_{H_{2} O_{N i}} \cdot \theta_{N i}-k_{H_{2} O_{N i}}^{D I S S-} \cdot \theta_{O H_{N i}} \cdot \theta_{H_{N i}}\right) \\
& v_{O H_{N i}}^{D I S S}=S p_{\text {pores }-N i} \cdot \Gamma_{N i}^{2} \cdot\left(k_{O H_{N i}}^{D I S S+} \cdot \theta_{O H_{N i}} \cdot \theta_{N i}-k_{O H_{N i}}^{D I S S-} \cdot \theta_{O_{N i}} \cdot \theta_{H_{N i}}\right) \\
& v_{H_{2 N i}}^{D E S}=S p_{\text {pores }-N i} \cdot \Gamma_{N i}^{2} \cdot\left(k_{H_{2 N i}}^{D E S} \cdot \theta_{H_{N i}}^{2}-k_{H_{2 N i}}^{A D S} \cdot \frac{p H_{2}}{p_{r e f}} \cdot \theta_{N i}^{2}\right) \\
& v_{R E D}^{c t}=\xi^{T P B l s} \cdot \Gamma_{N i} \cdot \Gamma_{Y S Z} \cdot\left(k^{r e d} \cdot \theta_{O_{N i}} \cdot \theta_{Y S Z} \cdot \exp \left(\frac{-2 \cdot \alpha_{c t}^{r e d} \cdot F}{R T} E\right)-k^{o x} \cdot \theta_{N i} \cdot \theta_{O_{Y S Z}^{2-}} \cdot \exp \left(\frac{2 \cdot \alpha_{c t}^{o x} \cdot F}{R T} E\right)\right) \\
& v_{O_{Y S Z}^{I N C}}^{I N C}=S p_{Y S Z \text {-pores }} \cdot \Gamma_{Y S Z} \cdot\left(k_{O_{Y S Z}^{I N C}}^{I N C} \cdot \theta_{O_{Y S Z}^{2-}} \cdot \frac{c_{V_{O}^{*}(Y S Z)}}{c_{O_{O}^{r}(Y S Z)}^{r e f}}-k_{O_{Y S Z}^{2-}}^{E X C} \cdot \theta_{Y S Z} \cdot \frac{c_{O_{O}^{x}(Y S Z)}}{c_{O_{O}^{x}(Y S Z)}^{r e f}}\right)
\end{aligned}
$$

The thermodynamic equilibrium constants for the five chemical reactions (CR1-CR5) are evaluated using Eqs. (7a) and (7b).

$$
\begin{aligned}
& K_{A D S, H_{2} O_{N i}}^{e q}=\frac{k_{H_{2} O_{N i}}^{A D S}}{k_{H_{2} O_{N i}}^{D E S}}=\exp \left(\frac{-\left[\left(h_{H_{2} O_{N i}}^{0}(T)-T s_{H_{2} O_{N i}}^{0}(T)\right)-\left(h_{H_{2} O(g)}^{0}(T)+h_{S_{N i}}^{0}(T)-T\left(s_{H_{2} O(g)}^{0}(T)+s_{S_{N i}}^{0}(T)\right)\right)\right]}{R T}\right) \\
& K_{D I S S, H_{2} O_{N i}}^{e q}=\frac{k_{H_{2} O_{N i}}^{D I S S+}}{k_{H_{2} O_{N i}}^{D I S S}}=\exp \left(\frac{-\left[h_{O H_{N i}}^{0}(T)+h_{H_{N i}}^{0}(T)-T\left(s_{O H_{N i}}^{0}(T)+s_{H_{N i}}^{0}(T)\right)-\left(h_{H_{2} O_{N i}}^{0}(T)+h_{S_{N i}}^{0}(T)-T\left(s_{H_{2} O_{N i}}^{0}(T)+s_{S_{N i}}^{0}(T)\right)\right)\right]}{R T}\right) \\
& K_{D I S S, O H_{N i}}^{e q}=\frac{k_{O H_{N i}^{D S S+}}^{D I S S+}}{k_{O H_{N i}}^{D D S S-}}=\exp \left(\frac{-\left[h_{O_{N i}^{0}}^{0}(T)+h_{H_{N i}}^{0}(T)-T\left(s_{O_{N i}}^{0}(T)+s_{H_{N i}}^{0}(T)\right)-\left(h_{O H_{N i}}^{0}(T)+h_{S_{N i}}^{0}(T)-T\left(s_{O H_{N i}}^{0}(T)+s_{S_{N i}}^{0}(T)\right)\right)\right]}{R T}\right) \\
& K_{D E S, H_{2 N i}}^{e q}=\frac{k_{H_{2 N i}}^{D E S}}{k_{H_{2 N i}}^{A D S}}=\exp \left(\frac{-\left[\left(h_{H_{2}(g)}^{0}(T)-T s_{H_{2}(g)}^{0}(T)+2\left(h_{S_{N i}}^{0}(T)-T s_{S_{N i}}^{0}(T)\right)\right)-2\left(h_{H_{N i}}^{0}(T)-T s_{H_{N i}}^{0}(T)\right)\right]}{R T}\right)
\end{aligned}
$$

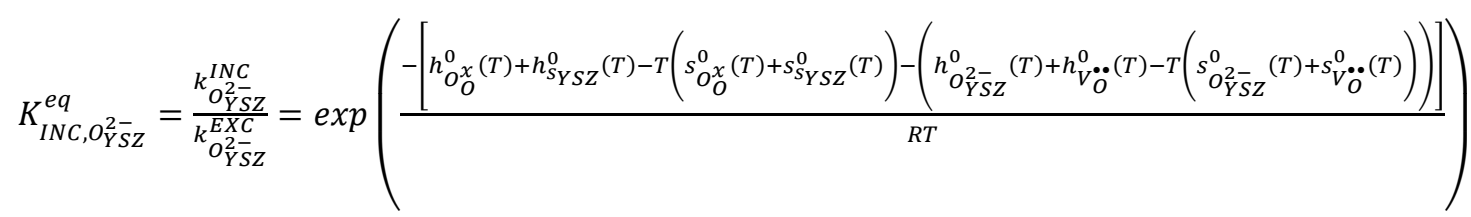

The thermodynamic data used for the calculations are reported in Table III.

Once the equilibrium constants have been determined, these have been used to evaluate the surface coverages at equilibrium on Ni and YSZ with Eq. (8).

For the equilibrium on Ni surface: 


$$
\begin{aligned}
& K_{A D S, H_{2} O_{N i}}^{e q}=\frac{\theta_{H_{2} O_{N i}}^{e q}}{\frac{p H_{2} e^{e q}}{p_{r e f}} \cdot \theta_{N i}^{e q}} \Rightarrow \theta_{H_{2} O_{N i}}^{e q}=K_{A D S, H_{2} O_{N i}}^{e q} \cdot \frac{p H_{2} O^{e q}}{p_{r e f}} \cdot \theta_{N i}^{e q} \\
& K_{D E S, H_{2 N i}}^{e q}=\frac{\frac{p H_{2} e q}{p_{r e f}} \cdot \theta_{N i}^{e q}}{\theta_{H_{N i}}^{e q}} \Rightarrow \theta_{H_{N i}}^{e q}=\sqrt{\frac{1}{K_{D E S, H_{2 N i}}^{e q}} \cdot \frac{p H_{2} e q}{p_{r e f}}} \cdot \theta_{N i}^{e q} \\
& K_{D I S S, H_{2} O_{N i}}^{e q}=\frac{\theta_{O H_{N i}}^{e q} \cdot \theta_{H_{N i}}^{e q}}{\theta_{H_{2} O_{N i}}^{e q} \cdot \theta_{N i}^{e q}} \Rightarrow \theta_{O H_{N i}}^{e q}=K_{D I S S, H_{2} O_{N i}}^{e q} \cdot K_{A D S, H_{2} O_{N i}}^{e q} \cdot \frac{p H_{2} O^{e q}}{p_{r e f}} \cdot\left(\sqrt{\frac{1}{K_{D E S, H_{2 N i}}^{e q}} \cdot \frac{p H_{2}^{e q}}{p_{r e f}}}\right)^{-1} \cdot \theta_{N i}^{e q} \\
& K_{D I S S, O H_{N i}}^{e q}=\frac{\theta_{O_{N i}}^{e q} \cdot \theta_{H_{N i}}^{e q}}{\theta_{O H_{N i}}^{e q} \cdot \theta_{N i}^{e q}} \Rightarrow \theta_{O_{N i}}^{e q}=K_{D I S S, O H_{N i}}^{e q} \cdot K_{D I S S, H_{2} O_{N i}}^{e q} \cdot K_{A D S, H_{2} O_{N i}}^{e q} \cdot K_{D E S, H_{2 N i}}^{e q} \cdot \frac{p H_{2} O_{2}^{e q}}{p H_{2} e q} \cdot \theta_{N i}^{e q} \\
& \sum \theta=1 \Rightarrow \theta_{N i}^{e q}=\left(1+K_{A D S, H_{2} O_{N i}}^{e q} \cdot \frac{p H_{2} e q}{p_{r e f}}+\sqrt{\frac{1}{K_{D E S, H_{2 N i}}^{e q}} \cdot \frac{p H_{2} e q}{p_{r e f}}}+K_{D I S S, H_{2} O_{N i}}^{e q} \cdot K_{A D S, H_{2} O_{N i}}^{e q} \cdot \frac{p H_{2} O^{e q}}{p_{r e f}} .\right. \\
& \left.\left(\sqrt{\frac{1}{K_{D E S, H_{2 N i}}^{e q}} \cdot \frac{p H_{2}^{e q}}{p_{r e f}}}\right)^{-1}+K_{D I S S, O H_{N i}}^{e q} \cdot K_{D I S S, H_{2} O_{N i}}^{e q} \cdot K_{A D S, H_{2} O_{N i}}^{e q} \cdot K_{D E S, H_{2 N i}}^{e q} \cdot \frac{p H_{2} e^{e q}}{p H_{2}^{e q}}\right)^{-1}
\end{aligned}
$$

Whereas on the YSZ surface:

$$
\begin{aligned}
& K_{I N C, O_{Y S Z}^{2-}}^{e q}=\frac{c_{O_{O}^{x}} \cdot \theta_{Y S Z}^{e q}}{C_{V_{O} *} * \theta_{O_{Y S Z}^{2}}^{e q}} \Rightarrow \theta_{O_{Y S Z}^{2-}}^{e q}=\frac{1}{K_{I N C, O_{Y S Z}^{2-} \overline{e q}}^{e q}} \cdot \frac{C_{O}^{x}}{C_{V_{0}^{*}}^{*}} \cdot \theta_{Y S Z}^{e q} \\
& \sum \theta=1 \Rightarrow \theta_{Y S Z}^{e q}=\left(1+\frac{1}{K_{I N C, O_{Y}^{2-} \bar{L} Z}^{e q}} \cdot \frac{c_{O_{O}^{x}}}{C_{V_{O}^{*}}}\right)^{-1}
\end{aligned}
$$

Subsequently the surface coverages at equilibrium have been used to evaluate the equilibrium constant for the electrochemical charge transfer reaction ER1 as reported in Eq. (9).

$K_{c t-R E D}^{e q}=\frac{\theta_{N i}^{e q} \cdot \theta_{O_{Y}^{2-}}^{e q}}{\theta_{O_{N i}}^{e q} \cdot \theta_{Y S Z}^{e q}} \exp \left(\frac{2 F}{R T} E^{e q}\right)$

The diffusion of all the species involved in the reaction mechanism has been modeled according to Eqs. (10) to (16) and using the diffusion coefficients reported in Table IV.

$$
\begin{aligned}
& \varepsilon_{\text {pores }} \frac{d C_{H_{2}}}{d t}+\nabla \cdot\left(-D_{H_{2}}^{e f f} \nabla C_{H_{2}}\right)=+v_{H_{2 N i}}^{D E S} \\
& \varepsilon_{\text {pores }} \frac{d C_{H_{2} O}}{d t}+\nabla \cdot\left(-D_{H_{2} O}^{e f f} \nabla C_{H_{2} O}\right)=-v_{H_{2} O_{N i}}^{A D S} \\
& S p_{N i-Y S Z} C_{d l} \frac{d E}{d t}=-\nabla \cdot\left(-\sigma_{e l}^{e f f} \nabla \varphi_{e l}\right)+2 F v_{R E D}^{c t} \\
& -S p_{N i-Y S Z} C_{d l} \frac{d E}{d t}=-\nabla \cdot\left(-\sigma_{i o}^{e f f} \nabla \varphi_{i o}\right)-2 F v_{O_{Y S Z}^{2}}^{I N C} \\
& S p_{\text {pores }-N i} \Gamma_{N i} \frac{d \theta_{H_{N i}}}{d t}+\nabla \cdot\left(-S p_{\text {pores }-N i} \Gamma_{N i} D_{H_{N i}} \nabla \theta_{H_{N i}}\right)=-2 v_{H_{2 N i} E S}^{D E S}+v_{H_{2} O_{N i}^{D I S S}}^{D I}+v_{O H_{N i}}^{D I S S} \\
& S p_{\text {pores }-N i} \Gamma_{N i} \frac{d \theta_{H_{2} O_{N i}}}{d t}+\nabla \cdot\left(-S p_{\text {pores }-N i} \Gamma_{N i} D_{H_{2} O_{N i}} \nabla \theta_{H_{2} O_{N i}}\right)=+v_{H_{2} O_{N i}}^{A D S}-v_{H_{2} O_{N i}^{D I S S}}^{D S} \\
& S p_{\text {pores }-N i} \Gamma_{N i} \frac{d \theta_{O H_{N i}}}{d t}+\nabla \cdot\left(-S p_{\text {pores }-N i} \Gamma_{N i} D_{O H_{N i}} \nabla \theta_{O H_{N i}}\right)=+v_{H_{2} O_{N i}^{D I S S}}^{D I S v_{O H}^{D I S S}} \\
& S p_{\text {pores }-N i} \Gamma_{N i} \frac{d \theta_{O_{N i}}}{d t}+\nabla \cdot\left(-S p_{\text {pores }-N i} \Gamma_{N i} D_{O_{N i}} \nabla \theta_{O_{N i}}\right)=+v_{O H_{N i}}^{D I S S}-v_{R E D}^{c t}
\end{aligned}
$$


$S p_{Y S Z-p o r e s} \Gamma_{Y S Z} \frac{d \theta_{O_{Y S Z}^{2-}}}{d t}+\nabla \cdot\left(-S p_{Y S Z-p o r e s} \Gamma_{Y S Z} D_{O_{Y S Z}^{2-}} \nabla \theta_{O_{Y S Z}^{2-}}\right)=+v_{R E D}^{c t}-v_{O_{Y S Z}^{I N C}}^{I N C}$

Solving this set of partial differential equations with the boundary conditions reported in Section 3.5 , the model is used to simulate the $\eta-i$ curves and the impedance spectra. 


\section{Appendix B: Development of Model II for the hydrogen spillover Mechanism}

The H spillover mechanism implemented in Model II is described by five chemical reactions and two electrochemical reactions.

These reaction steps are accompanied by the surface diffusion of the adsorbed species $\left(\mathrm{H}_{\mathrm{Ni}}, \mathrm{H}_{2} \mathrm{O}_{\mathrm{Ni}}\right.$, $\mathrm{H}_{2} \mathrm{O}_{Y S Z}, \mathrm{OH}_{Y S Z}^{-}$and $\mathrm{O}_{Y S Z}^{2-}$ ), the ionic conduction in the YSZ, the electronic conduction in the nickel and gas diffusion in the pores of the electrode $\left(\mathrm{H}_{2}\right.$ and $\left.\mathrm{H}_{2} \mathrm{O}\right)$.

For each one of the electrode reactions, the kinetic rate is expressed according to Eqs. (3a) and (3b).

$$
\begin{aligned}
& v_{\mathrm{H}_{2} O_{N i}}^{A D S}=S p_{\text {pores }-N i} \cdot \Gamma_{N i} \cdot\left(k_{H_{2} O_{N i}}^{A D S} \cdot \frac{p H_{2} O}{p_{\text {ref }}} \cdot \theta_{N i}-k_{H_{2} O_{N i}}^{D E S} \cdot \theta_{H_{2} O_{N i}}\right) \\
& v_{\mathrm{H}_{2} \mathrm{O}_{Y S Z}}^{A D S}=S p_{Y S Z-\text { pores }} \cdot \Gamma_{Y S Z} \cdot\left(k_{\mathrm{H}_{2} \mathrm{O}_{Y S Z}}^{A D S} \cdot \frac{p \mathrm{H}_{2} \mathrm{O}}{p_{\text {ref }}} \cdot \theta_{Y S Z}-k_{\mathrm{H}_{2} \mathrm{O}_{Y S Z}}^{D E S} \cdot \theta_{\mathrm{H}_{2} \mathrm{O}_{Y S Z}}\right) \\
& v_{\mathrm{H}_{2} \mathrm{O}_{Y S Z}}^{\text {IISS }}=S p_{Y S Z \text {-pores }} \cdot \Gamma_{Y S Z}^{2} \cdot\left(k_{\mathrm{H}_{2} \mathrm{O}_{N i}}^{D I S+} \cdot \theta_{\mathrm{H}_{2} \mathrm{O}_{Y S Z}} \cdot \theta_{O_{Y S Z}^{2-}}-k_{\mathrm{H}_{2} \mathrm{O}_{Y S Z}}^{D I S S-} \cdot \theta_{O \mathrm{H}_{Y S Z}^{-}}^{2}\right) \\
& v_{H_{2 N i}}^{D E S}=S p_{\text {pores }-N i} \cdot \Gamma_{N i}^{2} \cdot\left(k_{H_{2 N i}}^{D E S} \cdot \theta_{H_{N i}}^{2}-k_{H_{2 N i}}^{A D S} \cdot \frac{p H_{2}}{p_{\text {ref }}} \cdot \theta_{N i}^{2}\right) \\
& v_{R E D}^{c t, 1}=\xi^{T P B l s} \cdot \Gamma_{N i} \cdot \Gamma_{Y S Z} \cdot\left(k_{1}^{r e d} \cdot \theta_{H_{2} O_{N i}} \cdot \theta_{Y S Z} \cdot \exp \left(\frac{-\alpha_{c t, 1}^{r e d} \cdot F}{R T} E\right)-k_{1}^{o x} \cdot \theta_{O H_{Y S Z}^{-}} \cdot \theta_{H_{N i}} \cdot \exp \left(\frac{\alpha_{c t, 1}^{o x} \cdot F}{R T} E\right)\right) \\
& v_{R E D}^{c t, 2}=\xi^{T P B l s} \cdot \Gamma_{N i} \cdot \Gamma_{Y S Z} \cdot\left(k_{2}^{r e d} \cdot \theta_{O H_{Y S Z}^{-}} \cdot \theta_{N i} \cdot \exp \left(\frac{-\alpha_{c t, 2}^{r e d} \cdot F}{R T} E\right)-k_{2}^{o x} \cdot \theta_{O_{Y S Z}^{2-}} \cdot \theta_{H_{N i}} \cdot \exp \left(\frac{\alpha_{c t, 2}^{o x} \cdot F}{R T} E\right)\right) \\
& v_{O_{Y S Z}^{I N C}}^{I N C}=S p_{Y S Z-p o r e s} \cdot \Gamma_{Y S Z} \cdot\left(k_{O_{Y S Z}^{I N C}}^{I N C} \cdot \theta_{O_{Y S Z}^{2-}} \cdot \frac{c_{V_{O}^{*}(Y S Z)}}{c_{O_{O}^{x e}(Y S Z)}^{r e f}}-k_{O_{Y S Z}^{E X C}}^{E \bar{C}} \cdot \theta_{Y S Z} \cdot \frac{c_{O_{O}^{x}(Y S Z)}}{c_{O_{O}^{x}(Y S Z)}^{r e f}}\right)
\end{aligned}
$$

The thermodynamic equilibrium constants of the five chemical reactions (CR1-CR5) are obtained using Eqs. (7a) and (7b) and the thermodynamic data reported in Table III.

$$
\begin{aligned}
& K_{A D S, H_{2} O_{N i}}^{e q}=\frac{k_{H_{2} O_{N i}}^{A D S}}{k_{H_{2} O_{N i}}^{D E S}}=\exp \left(\frac{-\left[\left(h_{H_{2} O_{N i}}^{0}(T)-T s_{H_{2} O_{N i}}^{0}(T)\right)-\left(h_{H_{2} O(g)}^{0}(T)+h_{S_{N i}}^{0}(T)-T\left(s_{H_{2} O(g)}^{0}(T)+s_{S_{N i}}^{0}(T)\right)\right)\right]}{R T}\right) \\
& K_{A D S, H_{2} O_{Y S Z}}^{e q}=\frac{k_{H_{2} O_{Y S Z}}^{A D S}}{k_{H_{2} O_{Y S Z}}^{D E S}}=\exp \left(\frac{-\left[\left(h_{H_{2} O_{Y S Z}}^{0}(T)-T s_{H_{2} O_{Y S Z}}^{0}(T)\right)-\left(h_{H_{2} O(g)}^{0}(T)+h_{S_{Y S Z}}^{0}(T)-T\left(s_{H_{2} O(g)}^{0}(T)+s_{S_{Y S Z}}^{0}(T)\right)\right)\right]}{R T}\right)
\end{aligned}
$$

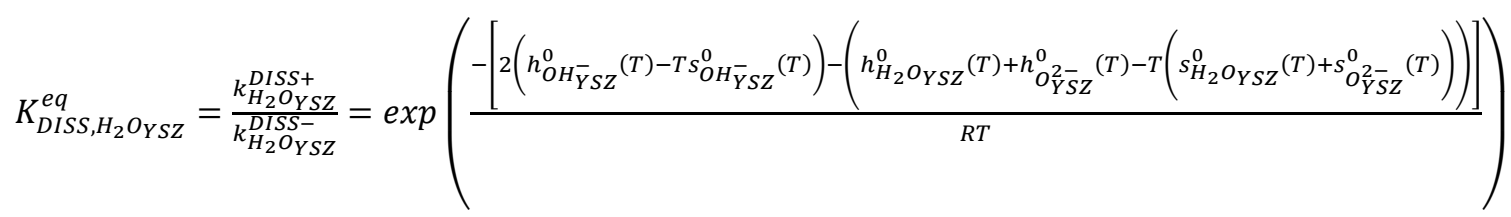

$$
\begin{aligned}
& K_{D E S, H_{2 N i}}^{e q}=\frac{k_{H_{2 N i}}^{D E S}}{k_{H_{2 N i}}^{A D S}}=\exp \left(\frac{-\left[\left(h_{H_{2}(g)}^{0}(T)-T s_{H_{2}(g)}^{0}(T)+2\left(h_{S_{N i}}^{0}(T)-T s_{S_{N i}}^{0}(T)\right)\right)-2\left(h_{H_{N i}}^{0}(T)-T s_{H_{N i}}^{0}(T)\right)\right]}{R T}\right)
\end{aligned}
$$

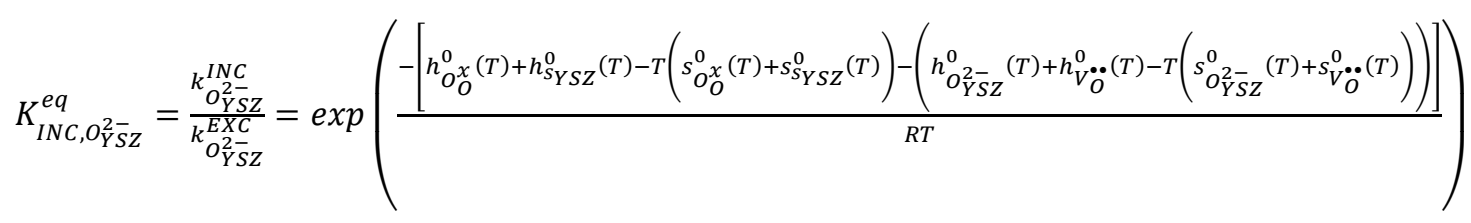


Once the equilibrium constants have been determined, these have been used to calculate the Ni and YSZ surface coverages at equilibrium with Eq. (8) and subsequently the equilibrium constants for the electrochemical reactions as reported in Eq. (9).

For the Ni surface, the coverages at equilibrium are:

$$
\begin{aligned}
& K_{A D S, H_{2} O_{N i}}^{e q}=\frac{\theta_{H_{2} O_{N i}}^{e q}}{\frac{p H_{2} O^{e q}}{p_{r e f}} \cdot \theta_{N i}^{e q}} \Rightarrow \theta_{H_{2} O_{N i}}^{e q}=K_{A D S, H_{2} O_{N i}}^{e q} \cdot \frac{p H_{2} O^{e q}}{p_{r e f}} \cdot \theta_{N i}^{e q} \\
& K_{D E S, H_{2 N i}}^{e q}=\frac{\frac{p H_{2}}{p_{r e f} e q} \cdot \theta_{N i}^{e q}}{\theta_{H_{N i}^{e q}}^{e q}} \Rightarrow \theta_{H_{N i}}^{e q}=\sqrt{\frac{1}{K_{D E S, H_{2 N i}}^{e q}} \cdot \frac{p H_{2} e q}{p_{r e f}} \cdot \theta_{N i}^{e q}} \\
& \sum \theta=1 \Rightarrow \theta_{N i}^{e q}=\left(1+K_{A D S, H_{2} O_{N i}}^{e q} \cdot \frac{p H_{2} O e q}{p_{r e f}}+\sqrt{\frac{1}{K_{D E S, H_{2 N i}}^{e q}} \cdot \frac{p H_{2} O^{e q}}{p_{r e f}}}\right)^{-1}
\end{aligned}
$$

While for the YSZ surface:

$$
\begin{aligned}
& K_{A D S, H_{2} O_{Y S Z}}^{e q}=\frac{\theta_{H_{2} O_{Y S Z}}^{e q}}{\frac{p H_{2} O^{e q}}{p_{r e f}} \cdot \theta_{Y S Z}^{e q}} \Rightarrow \theta_{H_{2} O_{Y S Z}}^{e q}=K_{A D S, H_{2} O_{Y S Z}}^{e q} \cdot \frac{p H_{2} O^{e q}}{p_{r e f}} \cdot \theta_{Y S Z}^{e q}
\end{aligned}
$$

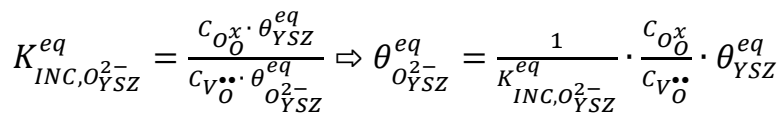

$$
\begin{aligned}
& K_{D I S, H_{2} O_{Y S Z}}^{e q}=\frac{\theta_{O H_{Y S Z}}^{e q^{2}}}{\theta_{H_{2} O_{Y S Z}}^{e q} \cdot \theta_{O_{Y S Z}^{2}}^{e q}} \Rightarrow \theta_{O H_{Y S Z}}^{e q}=\sqrt{K_{D I S S, H_{2} O_{Y S Z}}^{e q} \cdot K_{A D S, H_{2} O_{Y S Z}}^{e q} \cdot \frac{p H_{2} O^{e q}}{p_{r e f}} \cdot \frac{1}{K_{I N C, O_{Y S Z}^{2} \bar{S}}^{e q}} \cdot \frac{C_{O_{O}^{x}}}{C_{V_{O}^{*}}^{*}}} \cdot \theta_{Y S Z}^{e q}
\end{aligned}
$$

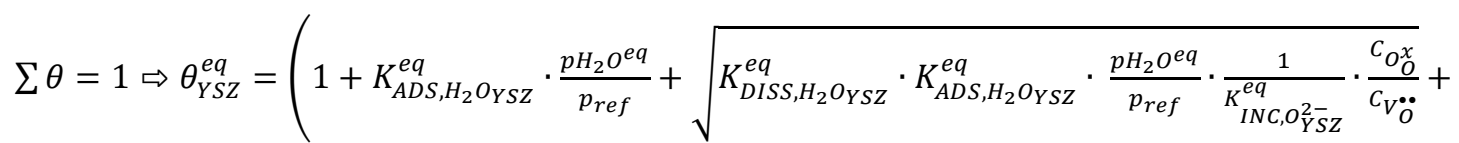

$$
\begin{aligned}
& \left.+\frac{1}{K_{I N C, O_{Y S Z}^{2-}}^{e q}} \cdot \frac{C_{O_{O}^{x}}}{C_{V_{O}^{*}}^{*}}\right)^{-1}
\end{aligned}
$$

Finally, the equilibrium constants of the charge transfer reactions are obtained:

$$
\begin{aligned}
& K_{c t, 1-R E D}^{e q}=\frac{\theta_{H_{N i}}^{e q} \cdot \theta_{O H_{Y S Z}}^{e q}}{\theta_{H_{2} o_{N i}}^{e q} \theta_{Y S Z}^{\theta_{Y}}} \exp \left(\frac{F}{R T} E^{e q}\right) \\
& K_{c t, 2-R E D}^{e q}=\frac{\theta_{H_{N i}}^{e q} \cdot \theta_{O_{Y S Z}^{e q}}^{e q}}{\theta_{O H_{Y S Z}}^{e q} \cdot \theta_{N i}^{e q}} \exp \left(\frac{F}{R T} E^{e q}\right)
\end{aligned}
$$

The diffusion of all the species involved in the reaction mechanism has been modeled according to Eqs. (10) to (16) and using the diffusion coefficients reported in Table IV.

$$
\begin{aligned}
& \varepsilon_{\text {pores }} \frac{d C_{H_{2}}}{d t}+\nabla \cdot\left(-D_{H_{2}}^{e f f} \nabla C_{H_{2}}\right)=+v_{H_{2 N i}}^{D E S} \\
& \varepsilon_{\text {pores }} \frac{d C_{H_{2} O}}{d t}+\nabla \cdot\left(-D_{H_{2} O}^{e f f} \nabla C_{H_{2} O}\right)=-v_{H_{2} O_{Y S Z}}^{A D S}-v_{H_{2} O O_{N i}}^{A D S} \\
& S p_{N i-Y S Z} C_{d l} \frac{d E}{d t}=-\nabla \cdot\left(-\sigma_{e l}^{e f f} \nabla \varphi_{e l}\right)+F\left(v_{R E D}^{c t, 1}+v_{R E D}^{c t, 2}\right) \\
& -S p_{N i-Y S Z} C_{d l} \frac{d E}{d t}=-\nabla \cdot\left(-\sigma_{i o}^{e f f} \nabla \varphi_{i o}\right)-2 F v_{O_{Y S Z}^{2}-}^{I N C} \\
& S p_{\text {pores }-N i} \Gamma_{N i} \frac{d \theta_{H_{N i}}}{d t}+\nabla \cdot\left(-S p_{\text {pores }-N i} I_{N i} D_{H_{N i}} \nabla \theta_{H_{N i}}\right)=-2 v_{H_{2 N i}}^{D E S}+v_{R E D}^{c t, 1}+v_{R E D}^{c t, 2}
\end{aligned}
$$


$S p_{\text {pores }-N i} \Gamma_{N i} \frac{d \theta_{\mathrm{H}_{2} \mathrm{O}_{\mathrm{Ni}}}}{d t}+\nabla \cdot\left(-S p_{\text {pores }-\mathrm{Ni}} \Gamma_{\mathrm{Ni}} D_{\mathrm{H}_{2} \mathrm{O}_{\mathrm{Ni}}} \nabla \theta_{\mathrm{H}_{2} \mathrm{O}_{\mathrm{Ni}}}\right)=+v_{\mathrm{H}_{2} \mathrm{O}_{\mathrm{Ni}}}^{A D S}-v_{R E D}^{c t, 1}$

$S p_{Y S Z-\text { pores }} \Gamma_{Y S Z} \frac{d \theta_{H_{2} O_{Y S Z}}}{d t}+\nabla \cdot\left(-S p_{Y S Z-\text { pores }} \Gamma_{Y S Z} D_{H_{2} O_{Y S Z}} \nabla \theta_{H_{2} O_{Y S Z}}\right)=+v_{H_{2} O_{Y S Z}}^{A D S}-v_{H_{2} O_{Y S Z} I S S}$

$S p_{Y S Z-\text { pores }} \Gamma_{Y S Z} \frac{d \theta_{O H_{Y S Z}^{-}}}{d t}+\nabla \cdot\left(-S p_{Y S Z-\text { pores }} \Gamma_{Y S Z} D_{O H_{Y S Z}} \nabla \theta_{O H_{Y S Z}^{-}}\right)=+2 v_{H_{2} O_{Y S Z} I S S}+v_{R E D}^{c t, 1}-v_{R E D}^{c t, 2}$

$S p_{Y S Z-\text { pores }} \Gamma_{Y S Z} \frac{d \theta}{d t}+\nabla \cdot\left(-S p_{Y S Z-\text { pores }}^{2-} \Gamma_{Y S Z} D_{O_{Y S Z}^{2-}} \nabla \theta_{O_{Y S Z}^{2-}}\right)=-v_{H_{2} O_{Y S Z}}^{\text {IISS }}+v_{R E D}^{c t, 2}-v_{O_{Y S Z}^{I N C}}$

Solving this set of partial differential equations with the boundary conditions reported in Section 3.5 , it is possible to simulate the $\eta-i$ curves and the impedance spectra. 


\section{References}

[1] A. Godula-Jopek, P. Millet, N. Guillet, J. Laurencin, J. Mougin, C. Bourasseau, B. Guinot, Hydrogen Production by Electrolysis, Wiley-VCH, Weinheim, 2015.

[2] S.P.S. Shaikh, A. Muchtar, M.R. Somalu, A review on the selection of anode materials for solid-oxide fuel cells, Renew. Sustain. Energy Rev. 51 (2015) 1-8. doi:10.1016/j.rser.2015.05.069.

[3] A. Arsalis, A comprehensive review of fuel cell-based micro-combined-heat-and-power systems, Renew. Sustain. Energy Rev. 105 (2019) 391-414. doi:10.1016/j.rser.2019.02.013.

[4] J.B. Hansen, Solid oxide electrolysis - a key enabling technology for sustainable energy scenarios., Faraday Discuss. 182 (2015) 9-48. doi:10.1039/c5fd90071a.

[5] B. V. Mathiesen, H. Lund, D. Connolly, H. Wenzel, P.A. Ostergaard, B. Möller, S. Nielsen, I. Ridjan, P. Karnoe, K. Sperling, F.K. Hvelplund, Smart Energy Systems for coherent 100\% renewable energy and transport solutions, Appl. Energy. 145 (2015) 139-154. doi:10.1016/j.apenergy.2015.01.075.

[6] M. Ni, M.K.H. Leung, D.Y.C. Leung, Technological development of hydrogen production by solid oxide electrolyzer cell (SOEC), Int. J. Hydrogen Energy. 33 (2008) 2337-2354. doi:10.1016/j.ijhydene.2008.02.048.

[7] M. Lehner, R. Tichler, M. Koppe, Power-to-Gas: Technology and Business Models, Springer, Springer, 2014. doi:10.1007/978-3-319-03995-4.

[8] F. Monaco, V. Tezyk, E. Siebert, S. Pylypko, B. Morel, J. Vulliet, T. Le Bihan, F. LefebvreJoud, J. Laurencin, Experimental validation of a $\mathrm{La} 0.6 \mathrm{Sr} 0.4 \mathrm{Co} 0.2 \mathrm{Fe} 0.8 \mathrm{O} 3-\delta$ electrode model operated in electrolysis mode: Understanding the reaction pathway under anodic polarization, Solid State Ionics. 319 (2018) 234-246. doi:10.1016/j.ssi.2018.02.012.

[9] E. Effori, H. Moussaoui, F. Monaco, R.K.K. Sharma, J. Debayle, Y. Gavet, G. Delette, G. Si Larbi, E. Siebert, J. Vulliet, L. Dessemond, J. Laurencin, Reaction Mechanism and Impact of Microstructure on Performances for the LSCF-CGO Composite Electrode in Solid Oxide Cells, Fuel Cells. 19 (2019) 429-444. doi:10.1002/fuce.201800185.

[10] J. Laurencin, M. Hubert, D.F. Sanchez, S. Pylypko, M. Morales, A. Morata, B. Morel, D. Montinaro, F. Lefebvre-Joud, E. Siebert, Degradation mechanism of $\mathrm{La} 0.6 \mathrm{Sr} 0.4 \mathrm{Co} 0.2 \mathrm{Fe} 0.8 \mathrm{O} 3-\delta / \mathrm{Gd} 0.1 \mathrm{Ce} 0.9 \mathrm{O} 2-\delta$ composite electrode operated under solid oxide electrolysis and fuel cell conditions, Electrochim. Acta. 241 (2017) 459-476. doi:10.1016/j.electacta.2017.05.011.

[11] C. Suciu, E. Dorolti, A.C. Hoffmann, Physico-chemical properties of nanocrystalline YSZ powders as a function of doping level and electrical properties after sintering, Mater. Sci. 
Energy Technol. 1 (2018) 136-145. doi:10.1016/j.mset.2018.06.007.

[12] M. Ghatee, M.H. Shariat, J.T.S. Irvine, Investigation of electrical and mechanical properties of 3YSZ/8YSZ composite electrolytes, Solid State Ionics. 180 (2009) 57-62. doi:10.1016/j.ssi.2008.10.006.

[13] M. Hubert, J. Laurencin, P. Cloetens, B. Morel, D. Montinaro, F. Lefebvre-Joud, Impact of Nickel agglomeration on Solid Oxide Cell operated in fuel cell and electrolysis modes, J. Power Sources. 397 (2018) 240-251. doi:10.1016/j.jpowsour.2018.06.097.

[14] F. Monaco, M. Hubert, J. Vulliet, J.P.P. Ouweltjes, D. Montinaro, P. Cloetens, P. Piccardo, F. Lefebvre-Joud, J. Laurencin, Degradation of Ni-YSZ Electrodes in Solid Oxide Cells: Impact of Polarization and Initial Microstructure on the Ni Evolution, J. Electrochem. Soc. 166 (2019) F1229-F1242. doi:10.1149/2.1261915jes.

[15] J.T.S. Irvine, D. Neagu, M.C. Verbraeken, C. Chatzichristodoulou, C. Graves, M.B. Mogensen, Evolution of the electrochemical interface in high-temperature fuel cells and electrolysers, Nat. Energy. 1 (2016) 1-13. doi:10.1038/nenergy.2015.14.

[16] J. Hanna, W.Y. Lee, Y. Shi, A.F. Ghoniem, Fundamentals of electro- and thermochemistry in the anode of solid-oxide fuel cells with hydrocarbon and syngas fuels, Prog. Energy Combust. Sci. 40 (2014) 74-111. doi:10.1016/j.pecs.2013.10.001 Review.

[17] A. Hauch, K. Brodersen, M. Chen, M.B. Mogensen, Ni/YSZ electrodes structures optimized for increased electrolysis performance and durability, Solid State Ionics. 293 (2016) 27-36. doi:10.1016/j.ssi.2016.06.003.

[18] J. Mizusaki, H. Tagawa, T. Saito, T. Yamamura, K. Kamitani, K. Hirano, S. Ehara, T. Takagi, T. Hikita, M. Ippommatsu, S. Nakagawa, K. Hashimoto, Kinetic studies of the reaction at the nickel pattern electrode on YSZ in $\mathrm{H} 2-\mathrm{H} 2 \mathrm{O}$ atmospheres, Solid State Ionics. 70-71 (1994) 52-58. doi:10.1016/0167-2738(94)90286-0.

[19] J. Mizusaki, H. Tagawa, T. Saito, K. Kamitani, T. Yamamura, K. Hirano, S. Ehara, T. Takagi, T. Hikita, M. Ippommatsu, S. Nakagawa, K. Hashimoto, Preparation of Nickel Pattern Electrodes on YSZ and Their Electrochemical Properties in H2-H2O Atmospheres, J. Electrochem. Soc. 141 (1994) 2129-2134. doi:10.1149/1.2055073.

[20] A. Bieberle, L.J. Gauckler, Reaction mechanism of Ni pattern anodes for solid oxide fuel cells, Solid State Ionics. 135 (2000) 337-345. doi:10.1016/S0167-2738(00)00462-8.

[21] A. Bieberle, L.P. Meier, L.J. Gauckler, The Electrochemistry of Ni Pattern Anodes Used as Solid Oxide Fuel Cell Model Electrodes, J. Electrochem. Soc. 148 (2001) A646-A656. doi:10.1149/1.1372219.

[22] D. Kek, M. Mogensen, S. Pejovnik, A Study of Metal (Ni, Pt, Au)/Yttria-Stabilized Zirconia 
Interface in Hydrogen Atmosphere at Elevated Temperature, J. Electrochem. Soc. 148 (2001) A878-A886. doi:10.1149/1.1383069.

[23] O.A. Marina, L.R. Pederson, M.C. Williams, G.W. Coffey, K.D. Meinhardt, C.D. Nguyen, E.C. Thomsen, Electrode Performance in Reversible Solid Oxide Fuel Cells, J. Electrochem. Soc. 154 (2007) B452-B459. doi:10.1149/1.2710209.

[24] D. Grondin, J. Deseure, P. Ozil, J.P. Chabriat, B. Grondin-Perez, A. Brisse, Computing approach of cathodic process within solid oxide electrolysis cell: Experiments and continuum model validation, J. Power Sources. $196 \quad$ (2011) 9561-9567. doi:10.1016/j.jpowsour.2011.07.033.

[25] H.P. Dasari, S.-Y. Park, J. Kim, J.-H. Lee, B.-K. Kim, H.-J. Je, H.-W. Lee, K.J. Yoon, Electrochemical characterization of $\mathrm{Ni}-\mathrm{yttria}$ stabilized zirconia electrode for hydrogen production in solid oxide electrolysis cells, J. Power Sources. 240 (2013) 721-728. doi:10.1016/j.jpowsour.2013.05.033.

[26] W. Pan, K. Chen, N. Ai, Z. Lü, S.P. Jiang, Mechanism and Kinetics of Ni-Y2O3-ZrO2 Hydrogen Electrode for Water Electrolysis Reactions in Solid Oxide Electrolysis Cells, J. Electrochem. Soc. 163 (2016) F106-F114. doi:10.1149/2.0801602jes.

[27] E.C. Shin, P.A. Ahn, H.H. Seo, J.S. Lee, Application of a general gas electrode model to NiYSZ symmetric cells: Humidity and current collector effects, J. Korean Ceram. Soc. 53 (2016) 511-520. doi:10.4191/kcers.2016.53.5.511.

[28] Y. Luo, W. Li, Y. Shi, Y. Wang, N. Cai, Reversible H2/H2O electrochemical conversion mechanisms on the patterned nickel electrodes, Int. J. Hydrogen Energy. 42 (2017) 25130 25142. doi:10.1016/j.ijhydene.2017.08.138.

[29] M.C. Doppler, J. Fleig, M. Bram, A.K. Opitz, Hydrogen oxidation mechanisms on Ni/yttria stabilized zirconia anodes: Separation of reaction pathways by geometry variation of pattern electrodes, J. Power Sources. 380 (2018) 46-54. doi:10.1016/j.jpowsour.2018.01.073.

[30] S. Primdahl, M. Mogensen, Oxidation of Hydrogen on Ni/Yttria-Stabilized Zirconia Cermet Anodes, J. Electrochem. Soc. 144 (1997) 3409-3419. doi:10.1149/1.1838026.

[31] V. Sonn, A. Leonide, E. Ivers-Tiffée, Combined Deconvolution and CNLS Fitting Approach Applied on the Impedance Response of Technical Ni8YSZ Cermet Electrodes, J. Electrochem. Soc. 155 (2008) B675-B679. doi:10.1149/1.2908860.

[32] P. Holtappels, L.G.J. de Haart, U. Stimming, Reaction of hydrogen water mixtures on nickelzirconia cermet electrodes I. DC polarization characteristics, J. Electrochem. Soc. 146 (1999) 1620-1625. doi:10.1149/1.1391816.

[33] P. Holtappels, L.G.J. de Haart, U. Stimming, Reaction of Hydrogen/Water Mixtures on 
Nickel-Zirconia Cermet Electrodes: II. AC Polarization Characteristics, J. Electrochem. Soc. 146 (1999) 2976-2982. doi:10.1149/1.1392038.

[34] S.P. Jiang, S.P.S. Badwal, An electrode kinetics study of $\mathrm{H} 2$ oxidation on Ni/Y2O3-ZrO2 cermet electrode of the solid oxide fuel cell, Solid State Ionics. 123 (1999) 209-224. doi:10.1016/S0167-2738(99)00124-1.

[35] S.P. Jiang, Y. Ramprakash, H2 oxidation on Ni/Y-TZP cermet electrodes - a comparison of electrode behaviour by GCI and EIS techniques, Solid State Ionics. 122 (1999) 211-222. doi:10.1016/S0167-2738(98)00461-5.

[36] S.P. Jiang, Y. Ramprakash, H2 oxidation on Ni/Y-TZP cermet electrodes - Polarisation behaviour, Solid State Ionics. 116 (1999) 145-156. doi:10.1016/s0167-2738(98)00269-0.

[37] S.P. Jiang, S.P.S. Badwal, Hydrogen Oxidation at the Nickel and Platinum Electrodes on Yttria-Tetragonal Zirconia Electrolyte, J. Electrochem. Soc. 144 (1997) 3777-3784. doi:10.1149/1.1838091.

[38] P. Costamagna, E.M. Sala, W. Zhang, M. Lund Traulsen, P. Holtappels, Electrochemical impedance spectroscopy of $\mathrm{La} 0.6 \mathrm{Sr} 0.4 \mathrm{Co} 0.2 \mathrm{Fe} 0.8 \mathrm{O} 3-\delta$ nanofiber cathodes for intermediate temperature-solid oxide fuel cell applications: A case study for the 'depressed' or 'fractal' Gerischer element, Electrochim. Acta. $319 \quad$ (2019) 657-671. doi:10.1016/j.electacta.2019.06.068.

[39] A. Enrico, W. Zhang, M. Lund Traulsen, E.M. Sala, P. Costamagna, P. Holtappels, $\mathrm{La} 0.6 \mathrm{Sr} 0.4 \mathrm{Co} 0.2 \mathrm{Fe} 0.8 \mathrm{O} 3-\delta$ nanofiber cathode for intermediate-temperature solid oxide fuel cells by water-based sol-gel electrospinning: Synthesis and electrochemical behaviour, J. Eur. Ceram. Soc. 38 (2018) 2677-2686. doi:10.1016/j.jeurceramsoc.2018.01.034.

[40] B.A. Boukamp, M. Verbraeken, D.H.A. Blank, P. Holtappels, SOFC-anodes, proof for a finite-length type Gerischer impedance?, Solid State Ionics. 177 (2006) 2539-2541. doi:10.1016/j.ssi.2006.03.002.

[41] B.A. Boukamp, H.J.M. Bouwmeester, Interpretation of the Gerischer impedance in solid state ionics, Solid State Ionics. 157 (2003) 29-33. doi:10.1016/S0167-2738(02)00185-6.

[42] J. Nielsen, T. Jacobsen, M. Wandel, Impedance of porous IT-SOFC LSCF:CGO composite cathodes, Electrochim. Acta. 56 (2011) 7963-7974. doi:10.1016/j.electacta.2011.05.042.

[43] J. Nielsen, J. Hjelm, Impedance of SOFC electrodes: A review and a comprehensive case study on the impedance of LSM:YSZ cathodes, Electrochim. Acta. 115 (2014) 31-45. doi:10.1016/j.electacta.2013.10.053.

[44] G. Kresse, J. Hafner, First-principles study of the adsorption of atomic H on Ni (111), (100) and (110), Surf. Sci. 459 (2000) 287-302. doi:10.1016/S0039-6028(00)00457-X. 
[45] S. Raz, K. Sasaki, J. Maier, I. Riess, Characterization of adsorbed water layers on Y2O3doped ZrO2, Solid State Ionics. 143 (2001) 181-204.

[46] M. Shishkin, T. Ziegler, Oxidation of H2, CH4 and CO molecules at the interface between Nickel and Yttria-Stabilized Zirconia: A theoretical study based on DFT, J. Phys. Chem. C. 113 (2009) 21667-21678. doi:10.1021/jp905615c.

[47] S. Liu, T. Ishimoto, D.S. Monder, M. Koyama, First-Principles Study of Oxygen Transfer and Hydrogen Oxidation Processes at the Ni-YSZ-Gas Triple Phase Boundaries in a Solid Oxide Fuel Cell Anode, J. Phys. Chem. C. 119 (2015) 27603-27608. doi:10.1021/acs.jpcc.5b10878.

[48] Z. Fu, M. Wang, P. Zuo, Z. Yang, R. Wu, Importance of oxygen spillover for fuel oxidation on Ni/YSZ anodes in solid oxide fuel cells, Phys. Chem. Chem. Phys. 16 (2014) 8536-8540. doi:10.1039/C3CP55076A.

[49] M. Shishkin, T. Ziegler, Hydrogen Oxidation at the Ni/Yttria-Stabilized Zirconia Interface : A Study Based on Density Functional Theory, J. Phys. Chem. C. 114 (2010) 11209-11214. doi:10.1021/jp1030575.

[50] C.S. Cucinotta, M. Bernasconi, M. Parrinello, Hydrogen oxidation reaction at the Ni/YSZ anode of solid oxide fuel cells from first principles, Phys. Rev. Lett. 107 (2011) 1-5. doi:10.1103/PhysRevLett.107.206103.

[51] A. Gorski, V. Yurkiv, D. Starukhin, H.R. Volpp, H2O chemisorption and H2 oxidation on yttria-stabilized zirconia: Density functional theory and temperature-programmed desorption studies, J. Power Sources. 196 (2011) 7188-7194. doi:10.1016/j.jpowsour.2010.09.090.

[52] A. Mohsenzadeh, K. Bolton, T. Richards, DFT study of the adsorption and dissociation of water on $\mathrm{Ni}(111), \mathrm{Ni}(110)$ and $\mathrm{Ni}(100)$ surfaces, Surf. Sci. 627 (2014) 1-10. doi:10.1016/j.susc.2014.04.006.

[53] D.T. Chaopradith, D.O. Scanlon, C.R.A. Catlow, Adsorption of Water on Yttria-Stabilized Zirconia, J. Phys. Chem. C. 119 (2015) 22526-22533. doi:10.1021/acs.jpcc.5b06825.

[54] A. Cadi-Essadek, A. Roldan, N.H. de Leeuw, Density functional theory study of the interaction of $\mathrm{H} 2 \mathrm{O}, \mathrm{CO} 2$ and $\mathrm{CO}$ with the $\mathrm{ZrO} 2$ (111), $\mathrm{Ni} / \mathrm{ZrO} 2$ (111), YSZ (111) and Ni/YSZ (111) surfaces, Surf. Sci. 653 (2016) 153-162. doi:10.1016/j.susc.2016.06.008.

[55] H. Seenivasan, B. Jackson, A.K. Tiwari, Water dissociation on Ni(100), Ni(110), and Ni(111) surfaces: Reaction path approach to mode selectivity, J. Chem. Phys. 146 (2017) 074705. doi:10.1063/1.4976133.

[56] S.C. Ammal, A. Heyden, Combined DFT and microkinetic modeling study of hydrogen oxidation at the Ni/YSZ anode of solid oxide fuel cells, J. Phys. Chem. Lett. 3 (2012) 2767- 
2772. doi:10.1021/jz301132b.

[57] B. De Boer, SOFC anode: hydrogen oxidation at porous nickel and nickel/zirconia electrodes, PhD Thesis. (1998). http://purl.utwente.nl/publications/9195.

[58] A. Bieberle, L.J. Gauckler, State-space modeling of the anodic SOFC system Ni, H2H2O|YSZ, Solid State Ionics. 146 (2002) 23-41. doi:10.1016/S0167-2738(01)01004-9.

[59] W.G. Bessler, S. Gewies, M. Vogler, A new framework for physically based modeling of solid oxide fuel cells, Electrochim. Acta. 53 (2007) 1782-1800. doi:10.1016/j.electacta.2007.08.030.

[60] D.G. Goodwin, H. Zhu, A.M. Colclasure, R.J. Kee, Modeling Electrochemical Oxidation of Hydrogen on Ni-YSZ Pattern Anodes, J. Electrochem. Soc. 156 (2009) B1004-B1021. doi:10.1149/1.3148331.

[61] M. Vogler, A. Bieberle-Hütter, L. Gauckler, J. Warnatz, W.G. Bessler, Modelling Study of Surface Reactions, Diffusion, and Spillover at a Ni/YSZ Patterned Anode, J. Electrochem. Soc. 156 (2009) B663-B672. doi:10.1149/1.3095477.

[62] W.G. Bessler, M. Vogler, H. Störmer, D. Gerthsen, A. Utz, A. Weber, E. Ivers-Tiffée, Model anodes and anode models for understanding the mechanism of hydrogen oxidation in solid oxide fuel cells, Phys. Chem. Chem. Phys. 12 (2010) 13888-13903. doi:10.1039/c0cp00541j.

[63] Y. Luo, Y. Shi, W. Li, N. Cai, Mechanism of rate-limiting step switchover for reversible solid oxide cells in $\mathrm{H} 2 / \mathrm{H} 2 \mathrm{O}$ atmosphere, Electrochim. Acta. 326 (2019) 135003. doi:10.1016/j.electacta.2019.135003.

[64] S.I. Bredikhin, D.A. Agarkov, A.S. Aronin, I.N. Burmistrov, D. V. Matveev, V. V. Kharton, Ion transfer in Ni-containing composite anodes of solid oxide fuel cells: A microstructural study, Mater. Lett. 216 (2018) 193-195. doi:10.1016/j.matlet.2018.01.022.

[65] S. Gewies, W.G. Bessler, Physically Based Impedance Modeling of Ni/YSZ Cermet Anodes, J. Electrochem. Soc. 155 (2008) B937-B952. doi:10.1149/1.2943411.

[66] S.P. Jiang, Placement of Reference Electrode, Electrolyte Thickness and Three-Electrode Cell Configuration in Solid Oxide Fuel Cells: A Brief Review and Update on Experimental Approach, J. Electrochem. Soc. 164 (2017) F834-F844. doi:10.1149/2.1331707jes.

[67] M. Hubert, J. Laurencin, P. Cloetens, J.C. da Silva, F. Lefebvre-Joud, P. Bleuet, A. Nakajo, E. Siebert, Role of microstructure on electrode operating mechanisms for mixed ionic electronic conductors: From synchrotron-based 3D reconstruction to electrochemical modeling, Solid State Ionics. 294 (2016) 90-107. doi:10.1016/j.ssi.2016.07.001.

[68] P. Cloetens, W. Ludwig, J. Baruchel, D. Van Dyck, J. Van Landuyt, J.P. Guigay, M. Schlenker, Holotomography: Quantitative phase tomography with micrometer resolution 
using hard synchrotron radiation $x$ rays, Appl. Phys. Lett. 75 (1999) 2912-2914. doi:10.1063/1.125225.

[69] J. Villanova, J. Laurencin, P. Cloetens, P. Bleuet, G. Delette, H. Suhonen, F. Usseglio Viretta, 3D phase mapping of solid oxide fuel cell YSZ/Ni cermet at the nanoscale by holographic X-ray nanotomography, J. Power Sources. 243 (2013) 841-849. doi:10.1016/j.jpowsour.2013.06.069.

[70] M. Hubert, A. Pacureanu, C. Guilloud, Y. Yang, J.C. Da Silva, J. Laurencin, F. LefebvreJoud, P. Cloetens, Efficient correction of wavefront inhomogeneities in X-ray holographic nanotomography by random sample displacement, Appl. Phys. Lett. 112 (2018) 203704. doi:10.1063/1.5026462.

[71] A.J. Bard, L.R. Faulkner, ELECTROCHEMICAL METHODS Fundamentals and Applications, 2nd ed., John Wiley \& Sons, New York, 2001.

[72] R.J. Kee, M.E. Coltrin, P. Glarborg, Chemically Reacting Flow: Theory and Practice, John Wiley \& Sons, 2003.

[73] K. Kawata, H. Maekawa, T. Nemoto, T. Yamamura, Local structure analysis of YSZ by Y89 MAS-NMR, Solid State Ionics. 177 (2006) 1687-1690. doi:10.1016/j.ssi.2006.02.030.

[74] R.H.J. Hannink, P.M. Kelly, B.C. Muddle, Transformation toughening in zirconia-containing ceramics, J. Am. Ceram. Soc. 83 (2000) 461-487. doi:10.1111/j.1151-2916.2000.tb01221.x.

[75] W.G. Bessler, J. Warnatz, D.G. Goodwin, The influence of equilibrium potential on the hydrogen oxidation kinetics of SOFC anodes, Solid State Ionics. 177 (2007) 3371-3383. doi:10.1016/j.ssi.2006.10.020.

[76] M.W. Chase, NIST-JANAF Thermochemical Tables, 4th ed., 1998.

[77] J. Laurencin, D. Kane, G. Delette, J. Deseure, F. Lefebvre-Joud, Modelling of solid oxide steam electrolyser: Impact of the operating conditions on hydrogen production, J. Power Sources. 196 (2011) 2080-2093. doi:10.1016/j.jpowsour.2010.09.054.

[78] L. Bernadet, J. Laurencin, G. Roux, D. Montinaro, F. Mauvy, M. Reytier, Effects of Pressure on High Temperature Steam and Carbon Dioxide Co-electrolysis, Electrochim. Acta. 253 (2017) 114-127. doi:10.1016/j.electacta.2017.09.037.

[79] B. Todd, J.B. Young, Thermodynamic and transport properties of gases for use in solid oxide fuel cell modelling, J. Power Sources. 110 (2002) 186-200. doi:10.1016/S03787753(02)00277-X.

[80] E. Lay-Grindler, J. Laurencin, G. Delette, J. Aicart, M. Petitjean, L. Dessemond, Micro modelling of solid oxide electrolysis cell: From performance to durability, Int. J. Hydrogen Energy. 38 (2013) 6917-6929. doi:10.1016/j.ijhydene.2013.03.162. 
[81] H. Moussaoui, J. Laurencin, Y. Gavet, G. Delette, M. Hubert, P. Cloetens, T. Le Bihan, J. Debayle, Stochastic geometrical modeling of solid oxide cells electrodes validated on 3D reconstructions, Comput. Mater. Sci. $143 \quad$ (2018) 262-276. doi:10.1016/j.commatsci.2017.11.015.

[82] P. Perona, J. Malik, Scale-space and edge detection using anisotropic diffusion, IEEE Trans. Pattern Anal. Mach. Intell. 12 (1990) 629-639. doi:10.1109/34.56205.

[83] N. Otsu, A Threshold Selection Method from Gray-Level Histograms, IEEE Trans. Syst. Man. Cybern. C (1979) 62-66. doi:10.1109/TSMC.1979.4310076.

[84] J. Laurencin, R. Quey, G. Delette, H. Suhonen, P. Cloetens, P. Bleuet, Characterisation of Solid Oxide Fuel Cell Ni-8YSZ substrate by synchrotron X-ray nano-tomography: From 3D reconstruction to microstructure quantification, J. Power Sources. 198 (2012) 182-189. doi:10.1016/j.jpowsour.2011.09.105.

[85] R.U. Atangulov, I. V. Murygin, Gas electrode impedance with slow adsorption and surface diffusion, Solid State Ionics. 67 (1993) 9-15. doi:10.1016/0167-2738(93)90302-J.

[86] M.G.H.M. Hendriks, J.E. Ten Elshof, H.J.M. Bouwmeester, H. Verweij, The electrochemical double-layer capacitance of yttria-stabilised zirconia, Solid State Ionics. 146 (2002) 211-217. doi:10.1016/S0167-2738(01)01017-7. 